\title{
Estudo da ação da Doxiciclina em diferentes modelos de osteopenia
}

\author{
Versão Corrigida
}

Tese apresentada à Faculdade de Medicina de Ribeirão Preto da Universidade de São Paulo para obtenção do título de Doutor em Ciências.

Orientador: Prof. Dr. João Paulo Mardegan Issa

Ribeirão Preto

2017 
Autorizo a reprodução e divulgação total ou parcial deste trabalho, por qualquer meio convencional ou eletrônico, para fins de estudo e pesquisa, desde que citada a fonte.

de Figueiredo, Fellipe Augusto Tocchini

Estudo da ação da Doxiciclina em diferentes modelos de osteopenia. Ribeirão Preto, 2017.

89 p.: il.; $30 \mathrm{~cm}$

Tese de Doutorado, apresentada à Faculdade de Medicina de Ribeirão Preto/USP.

Orientador: Issa, João Paulo Mardegan.

1. Osteopenia. 2. Osteoporose. 3. Doxiciclina.

4. Ovariectomia. 5. Sedentarismo.

A versão original encontra-se disponível tanto na Biblioteca da Unidade que aloja o Programa, quanto na Biblioteca Digital de Teses e Dissertações da USP (BDTD) 
de Figueiredo, Fellipe Augusto Tocchini

Título: Estudo da ação da Doxiciclina em diferentes modelos de osteopenia

Tese apresentada à Faculdade de Medicina de Ribeirão Preto da Universidade de São Paulo para obtenção do título de Doutor em Ciências do Programa de Pós-Graduação em Ciências da Saúde Aplicadas ao Aparelho Locomotor.

Aprovado em:

Banca Examinadora

Prof. Dr.

Instituição:

Assinatura:

Prof. Dr.

Instituição:

Assinatura:

Prof. Dr.

Instituição:

Assinatura:

Prof. Dr.

Instituição:

Assinatura:

Prof. Dr.

Instituição:

Assinatura: 


\section{DEDICATÓRIA}

À minha esposa Ana Lúcia pela paciência, amor, compreensão, ajuda e suporte. Sem você este trabalho não seria possível.

Aos meus pais Shirlene e Celso por tudo 


\section{AGRADECIMENTOS}

Ao meu orientador e amigo Prof. Dr. João Paulo Mardegan Issa.

Aos meus amigos: Roberta C. Shimano, Junia Ramos e Vitor Castania que me ajudaram muito em todos os momentos, principalmente quando mais precisei nos períodos de outubro e novembro de 2014. Sem eles, este trabalho não seria possível.

Ao técnico e amigo Dimitrius Leonardo Pitol pela grandiosa ajuda e por quem tenho imensa estima.

Aos técnicos e amigos Luis Gustavo de Souza e Paulo Batista de Vasconcelos pelos conhecimentos compartilhados.

À professora Raquel Fernanda Gerlach pela ajuda e orientação.

Ao professor Marcelo Riberto pela orientação na exposição dos resultados do presente trabalho.

À professora Mamie Mizusaki lyomasa pela sabedoria e lições que me foram repassadas neste doutorado.

À Aline Azevedo que me ajudou nos experimentos.

Ao Departamento de Bioengenharia, aos docentes e funcionários que prestaram um valioso serviço para a minha formação. 

Enquanto tivermos fé em nossa causa e força de vontade inconquistável, a
salvação não nos será negada
Winston Churchill 


\section{RESUMO}

de Figueiredo, Fellipe Augusto Tocchini. Estudo da ação da Doxiciclina em diferentes modelos de osteopenia. 2017. 86p. Tese (Doutorado em Ciências) - Faculdade de Medicina de Ribeirão Preto, Universidade de São Paulo, Ribeirão Preto, 2017. Versão Corrigida.

Introdução: A doxiciclina, membro da família das tetraciclinas, é uma droga utilizada como antibiótico (posologia de $100 \mathrm{mg} / \mathrm{dia}$ ) e como inibidora de metaloproteinases de matriz - MMPs - (posologia de $20 \mathrm{mg}$ duas vezes ao dia), uso que tem efeito de droga anti-inflamatória. A doxiciclina é quelante de cálcio e portanto interfere na remodelação óssea. Objetiva-se neste trabalho avaliar ação do medicamento doxiciclina no controle da osteopenia. Materiais e métodos: 63 ratas Wistars obtidas no biotério central da Universidade de São Paulo campus de Ribeirão Preto foram divididas em 9 grupos com $n=7$ cada, sendo estes: grupo Controle com doxiciclina $10 \mathrm{mg} / \mathrm{kg} /$ dia (C10), Controle com doxiciclina $30 \mathrm{mg} / \mathrm{kg} / \mathrm{dia}$ (C30) e Controle (C), Grupo Ovariectomizado com doxiciclina 10 mg/kg/dia (OVX10), Ovariectomizado com doxiciclina 30 mg/kg/dia (OVX30) e Ovariectomizado com água (OVX), Grupo Sedentarismo $10 \mathrm{mg} / \mathrm{kg} / \mathrm{dia}$ (Se10), Sedentarismo $30 \mathrm{mg} / \mathrm{kg} /$ dia (Se30) e Sedentário com água (Se). Todos os grupos tiveram seus modelos de indução a osteopenia por 90 dias. Em seguida, os grupos que receberam o medicamento, foram submetidos as doses diárias $(10 \mathrm{mg} / \mathrm{kg} / \mathrm{dia}$ e $30 \mathrm{mg} / \mathrm{kg} / \mathrm{dia}$ ) por 60 dias. As amostras dos fêmures esquerdos foram destinadas para densitometria óssea enquanto as amostras de fêmures direitos foram submetidos a análises de microscopia de luz. As amostras de tíbia direita foram destinadas à quantificação química de cálcio, magnésio, zinco e fósforo e, amostras de soro total foram submetidos a análises de quantificação de cálcio e colesterol total. O peso das ratas foi aferido em balança de precisão no próprio biotério. O fêmur esquerdo foi posteriormente seco em estufa a 37 graus Celsius e pesado em balança de precisão e o comprimento destes ossos fêmures foram aferidos com auxílio de um paquímetro digital para medição dos ossos em seu longo eixo. Foi empregada análise estatística modelo linear geral, multivariado e as análises de TRAP foram submetidas a teste de normalidade e em seguida à teste não paramétricos com Kurskal Wallis com análise de variância, havendo diferenças o post-test de Dunn foi realizado para especificar as diferenças ambas com significância de $p \leq 0,05$. Resultados: Foram encontradas diferenças estatisticamente significantes entre Se vs. Se10 e Se30 para BMC, quantificação de Magnésio e quantificação do trabeculado ósseo por Tricromo de Masson na porção distal, OVX vs. OVX10 para densitometria óssea e Cálcio em soro, OVX vs. OVX10 e OVX30 para quantificação de trabeculado ósseo por Tricromo de Masson na porção proximal e distal e Se vs. Se30 e OVX vs. OVX30 para imunomarcação por TRAP, todos os resultados com $p \leq 0,05$. Conclusão: Neste modelo experimental a doxiciclina teve um papel chave no transporte sanguíneo do quelato de cálcio (dados comprovados pela maior presença de cálcio no soro do grupo OVX30) e contribuiu positivamente em ossos de ratas acometidas pela osteopenia induzida por ovariectomia bilateral e sedentarismo, dados comprovados por densitometria, quantificação do trabeculado ósseo de fêmur porção distal, análise qualitativa por imunomarcação por TRAP e quantificação de Mg no osso.

Palavras chave: 1. Osteopenia. 2. Osteoporose. 3. Doxiciclina. 4. Ovariectomia. 5. Sedentarismo. 


\section{ABSTRACT}

de Figueiredo, Fellipe Augusto Tocchini. Study of action of Doxycycline on diferent models of osteopenia. 2017. 86p. Thesis (Doctorate degree in Sciences) - School of Medicine of Ribeirao Preto, University of Sao Paulo, Ribeirao Preto, 2017. Revised Version.

Introduction: Doxycycline, a member of the tetracycline family, is a drug used as an antibiotic (100 mg / day dosage) and as an inhibitor of matrix metalloproteinases - MMPs (20 mg twice daily), a use that has anti-inflammatory effect. Doxycycline is a calcium chelator and therefore interferes with bone remodeling. The main objective of this study was to evaluate the action of the drug doxycycline in the control of osteopenia. Materials and methods: Sixty-three Wistars rats obtained from the USP, campus Ribeirão Preto, were divided into 9 groups with $\mathrm{n}=7$ each, being: Control group with Doxycycline $10 \mathrm{mg} / \mathrm{kg} /$ day (C10), Control with Doxycycline $30 \mathrm{mg} / \mathrm{kg} /$ day (OVX10), Ovariectomized with Doxycycline 30 $\mathrm{mg} / \mathrm{kg} /$ day (OVX30) and Ovariectomized with water (OVX), Sedentarism Group 10mg/kg/day (C30) and Control (C30), Ovariectomized Group with Doxycycline $10 \mathrm{mg} / \mathrm{kg} /$ day (Se10), sedentarism $30 \mathrm{mg} / \mathrm{kg} /$ day (Se30) and Sedentarism with water (Se). All groups had their induction models to osteopenia for 90 days. Subsequently, the groups receiving the medication were submitted to daily doses $(10 \mathrm{mg} / \mathrm{kg} / \mathrm{day}$ and $30 \mathrm{mg} / \mathrm{kg} /$ day) for 60 days. The left femur samples were assigned to Bone Densitometry, right femur samples were subjected to light microscopy, right tibia samples for chemical quantification of calcium, magnesium, zinc and phosphorus, and total serum samples were submitted to quantification of calcium and total cholesterol. The weight of the rats was measured on a precision scale at the animal house. The left femur was dried at 37 degrees Celsius on dried oven and then weighed on a precision scale, and the length of these femur bones were measured using a digital caliper to measure the bones along its long axis. Statistical analysis was used for linear general model, multivariate analysis and the TRAP analyzes were submitted to normality test and then to non-parametric test with Kurskal Wallis with analysis of variance, having differences a Dunn post-test was performed to specify the differences both with significance of $p \leq 0.05$. Results: Statistically significant differences were found between Se vs. Se10 and Se30 for BMC, quantification of Magnesium and quantification of bone trabeculation by Masson trichrome in the distal portion, OVX vs. OVX10 for bone densitometry and Calcium in serum, OVX vs. OVX10 and OVX30 for quantification of bone trabeculation by Masson trichrome in the proximal and distal portion and Se vs. Se30 and OVX vs. OVX30 for TRAP immunostaining, all results with $p \leq 0.05$. Conclusion: At this experimental model, doxycycline played a key role in the blood transport of calcium chelate (data evidenced by the higher presence of calcium in the serum of the OVX30 group) and contributed positively to bone from rats affected by osteopenia induced by bilateral ovariectomy and sedentary lifestyle, supporting data of bone densitometry, quantification of bone trabeculation of the distal femur, qualitative analysis by TRAP immunostaining and quantification of $\mathrm{Mg}$ in the bone.

Keywords: Osteopenia. 2. Osteoporosis. 3. Doxycycline. 4. Ovariectomy. 5. Sedentary lifestyle. 


\section{LISTA DE FIGURAS}

Figura 1- Representação da estrutura química da Doxiciclina anidra..21

Figura 2- Gráfico dos pesos das ratas desde o primeiro dia de experimento até o dia de indução da morte $\left(20^{\mathrm{a}}\right.$ semana). 27

Figura 3- Raio $X$ obtido através da técnica de densitometria óssea demonstrando a diferença anatômica visível em observação macroscópica dos fêmures das ratas do grupo C30 (Doxiciclina $30 \mathrm{mg} / \mathrm{kg}$ induzidos). Nas setas brancas são demonstrados os ossos com as diferenças anatômicas em relação aos outros ossos dos grupo. As diferenças são de tamanho diminuído e forma..... 29

Figura 4- Equipamento AAS400 da Perkin Elmer em processo de quantificação de Cálcio das biópsias ósseas diluídas em ácido nítrico. 30

Figura 5- Figura 4: Amostra de uma placa de ELISA usada para medição de fósforo pelo Método de Fiske (FISKE CH, 1925) 31

Figura 6- Fotomicrografia de uma lâmina histológica de fêmur na porção distal ilustrando o trabeculado ósseo, destacando a placa de crescimento corado por Tricromo de Masson verde-luz em aumento real de $25 x$. 33

Figura 7- Fotomicrografia de uma lâmina de fêmur na porção distal, corado por picro-sirius red em objetiva com aumento real de $40 x$ sob luz polarizada. 34

Figura 8- Gráficos obtidos a partir do Graphprism $5.0 \mathrm{com}$ os resultados de cada um dos experimentos executados nessa tese ilustrados. É importante salientar que as diferenças apresentadas podem não ter alcançado o valor de $p$ mínimo para ser diferente estatisticamente. 37

Figura 9- Fotomicrografia de um corte histológico do osso fêmur porção distal, demonstrando o osso trabecular (OT) e a placa de crescimento (PC). As figuras demonstram que se obteve para o grupo Controle que A vs. C (C vs. C30) $p=0,036$, para o grupo OVX que G vs. H (OVX vs. OVX10) $p<0,01$ e G vs. I (OVX vs. OVX30) $p=0,03$ e para o grupo Se que D vs. $G$ (Se vs Se10) $p=0,05$ e $D$ vs. $F$ (Se vs. Se30) $p=0,02$ possuem diferenças estatisticamente significantes. As letras superiores-esquerda indicam os grupos de estudo: $A=C ; B=C 10$; $\mathrm{C}=\mathrm{C} 30 ; \mathrm{D}=\mathrm{Se}$; E=Se10; $\mathrm{F}=\mathrm{Se} 30 ; \mathrm{G}=\mathrm{OVX} ; \mathrm{H}=\mathrm{OVX10}$ e; I=OVX30. Coloração: Tricromo de Masson, 25x de aumento real. 50

Figura 10- Fotomicrografia de um corte histológico do osso fêmur porção proximal, demonstrando o osso trabecular (OT) e a placa de crescimento (PC). As figuras demonstram que se obteve que G vs. H (OVX vs. OVX10) $p=0,04$ e G vs. I (OVX vs. OVX30) $p=0,05$ possuem diferenças estatisticamente significantes. As letras superiores-esquerda indicam os grupos de estudo: $A=C ; B=C 10 ; C=C 30 ; D=S e ; E=S e 10 ; F=S e 30 ; G=O V X ; H=O V X 10$ e; I=OVX30. Coloração: Tricromo de Masson, aumento real de 25x....... 52

Figura 11- Fotomicrografia de um corte histológico do osso fêmur porção proximal, demonstrando colágeno total refrigente à luz polarizada. Não ocorreram diferenças estatisticamente significantes. As letras superiores-esquerda indicam os grupos de estudo: $\mathrm{A}=\mathrm{C} ; \mathrm{B}=\mathrm{C} 10 ; \mathrm{C}=\mathrm{C} 30 ; \mathrm{D}=\mathrm{Se}$; $\mathrm{E}=\mathrm{Se} 10 ; \mathrm{F}=\mathrm{Se} 30 ; \mathrm{G}=\mathrm{OVX} ; \mathrm{H}=\mathrm{OVX10}$ e; I=OVX30. Coloração: Picro-sirius red, aumento real de 40x. 54 
Figura 12- Fotomicrografia de um corte histológico do osso fêmur porção distal, demonstrando colágeno total refrigente à luz polarizada. Não ocorreram diferenças estatisticamente significantes. As letras superiores-esquerda indicam os grupos de estudo: $A=C ; B=C 10 ; C=C 30 ; D=S e ; E=S e 10 ; F=S e 30 ; G=O V X ; H=O V X 10$ e; I=OVX30. Coloração: Picro-sirius red, aumento real de 40x. 55

Figura 13- Apresentação do corte histológico de um osso corado por Tricromo de Masson em condições normais inerentes ao grupo controle $(C)$, demonstrando uma distribuição normal do trabeculado ósseo (OT) e presença normal da placa de crescimento (PC) nos 3 aumentos (I, II e III). Coloração: Tricromo de Masson, aumento real: 16x ( I ), 25x (II) e 40x (III). 57

Figura 14- Apresentação do trabeculado ósseo com indicativos de prejuízo provocado pela doxiciclina em dose de $10 \mathrm{mg} / \mathrm{kg} / \mathrm{dia}$ (C10) na região distal, com um trabeculado ósseo (OT) sensivelmente mais espaçado e uma placa de crescimento mais espessa (PC). A região proximal não se tem essa diferença. Coloração: Tricromo de Masson, aumento real: 16x (I), $25 x$ (II) e $40 x$ (III)..... 58

Figura 15- Apresentação de uma fotomicrografia de uma amostra submetida a doxiciclina de $30 \mathrm{mg} / \mathrm{kg} / \mathrm{dia}$ (C30) com anomalia na placa de crescimento (PC) indicado pelas setas escuras, tanto nas amostras distais quanto proximais. Na região distal de maior aumento (III), tem-se a presença de um tecido ósseo hipomineralizado difuso em região de trabeculado ósseo (OT) indicado com o círculo vermelho e setas vermelhas (III - Seta vermelha). Na região proximal tem-se a presença da placa de crescimento (PC) mais espessa e anômala (indicada pela seta escura em I, II e III). Coloração: Tricromo de Masson, aumento real: 16x ( I ), 25x (II) e 40x (III). 59

Figura 16- Apresentação do osso osteopênico acometido pelo sedentarismo (Se) induzido em ratas wistar. Com os trabeculados mais espaçados (OT), tem-se nesta Figura as placas de crescimento (PC) presente de maneira normal tanto na região proximal quanto distal. Coloração: Tricromo de Masson, aumento real: 16x (I), 25x (II) e 40x (III)...... 60

Figura 17- Fotomicrografia de um osso acometido pela osteopenia induzida por sedentarismo tratado com doxiciclina na dose $10 \mathrm{mg} / \mathrm{kg} / \mathrm{dia}$ (Grupo Se10) demonstrando uma melhora na região distal (quando se compara com a Figura 14, na mesma região) com um trabeculado ósseo menos espaçado (OT), porém se observa a presença de uma placa de crescimento mais espessa (PC). Na região proximal é observado uma maior espessura na placa de crescimento (PC). Coloração: Tricromo de Masson, aumento real: 16x (I), 25x (II) e 40x (III). 61

Figura 18- Fotomicrografia de um osso acometido pela osteopenia induzida por sedentarismo tratado com doxiciclina na dose 30mg/kg/dia (Grupo Se30) demonstrando uma melhora na região distal (quando se compara com a Figura 14, na mesma região). Observa-se um trabeculado ósseo menos espaçado (OT) e se observa a presença de uma placa de crescimento mais espessa (PC). Na região proximal é observado uma maior espessura na placa de crescimento (PC). Coloração: Tricromo de Masson, aumento real: 16x (I), 25x (II) e $40 \mathrm{x}(\mathrm{III})$. 
Figura 19- Fotomicrografia demonstrando um osso acometido pela osteopenia induzida por ovariectomia bilateral em ratas Wistar (OVX). Na região distal, se observa o trabeculado ósseo (OT) quase que inexistente e uma placa de crescimento bem disforme (PC). Na região proximal, não se observa este problema tão evidente, apesar de termos um osso trabecular (OT) mais espaçado se compararmos com os grupos controle (C Figura 11). Coloração: Tricromo de Masson, aumento real: 16x (I), 25x (II) e 40x (III). 63

Figura 20- Quando se analisa a região distal tem-se uma sensível melhora do quadro (OVX10), se comparado com a Figura 17. Há a ocorrência de um osso trabecular (OT) na região onde havia a placa de crescimento $(\mathrm{PC})$, porém se vê uma anormalidade na placa de crescimento. Na seta escura tem-se a placa de crescimento (PC) interrompida na região sagital do corte histológico. Olhando na região proximal, nota-se uma placa de crescimento sensivelmente mais espessa (PC). Coloração: Tricromo de Masson, aumento real: 16x (I), 25x (II) e 40x (III) 64

Figura 21- Na região distal é apresentado um osso osteopênico tratado por doxiciclina $30 \mathrm{mg} / \mathrm{kg} / \mathrm{dia}$ (OVX30) com uma melhora real no trabeculado ósseo (OT) se compararmos com a Figura 18. Na seta escura tem-se a placa de crescimento apresentando uma anomalia morfológica. Na região proximal, não se atesta grandes diferenças. Coloração: Tricromo de Masson, aumento real: 16x (I), 25x (II) e 40x (III) 65

Figura 22- Padrão de imunomarcação para TRAP. A-R: fotomicrograficas evidenciando o padrão de imunomarcação para TRAP nos grupos $\mathbf{C}(\mathbf{A}, \mathbf{D}), \mathrm{C} 10(\mathbf{B}, \mathbf{E}), \mathrm{C} 30(\mathbf{C}, \mathbf{F})$, OVX (G, J), OVX10 (H, K), OVX30 (I, L), SE (M, P), SE10 (N, Q), SE30 (O, R). Símbolos: setas vermelhas: células imunomarcadas e, retângulos: aumentos nas áreas indicadas. Contracoloração: Hematoxilina de Harris. Aumento: A-C, G-I, M-O: 400x; D-F, J-L, P-R: 1000x. 


\section{LISTA DE TABELAS}

Tabela 1- Padrão de imunomarcação para TRAP. A-I: fotomicrograficas evidenciando o padrão de imunomarcação para TRAP nos grupos C (A), C10 (B), C30 (C), OVX (D), OVX10 (E), OVX30 (F), SE (G), SE10 (H), SE30 (I). ${ }^{a} \mathrm{e}^{\mathrm{b}}$ são diferentes entre si com $\mathrm{p}<0,00001$ 39

Tabela 2- Comparação entre os grandes grupos de indução de osteopenia com o valor de $p$ demonstrado somente em caso de diferenças estatisticamente significantes $(p \leq 0,05)$. Quando não há o valor de "p" é porque não foi estatisticamente diferente.

Tabela 3- Comparação entre os grupos de indução com suas respectivas doses, verificando se há diferenças estatisticamente significantes $(p \leq 0,05)$. Quando não há o valor de "p" é porque não foi estatisticamente diferente. 42

Tabela 4- Tabela demonstrativa da significância dos medicamentos em cada modelo de indução de osteopenia. Valores de "p" demonstrados somente $p \leq 0,05$. *Valor de $\mathrm{P}$ próximo ao patamar máximo de diferença. Quando não há o valor de "p" é porque não foi estatisticamente diferente. 


\section{SUMÁRIO}

1 INTRODUÇÃO

1.1 Tecido ósseo e sua remodelação

1.2 Osteoporose/Osteopenia e sua indução em modelos animais $\quad$....................... 17

1.3 Sedentarismo e sua importância na saúde pública

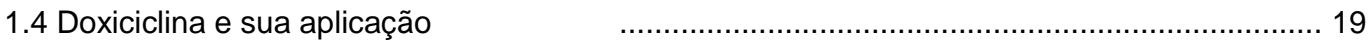

2. JUSTIFICATIVA

3. OBJETIVOS

4. MATERIAIS E MÉTODOS

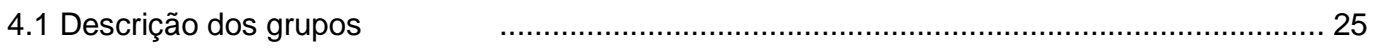

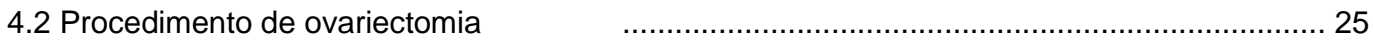

4.3 Procedimentos para os grupos de sedentarismo $\quad$........................................... 26

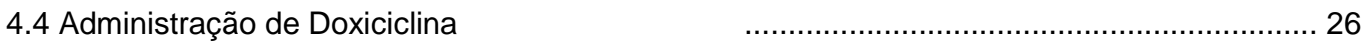

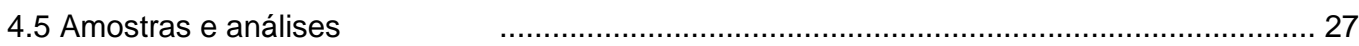

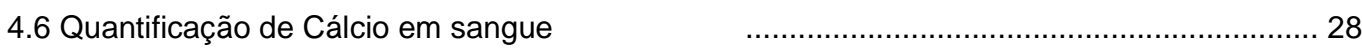

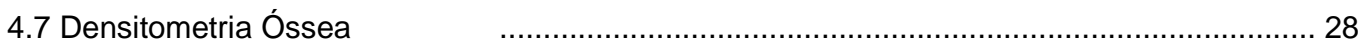

4.8 Análises químicas de cálcio, magnésio e zinco nos ossos $\quad$................................. 29

4.9 Análise de fósforo

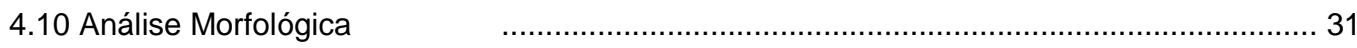

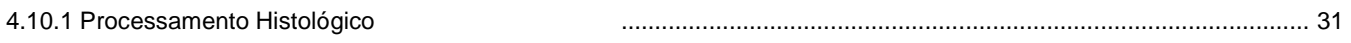

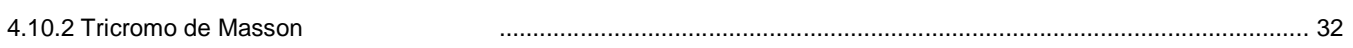

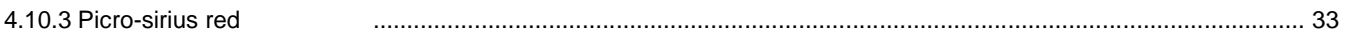

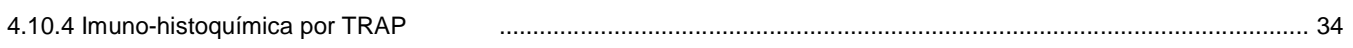

4.10.5 Análise por microscopia de luz

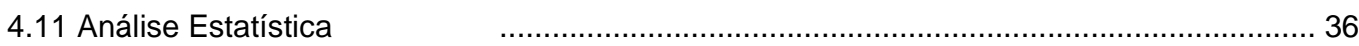

5. RESULTADOS

5.1 Análises macroscópicas das amostras e comportamento das ratas $\quad$......................37

5.2 Apresentação dos resultados para cada análise

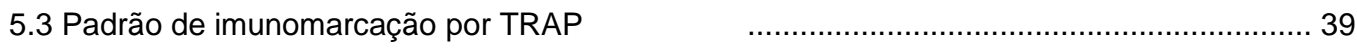

5.4 Comparação entre as induções de osteopenia

5.5. Comparando-se os grupos de indução a osteopenia com as doses de medicamentos........ 41

5.6. Comparando-se as doses de medicamentos com os grupos de indução à osteopenia......... 44 
5.7 Análise qualitativa das lâminas histológicas coradas por tricromo de Masson verde-luz, picrosirius red e imunomarcação por TRAP

5.7.1 Tricromo de Masson verde-luz

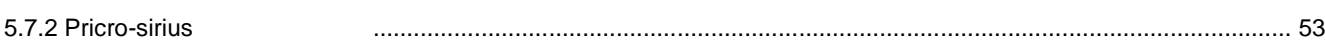

5.7.3 Análise qualitativa das lâminas coradas por tricromo de Masson $\quad$.......................................... 56

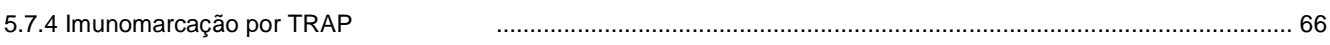

6. DISCUSSÃO $\quad$................................................................................................68

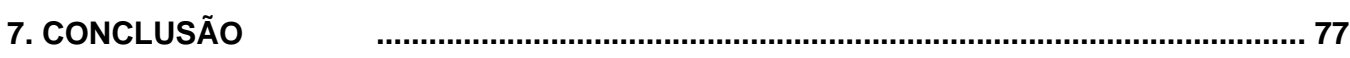

8. REFERÊNCIAS 


\section{INTRODUÇÃO}

\subsection{Tecido ósseo e sua remodelação}

Os ossos são um tipo de tecido conjuntivo especializado formado por uma matriz mineralizada e células (JUNQUEIRA; CARNEIRO, 2008), representando um complexo mineral que tem a função de armazenamento de cálcio e fósforo para o organismo. Além disso, os ossos têm função estrutural e hematopoetico, sendo então um órgão complexo de funções muito variadas (LORENZO; HOROWITZ; CHOI, 2008).

A mineralização óssea é composta em duas etapas distintas, a primeira etapa corresponde numa mineralização rápida chegando a $60 \%$ do total da mineralização óssea, a segunda etapa corresponde a uma mineralização óssea mais lenta chegando a 95\% do total da mineralização óssea. O grau de mineralização secundária é dependente da remodelação óssea; quando a remodelação se apresenta diminuída, é mais longo o tempo de mineralização secundária. Quando a remodelação acontece de forma rápida, o osso recémformado é removido antes do tempo ideal de mineralização secundária (MARTIN; CORREA, 2010). Um osso hipermineralizado se torna friável, ou seja, não deforma como deveria se tornando muito quebradiço. Isso ocorre porque quando a segunda etapa de mineralização ocorre de maneira mais intensa, o resultado final é um osso mais mineralizado e portanto, mais frágil que um hipomineralizado. Um osso hipomineralizado tem menos quantidade de cálcio, pois a reabsorção óssea neste caso é maior que o grau de mineralização, ou seja, o osso se torna menos rígido e então deixa de ter sua função estrutural em plenitude (RIGGS et al., 1994). O tempo de desmineralização óssea está relacionado com a quantidade de cálcio presente no osso e varia de acordo com o tipo de osso analisado e o grupo de estudo animal (LEWANDROWSKI et al., 1997).

A qualidade óssea é determinada pela taxa de remodelação óssea que é um processo contínuo de renovação óssea, onde um tecido velho ou danificado é reabsorvido e um novo tecido é formado, mantendo assim a integridade mecânica do osso e a homeostase do cálcio 
no organismo. As propriedades estruturais dos ossos incluem sua geometria (tamanho e forma) e sua microarquitetura (trabecular ou cortical), enquanto suas propriedades materiais incluem sua composição mineral e concentração de colágeno (JUNQUEIRA; CARNEIRO, 2008; MARTIN; CORREA, 2010).

A remodelação óssea se inicia com a reabsorção osteoclástica, sendo essa uma atividade erosiva que cria lacunas de $60 \mu \mathrm{m}$ em indivíduos jovens e $40 \mu \mathrm{m}$ em indivíduos mais velhos. A reabsorção tem uma média de 35 dias de duração enquanto a formação óssea é de, em média, 150 dias (ERIKSEN; GUNDERSEN; et al., 1984; ERIKSEN; MELSEN; MOSEKILDE, 1984). Uma remodelação acelerada leva a uma redução irreversível da estrutura trabecular, resultando em um osso mais frágil e aumentando o risco de fraturas. Os marcadores da remodelação são passíveis de identificação na urina e no sangue. São subprodutos de osteoblastos/osteócitos e osteoclastos, como por exemplo, fragmentos de quebras de colágeno tipo 1 (CTx - telopeptídeo-C do colágeno tipo 1 ósseo), decorrentes da degradação do colágeno. Níveis elevados de CTx geralmente indicam remodelação acelerada (MARTIN; CORREA, 2010).

Os ossos são compostos majoritariamente por cálcio $(37,6 \% \sim 38.2 \%)$, seguido de fósforo $(17,6 \% \sim 18,2 \%)$, sódio $(1,07 \% \sim 1,10 \%)$, magnésio $(0,56 \% \sim 0,61 \%)$ (AMMERMAN et al., 1974) e zinco, sendo este em menor proporção (0,067\%) (STEWART; MAGEE, 1964), porém igualmente considerado um macroelemento. Para que o cálcio chegue aos ossos, é necessário que ele seja antes absorvido pelo organismo. De fato, sabe-se que apenas $30 \%$ de cálcio é absorvido pelo organismo e isso significa que uma dieta rica em cálcio não leva a aumentos de sua concentração em osso (INSTITUTE OF MEDICINE STANDING COMMITTEE ON THE SCIENTIFIC EVALUATION OF DIETARY REFERENCE, 1997), além disso sabe-se que o próprio corpo "excreta" cálcio para o intestino e isso representa que podemos estar presenciando uma menor concentração de cálcio advindo de dietas no organismo (ou seja, absorção menor que 30\%) (HEANEY; ABRAMS, 2004). 


\subsection{Osteoporose/Osteopenia e sua indução em modelos animais}

A osteoporose é um distúrbio clássico inerente à idade, responsável pelo aumento do risco de fraturas ósseas (RIGGS; MELTON, 1986). A incidência de fraturas devido à osteoporose está aumentando e isso aumenta também os custos de saúde pública (BANDEIRA; CARVALHO, 2007; ROSS et al., 1993). Foi demonstrado em estudo que as condições (alimentação e exercícios físicos) que o indivíduo vive em sua juventude é crucial para o aparecimento da osteoporose no futuro, sendo a adolescência e a infância essenciais para proporcionar aumento da densidade óssea e o crescimento ósseo em humanos (MALINA; BOUCHARD; BAR-OR, 2004).

A remodelação óssea depende de um balanço entre a reabsorção e a formação óssea (MATSUO, 2009). A osteoporose é decorrente da diminuição da massa óssea gerando uma osteopenia e deteriorando, portanto, a microarquitetura óssea, criando assim um maior risco à fraturas ósseas. Os traumas de quadril são um exemplo clássico de sua relação com a morte, deficiências permanentes e aumentos nos custos médicos (CUMMINGS, S. R. et al., 1985), por isso não há dúvidas em relação a este tipo de fratura com o quadro osteoporose (GALLAGHER, 1990).

A World Health Organization (WHO), criou a sigla bone mineral density (BMD) ou densidade de massa óssea para quantificar quando uma pessoa está com o quadro de osteoporose sedimentada e isso ocorre quando se chega a "2,5 T-Score" (índice T). A Organização sugere que se uma pessoa é um adulto jovem sem fraturas ósseas, porém com o BMD menor que 2,5, então é chamado de osteoporose estabelecida, caso haja fraturas é considerado como osteoporose severa. Sabendo disso, se criou os modelos animais para indução a osteopenia, sendo um deles o de ovariectomia que induz mimeticamente a menopausa que por sua vez é marcada pela remodelação óssea em que a atividade osteoclástica excede a atividade osteoblástica, sendo assim ocorre uma indução à osteoporose (TEITELBAUM, 2000), sendo este o modelo animal usado para este fim (JEE; YAO, 2001). Grupos de estudos trabalham com este tipo de indução à osteopenia no modelo animal de ratas Wistar há muitos anos e trazem resultados muito relevantes para a prática 
em pesquisa (ISSA et al., 2015; MACEDO et al., 2017; MONTEIRO et al., 2016; SHIMANO; VOLPON; LIMA, 2008; SHIMANO, ROBERTA CARMINATI et al., 2014).

\subsection{Sedentarismo e sua importância na saúde pública}

Hoje em dia os adolescentes e crianças estão sendo "vítimas" das comodidades e da obesidade (WANG; MONTEIRO; POPKIN, 2002), (DUNCAN et al., 2011), sem contar que a prevenção contra doenças da vida adulta deve ser feita neste período de vida (pressão alta, diabete mellitus, dislipidemias) (FERNANDES et al., 2011; MALINA et al., 2004). Um estudo trouxe um dado agravante em matéria de osteoporose e sua relação com o sedentarismo, em ossadas encontradas em criptas entre os anos de 1729 e 1852. Os autores demonstraram que uma mulher na menopausa com 70 anos nos dias atuais tem uma densidade óssea muito menor do que uma mulher de idade equivalente há dois séculos atrás e o fator primordial dessa diminuição na qualidade óssea estaria relacionada à ausência de exercícios físicos na idade moderna (LEES et al., 1993). Além disso, é salientado que exercícios na juventude, mesmo quando os ossos são mais maleáveis promovem uma melhor qualidade óssea no futuro (BASS et al., 1998; KONTULAINEN et al., 2001; MACKELVIE et al., 2003; MORRIS et al., 1997) e no caso da prática de esportes quando se discute sobre jogadores de futebol que abandonaram sua profissão há mais de 20 anos, Karlsson e colaboradores demonstraram uma qualidade óssea residual protetora depois de todo este tempo parados (KARLSSON et al., 2000).

A dieta de cálcio deficitária também é importante para o agravamento do quadro de osteopenia, uma vez que a ausência de cálcio na dieta piora ainda mais sua absorção pelo organismo. Isso é demonstrado por uma metanálise feita em 1996 por Specker que apresentou resultados demonstrando que uma vida sedentária (sem exercícios físicos) aliada a uma alimentação pobre em cálcio piora o quadro de osteopenia, dados obtidos a partir de densitometria óssea (SPECKER, B. L., 1996). Além disso, estudos mais recentes com jovens adolescentes europeus demonstraram uma associação positiva entre exercícios e uma dieta balanceada, melhorando assim a qualidade óssea (SPECKER, B.; VUKOVICH, 2007; 
VALTUENA et al., 2012). Esta relação foi encontrada também em amostragens de infantes 6-12 anos quando sujeitos a exercícios moderados a vigorosos (SIOEN et al., 2015), além disso em idosos, Blumentthal e colaboradores chegaram à conclusão que, em idosas, uma dieta rica em cálcio aliada a exercícios físicos levou a um quadro de osteopenia amenizado em um curto período de meses (4-8 meses) (BLUMENTHAL et al., 1991). Por isso deve-se evitar a vida sedentária e procurar tratamento adequado para se evitar uma perda de qualidade óssea por toda a nossa vida.

Um dado alarmante se dá no estudo feito em 1980 onde foi demonstrado que há trocas do osso cortical por osso trabecular de baixa qualidade em traumas de porção proximal de fêmures de idosos com idade acima de 60 anos e a incidência de fraturas em idosos de 90 anos são 33\% para mulheres e 17\% para homens (GALLAGHER et al., 1980).

Portanto, torna-se imprescindível os estudos sobre qualidade óssea em amostras animais sujeitos ao sedentarismo, pois a população mundial está ficando cada vez mais velha e mais propensa a traumas ósseos decorrentes de uma vida mais sedentária.

\subsection{Doxiciclina e sua aplicação}

A Doxiciclina é um membro da família das tetraciclinas, sendo uma droga utilizada como antibiótico (posologia de 100 mg/dia) e como inibidor de metaloproteinases de matriz, MMPs (na posologia de $20 \mathrm{mg}$ duas vezes ao dia), uso que tem efeitos de droga antiinflamatória. Com esta última indicação ela é utilizada no tratamento da periodontite crônica (GOLUB et al., 2001) e de inflamações crônicas na pele (TAN et al., 2011). Para estes usos a doxiciclina em "subdoses" (doses não antimicrobianas) foi aprovada em 1998 pela Food and Drug Administration (FDA) nos EUA (equivalente à ANVISA no Brasil) e também pelas agências regulatórias do Canadá e Europa. Estas formulações de doxiciclina têm o nome Periostat e Oracea (nos EUA) e o uso pode ser feito continuamente por 9 meses. Nesta dose está descrito que não ocorre o surgimento de resistência microbiana à doxiciclina (THOMAS; WALKER; BRADSHAW, 2000). 
Foi demonstrado que a doxiciclina pode inibir o remodelamento vascular induzido em modelo experimental 2R1C, em dose de 30mg/kg/dia (CASTRO, M. M. et al., 2008), portanto uma dose maior (20mg, duas vezes ao dia), porém ainda não antimicrobiana comparativamente as doses já aplicadas em humanos, cerca de $1 \mathrm{mg} / \mathrm{kg}$ a $1,5 \mathrm{mg} / \mathrm{kg}$ (PRALL et al., 2002).

As MMPs são as principais proteases responsáveis pela degradação periodontal (GURKAN et al., 2008). A Colagenase-2 (MMP-8) é inibida por doxiciclina e esta MMP é atualmente a mais estudada e diretamente associada com a severidade da doença periodontal (SORSA et al., 2011; SORSA; TJADERHANE; SALO, 2004). Foram comprovados vários efeitos benéficos do uso da doxiciclina em doença periodontal como coadjuvante à terapia convencional (GOLUB et al., 1995). A doxiciclina também tem um potencial de inibição da degradação da matrix extracelular (NOVAK et al., 2002).

Como inibidor de MMPs, trabalhos com a doxiciclina tem demonstrado efeitos muito benéficos em várias doenças cardiovasculares, particularmente em aneurismas (ABDULHUSSIEN et al., 2009), aterosclerose (CASTRO, M. M. et al., 2008), calcificação de aorta (BOUVET et al., 2008), hipertensão arterial (CASTRO, M. M. et al., 2008), além da diminuição de biomarcadores de inflamação em mulheres com histórico de doença periodontal. Como no caso da periodontite e das doenças de pele, a grande vantagem do uso da doxiciclina para as doenças cardiovasculares, com grande envolvimento de MMPs, se refere ao fato da doxiciclina ser uma droga conhecida desde 1958, portanto são conhecidos os seus efeitos colaterais. Além desta, a outra enorme vantagem é seu baixo preço, especialmente quando comparada ao preço de novos inibidores enzimáticos que são extremamente caros e com efeitos colaterais ainda não descritos.

As tetraciclinas foram descobertas em 1948 e sua indicação, primariamente como antibiótico, foi bastante ampliada atualmente para o uso como antiinflamatório em doenças em que a atividade de MMPs é muito alta. Assim, hoje as tetraciclinas, têm sido indicadas no tratamento de doenças de pele como acne, dermatoses, escleroderma, rosácea e doenças sistêmicas como artrite reumatoide (SAPADIN; FLEISCHMAJER, 2006). 
Figura 1: Representação da estrutura química da Doxiciclina anidra.

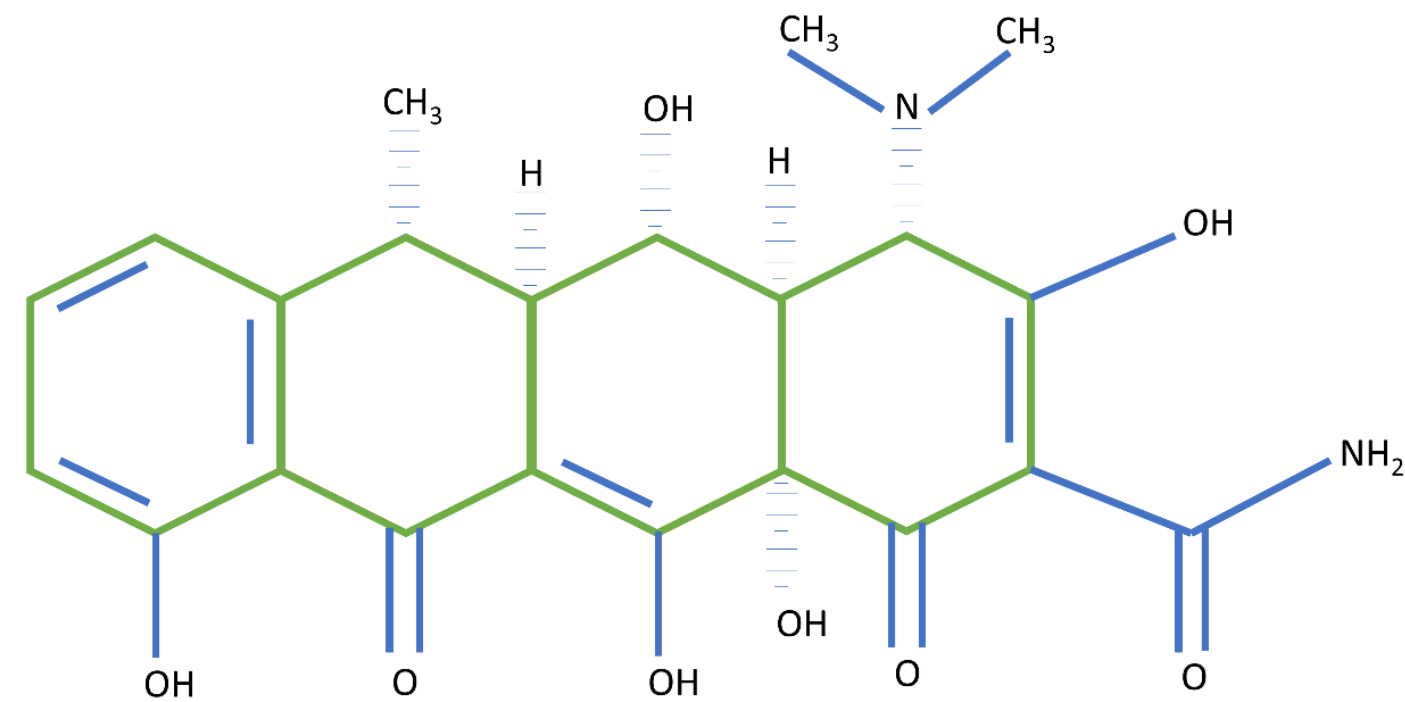

Na Figura 1 está referenciada a molécula da doxiciclina (BABU et al., 2002; GRIFFIN et al., 2010) anidra (Anidra pois, olhando na porção superior da molécula, é observado duas ligações carbono com hidrogênio nos anéis de carbono). Na porção mais inferior da molécula doxiciclina tem-se uma maior suscetibilidade para ligação com os metais bivalentes, pois as ligações com oxigênio e hidrogênio são as mais facilmente rompíveis para serem compostas pelo metal bivalente (SAPADIN; FLEISCHMAJER, 2006). Outro estudo afirma que em presença dos íons $Z^{2+}$, há a ocorrência de competição pelo sítio catalítico da MMP-7 ligado previamente ao íon $\mathrm{Ca}^{2+}$, sendo assim inibindo atividade da MMP-7 (GARCÍA et al., 2005), embora seja de conhecimento que as tetraciclinas são quelantes de íons $\mathrm{Zn}^{2+}$ (PETERSON, 2004), o seu real mecanismo de inibição das MMPs ainda não são esclarecidos.

As tetraciclinas têm 4 anéis aromáticos (Figura 1) e têm a característica de quelar metais bivalentes em condições fisiológicas, formando complexos de quelato (PALM et al., 2008). Segundo estes autores “[...] Estes complexos de metais bivalentes são as moléculas biologicamente relevantes que conferem o caráter antibiótico a estas drogas e inibem a 
síntese de proteína ribossomal em procariotos [...]". Neste artigo os autores testaram a associação (calculando as constantes de equilíbrio de associação) entre vários metais bivalentes e a tetraciclina, sendo estes: magnésio, cálcio, estrôncio, bário, manganês, ferro, cobalto, níquel, cobre, zinco e cadmio. As constantes de associação destes elementos variaram em 3 ordens de magnitude, e os resultados mostram que, em condições fisiológicas, os metais com maior afinidade pela tetraciclina são bário, estrôncio, cadmio, seguido de cálcio, magnésio, cobre, manganês e zinco. Somente o ferro, níquel e cobalto tiveram afinidade menor do que o zinco (cerca de 5 vezes menor). Este estudo demonstra que a tetraciclina tem afinidade maior por vários outros metais em comparação com cálcio e zinco. Entretanto, como os níveis fisiológicos do cálcio são da ordem de milimolar, este é o metal que normalmente no organismo está ligado a tetraciclina, uma vez que os outros metais bivalentes estão em concentrações muito menores (PALM et al., 2008).

Além disso, as tetraciclinas inibem a MMP-13 e sabe-se muito bem que esta MMP está intrinsecamente relacionada com a biologia da placa de crescimento e que, juntamente com o colágeno do tipo $\mathrm{X}$, foi encontrada em menor quantidade em camundongos nocaute e essa falta de expressão está relacionada com o nanismo e, assim estão relacionadas com alterações em atividades dos condrócitos (IONESCU et al., 2012). É sabido que o condrócito hipertrofiado é responsável por $60 \%$ do crescimento ósseo, $30 \%$ pela deposição mineral e 10\% pela proliferação mineral (WILSMAN et al., 1996). Sabe-se que a doxiciclina está intimamente envolvida na biologia do reparo tecidual onde os achados demonstram que este medicamento age na angiogênese e na modulação de colágeno. Inicialmente a doxiciclina inibe a formação tecidual da bolsa inflamatória (uma espécie de coágulo induzido), conforme o tempo passa o tratamento com doxiciclina inibe a degradação de colágeno e a reabsorção da bolsa inflamatória, melhorando assim a qualidade do tecido e modulando sua resposta inflamatória (LAMPARTER; SLIGHT; WEBER, 2002).

Tendo em vista que cálcio, sódio, zinco e o magnésio têm certas características químicas em comum, a doxiciclina poderia ser utilizada como agente "quelante" (embora este termo não seja o mais correto) destes íons, e talvez este efeito possa levar ao aumento da excreção 
nas fezes e urina, bem como a diminuição destes quatro metais no sangue total e consequentemente no osso. Como é sabido que a doxiciclina se deposita em tecidos ósseos (BOULOS; KNOEPP; RUBIN, 2007; DEMPSTER, 2008; PAUTKE; BAUER; et al., 2010), talvez este quelato se deposite nos ossos, aumentando assim a quantidade de minerais totais nos ossos.

\section{JUSTIFICATIVA}

No presente trabalho não se procura melhorar a qualidade óssea aumentando a concentração de cálcio em dieta para ratas, usando hormônios como a vitamina D ou até mesmo usando os exercícios para melhorar a qualidade óssea. Neste estudo procura-se usar um agente quelante de metais divalentes que tem sua deposição óssea conhecida (PAUTKE; VOGT; et al., 2010) e ver se ocorre uma melhora na qualidade óssea, uma vez que sabe-se que as tetraciclinas tem capacidade de ligação com proteínas do soro (albuminas e globulinas) na medula óssea (MCEVOY, 2008).

No presente trabalho, abrangemos duas técnicas clássicas de indução à osteoporose (LELOVAS et al., 2008) e acreditamos na possibilidade de amenizar os efeitos deletérios da osteoporose (ou osteopenia) com administração de Doxiciclina em duas posologias, 10mg e 30mg (de modo dose-dependente). Neste sentido, nos embasamos em literatura para que isso seja possível, uma vez que a Doxiciclina é um medicamento capaz de quelar cálcio (ou metais divalentes) e então sua administração poderia reduzir o quadro de osteoporose. Além disso, sabemos que este medicamento pode atuar como coadjuvante ou amenizador dos quadros de osteopenia mencionados, uma vez que já são conhecidas as respostas das MMPs nestas condições de indução (ISSA et al., 2015) e assim modular a resposta no equilíbrio de reabsorção e deposição óssea dadas as condições de ovariectomia e sedentarismo (DAI et al., 2008; PRESTES et al., 2009) (PEREIRA, G. B. et al., 2010).

O presente trabalho foi embasado nos parâmetros já conhecidos pela comunidade científica de que um modelo animal apropriado para qualquer investigação de metodologia deva ser baseado nas seguintes considerações: (1) modelo adequado, (2) apropriado como 
análogo, (3) a uniformidade genética de organismos quando aplicável, (4) o conhecimento a fundo de propriedades biológicas, (5) custo e disponibilidade, (6) generalização dos resultados, (7) facilidade e adaptabilidade para experimental e manipulação, (8) as considerações ecológicas e (9) implicações éticas e sociais (TURNER, 2001), (DAVIDSON; LINDSEY; DAVIS, 1987).

\section{OBJETIVOS}

Objetivamos neste trabalho avaliar o potencial de ação da doxiciclina no controle da osteopenia.

Para tanto, nós justificamos o presente trabalho com o emprego da metodologia de quantificação cálcio no sangue, histologia qualitativa e quantitativa, imuno-histoquímica por TRAP e a metodologia "padrão ouro" (espectrometria de absorção atômica) de análise química, para assim sabermos o quanto realmente tem-se de perda (ou não-perda) óssea nestes grupos expostos à doxiciclina em comparação com os controles e assim possamos concluir as vantagens do medicamento doxiciclina com dados quantitativos e qualitativos.

\section{MATERIAIS E MÉTODOS}

O presente trabalho foi aprovado pelo Comitê de Ética para uso de animais em pesquisa sob o protocolo $\mathrm{n}^{0}$ 2013.1.1528.58.5 da FORP-USP que segue os parâmetros internacionais sobre uso e manipulações animais. Sessenta e três ratas Wistar fêmeas em torno de 45 dias de vida (ou 150g) foram obtidas a partir da colônia do Biotério Central do campus da Universidade de São Paulo, Ribeirão Preto e ficaram no biotério da Faculdade de Odontologia para ambientação por 30 dias até procedimento metodológico. Em seguida, as ratas foram pesadas e posteriormente divididas aleatoriamente em 9 grupos com 7 ratas em cada um. Os procedimentos experimentais dos grupos foram iniciados com 80 dias de idade de vida, uma vez que as fêmeas alcançam a maturidade sexual com esta idade e sabe-se que a maturidade óssea é adquirida somente com 10 meses de idade (ou 300 dias de vida) (JEE; YAO, 2001). As ratas foram submetidas à indução de osteopenia/osteoporose por 90 
dias e somente depois foram tratadas por 60 dias com Doxiciclina nas 2 concentrações mencionadas quando pertinente ao grupo.

\subsection{Descrição dos grupos}

Quanto à divisão dos grupos:

Grupo Controle com Doxiciclina 10mg/kg/dia (C10), Controle com Doxiciclina 30 mg/kg/dia (C30) e Controle(C), Grupo Ovariectomizado com Doxiciclina 10mg/kg/dia (OVX10), Ovariectomizado com Doxiciclina 30mg/kg/dia (OVX30) e Ovariectomizado com água (OVX), Grupo Sedentarismo 10mg/kg/dia (Se10), sedentarismo 30mg/kg/dia (Se30) e Sedentarismo com água (Se).

No grupo sem qualquer intervenção de indução de osteopenia, foram induzidas as mortes dos animais e as mesmas metodologias científicas foram aplicadas. Os grupos C, Se e OVX tomaram água corrente. No grupo com ovariectomia e no grupo controle-Sham foram feitos os acessos cirúrgicos, porém não houve o procedimento final de ovariectomia. No grupo de Sedentarismo, o grupo Sham foi contido em gaiolas para limitar seus movimentos.

A alimentação de todos os grupos foi dada Ad Libitum.

\subsection{Procedimento de ovariectomia}

Os animais foram anestesiados com Xilazina (relaxante muscular) e Ketamina (anestésico) na concentração $100 \mathrm{mg} / \mathrm{kg}$ e $10 \mathrm{mg} / \mathrm{kg}$ de peso do animal respectivamente, seguido de tricotomia entre o rebordo costal inferior e o início da pelve e posteriormente submetido à antissepsia da área, acesso cirúrgico e divulsão do tecido. Logo em seguida realizou-se a evisceração do corno ovariano e ligadura para que não houvesse sangramento pós-operatório. O mesmo procedimento foi realizado no lado oposto para que houvesse a excisão de ambos os ovários (SHIMANO et al., 2008), seguido de aplicação de pentabiótico (Zoetis, Parsippany-Troy Hills, Nova Jersey, EUA) por um período de 48 horas após a cirurgia. A osteopenia foi induzida em 90 dias após o procedimento cirúrgico, uma vez que houve achados significativos com esta idade (WRONSKI; CINTRON; DANN, 1988), (WRONSKI et 
al., 1989). Em seguida os grupos receberam a doxiciclina (Bioquanti, farmácia de manipulação, Ribeirão Preto, SP, Brasil) nas 2 concentrações por 60 dias.

\subsection{Procedimentos para os grupos de sedentarismo}

Para o grupo Sedentarismo, as fêmeas ficaram em gaiolas individuais de plástico no Biotério da FORP-USP com grade superior de $30 \mathrm{~cm} \times 20 \mathrm{~cm} \times 16 \mathrm{~cm}$, limitando seus movimentos por 90 dias para imitar um quadro de sedentarismo (TSCHOP; HEIMAN, 2001). Em seguida, receberam o medicamento por 60 dias.

\subsection{Administração de Doxiciclina}

A doxiciclina foi administrada na água de beber, conforme utilizado no estudo de (ISSA et al., 2015), após o período de 90 dias (para efeito de comparação entre os grupos) por 60 dias corridos e foi feita a manutenção de acordo com um gráfico diário do quanto o animal ingeria de água, com tudo devidamente anotado e controlado (Figura 2). As duas doses escolhidas foram baseadas em estudos previamente publicados (BRIEST et al., 2003; CASTRO, MICHELE M. et al., 2012; GUIMARAES et al., 2011; THARAPPEL et al., 2016). 
Figura 2: Gráfico dos pesos das ratas desde o primeiro dia de experimento até o dia de indução da morte $\left(20^{\mathrm{a}}\right.$ semana).

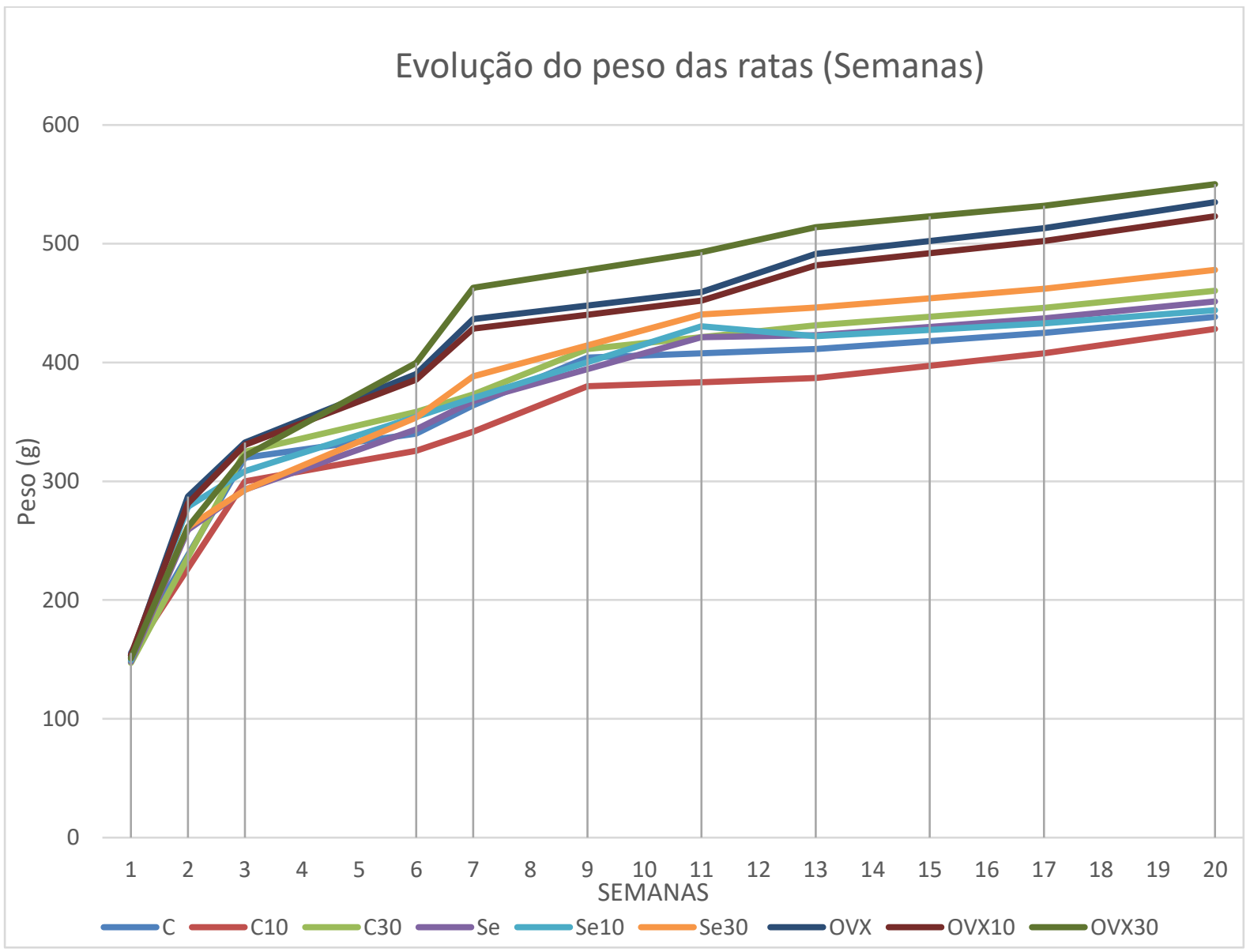

\subsection{Amostras e análises}

As amostras de fêmures esquerdos foram destinadas para densitometria óssea, já as amostras de fêmures direito foram destinadas para análises histológicas. Utilizou-se amostras de tíbia direita para quantificação química de cálcio, magnésio, zinco e fósforo. O peso das ratas foi aferido em balança de precisão no próprio biotério. O fêmur esquerdo (seco em estufa a 37 graus Celsius) foi posteriormente pesado em balança de precisão laboratorial BioPrecisa FA2104N (Curitiba, PR, Brasil) e o comprimento dos ossos fêmures foram aferidos com auxílio de um paquímetro digital, medindo os ossos no seu longo eixo. O soro sanguíneo foi usado para medição de cálcio e colesterol total. 


\subsection{Quantificação de Cálcio em sangue}

O sangue dos animais foi obtido através da punção cardíaca com seringas e agulhas previamente descontaminadas em ácido nítrico 3\% e sujeito à separação de soro em falcons livre de metais (BD Line Biosciences, São Paulo, Brasil). O catalizador para separação do fosfato foi o lantânio sendo este um interferente típico desta amostra neste tipo de análise. 0 lantânio foi dosado na proporção máxima de 0,1 a $1 \%$ do volume total diluído e as amostras foram analisadas em um equipamento de absorção atômica por chama (AAS400 Perkin Elmer, Norwalk, USA).

\subsection{Densitometria Óssea}

Os fêmures esquerdos foram submetidos à análise densitométrica por equipamento densitômetro dual-energy de raios-X, DPX-Alpha, Lunar® (Lunar, Madison, WI, Estados Unidos) instalado na Faculdade de Medicina de Ribeirão Preto-USP, adaptado para medição em pequenos animais com o software PIXImus (Lunar, Madison, WI, Estados Unidos) (JOHNSON et al., 2005; OKUBO et al., 2017). A aquisição de imagem se procedeu com os fêmures na mesma posição, imersos numa profundidade de $2 \mathrm{~cm}$ de água deionizada (simulando os tecidos moles) e as seguintes opções foram selecionadas: Osso Tipo 1 Apendicular; modo de alta resolução; $76 \mathrm{kVp}$; $150 \mu \mathrm{A}$; colimação; áreas padrão $40 \mathrm{~mm} \mathrm{X}$ $20 \mathrm{~mm}$.

Foram coletadas as informações sobre conteúdo de massa óssea (BMC - bone mass content) e densidade mineral óssea (BMD - bone mineral density) (Figura 3). As setas brancas serão discutidas na Seção 5.1 . 
Figura 3. Raio X obtido através da técnica de densitometria óssea demonstrando a diferença anatômica visível em observação macroscópica dos fêmures das ratas do grupo C30 (Doxiciclina $30 \mathrm{mg} / \mathrm{kg}$ induzidos). Nas setas brancas são demonstrados os ossos com as diferenças anatômicas em relação aos outros ossos dos grupos. As diferenças são de tamanho diminuído e forma.

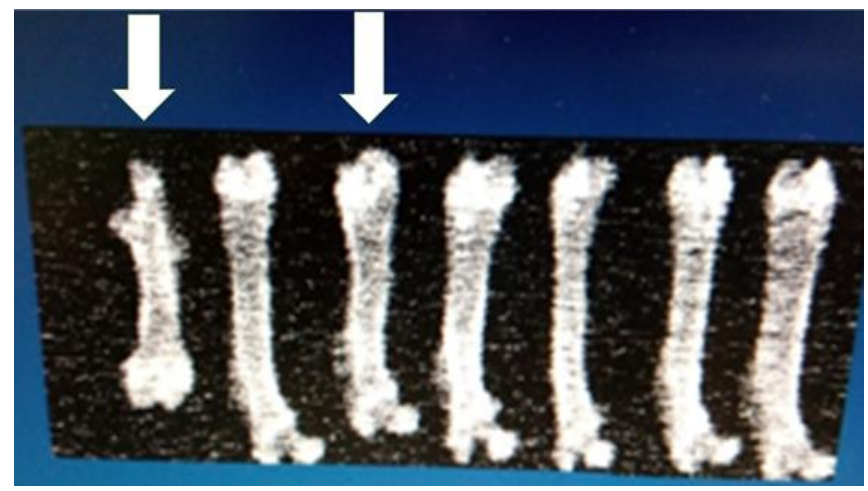

\subsection{Análises químicas de cálcio, magnésio e zinco nos ossos}

Toda a vidraria, ponteiras e materiais empregados na análise foram descontaminados em ácido nítrico ultrapuro (AUGUSTO TOCCHINI DE FIGUEIREDO et al., 2014), diluído em água deionizada para chegar a 3\% e secos em capela de fluxo laminar Pa400-eco (Pachane, Piracicaba, SP, Brasil) para evitar a deposição de poeira. Tudo isso foi feito para que fosse evitado a contaminação dos espécimes.

As tíbias direitas foram mergulhadas pela metade em ácido nítrico bidestilado 3\% por 1 minuto (SAWAN et al., 2010) e, a partir desta solução, foram feitas diluições para que os resultados entrassem na curva de calibração e com isso se iniciaram as análises químicas. As amostras foram analisadas em um equipamento de absorção atômica por chama (AAS400 Perkin Elmer, Norwalk, USA) (Figura 4). 
Figura 4: Equipamento AAS400 da Perkin Elmer em processo de quantificação de Cálcio das biópsias ósseas diluídas em ácido nítrico.

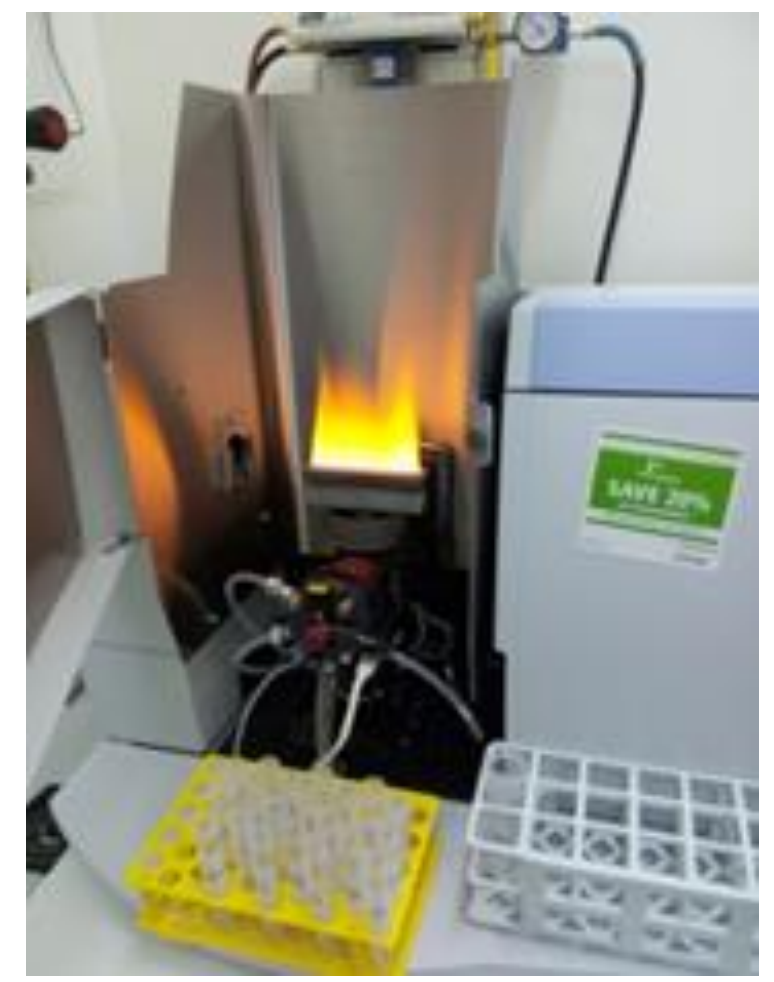

\subsection{Análise do fósforo}

A análise de fósforo foi executada para que se pudesse estimar a massa de tecido mineralizado e assim expressar a concentração dos minerais como quantidade dos minerais por massa de tecido mineralizado, uma vez que se espera que este mineral não seja afetado pela presença da Doxiciclina nos ossos. A técnica da quantificação de fósforo é o método colorimétrico estabelecido por Fiske (FISKE CH, 1925). Nós utilizamos um leitor colorimétrico sob o comprimento de onda de $660 \mathrm{~nm}$ para a visualização exata do espectro em uma placa de ELISA (Figura 5). 
Figura 5: Amostra de uma placa de ELISA usada para medição de fósforo pelo Método de Fiske (FISKE CH, 1925).

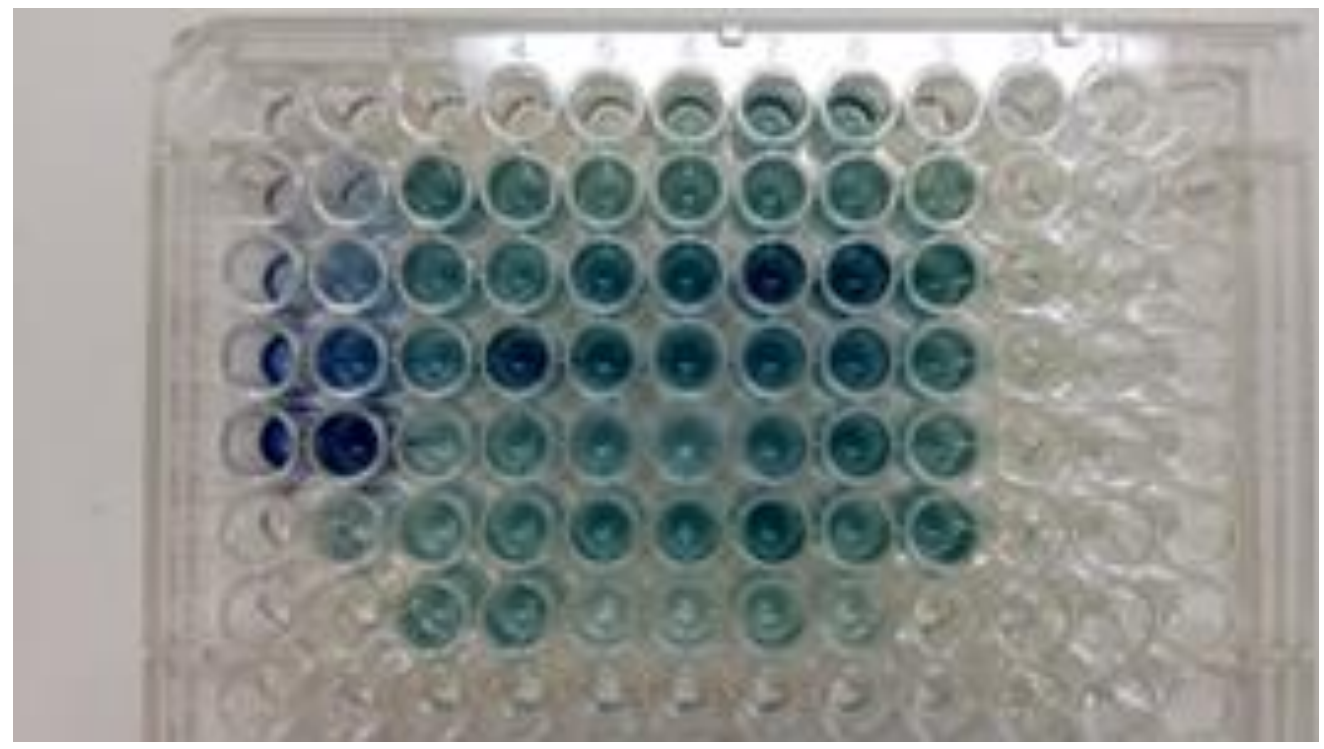

\subsection{Análise Morfológica}

\subsubsection{Processamento Histológico}

O osso fêmur esquerdo foi removido e imerso em solução fixadora formaldeído tamponado por 48 horas. Em seguida, os espécimes foram descalcificados em EDTA (ácido etilenodiamino tetra-acético) a 10\%. Após o período de descalcificação, que variou de 30 a 45 dias, foram desidratados em série crescente de álcoois: 70\% (overnight), 90\%, 95\% e 3 banhos de álcool absoluto I, II e III (2 horas em cada concentração). Feito isso, esses ossos foram colocados em partes iguais de álcool e xilol (overnight) e diafanizados em xilol, com trocas a cada 2 horas, sendo executadas 3 trocas; e em seguida, incluídos em parafina. De posse dos blocos (osso incluído em parafina), de cada amostra $(n=63)$ foram realizados 20 cortes semi-seriados de $6 \mu \mathrm{m}$ de espessura. A partir daí foram dispostos 20 cortes sagitais sendo estes distribuídos em 10 cortes para colorações de Tricromo de Masson, 5 para Picrosirius red e, 5 para o processo de imuno-histoquímica por TRAP. 


\subsubsection{Tricromo de Masson}

As lâminas parafinizadas foram imersas em 2 soluções de xilol para remoção da parafina durante 10 minutos em cada. Logo em seguida, para secagem, estas foram imersas em 3 soluções de álcool absoluto, 5 minutos cada. Logo após foi realizada uma lavagem abundante das lâminas com água corrente.

Feito isso, as lâminas foram introduzidas em uma solução de Hematoxilina de Harris durante 1 minuto. Posteriormente, foram realizadas duas lavagens abundantes com água corrente; primeiramente durante 20 segundos e a segunda lavagem por 5 minutos. Em seguida, foi imerso no corante de Tricromo de Masson (verde-luz) por 20 minutos, seguido de uma lavagem simples, por no máximo 20 segundos.

O próximo passo foi realizar a imersão em 3 soluções de álcool absoluto (5 minutos cada). Por último, as lâminas foram imersas em 2 soluções de xilol por 5 minutos cada, para secagem final.

Após o procedimento descrito acima, todas as lâminas foram sobrepostas com lamínulas embebidas em Entellan (Millipore-Merck, California, Estados Unidos), para posterior análise qualitativa e quantitativa. Na Figura 6 é possível visualizar o resultado após a coloração realizada em uma lâmina do osso fêmur de uma das ratas do grupo $C$ (controle com ingestão de água). 
Figura 6. Fotomicrografia de uma lâmina histológica de fêmur na porção distal ilustrando o trabeculado ósseo, destacando a placa de crescimento corado por Tricromo de Masson verde-luz em aumento real de $25 x$.

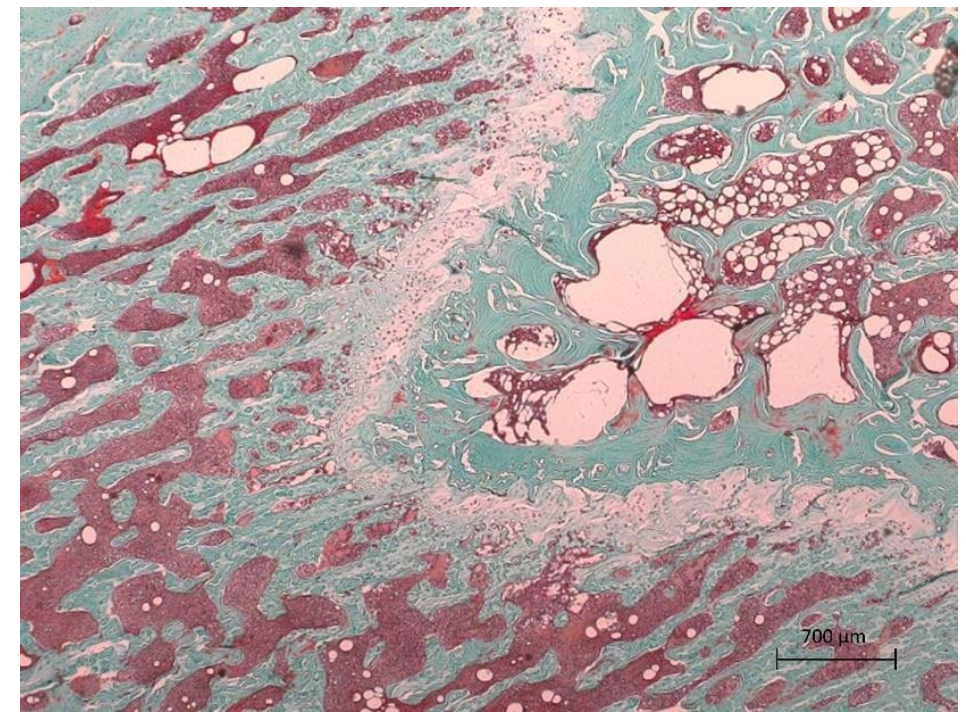

\subsubsection{Picro-sirius red}

As lâminas parafinadas foram imersas em 3 soluções de xilol I, II e III (5 minutos por banho), para remoção da parafina. Logo em seguida foram introduzidas em 3 soluções de álcool absoluto I, II e III (durante 5 minutos cada), tendo logo em seguida uma imersão em álcool $95 \%$ por 5 minutos também. O próximo passo foi introduzir as amostras em uma solução de ácido fosfomolibídico $5 \%$, durante 2 minutos. Feito este processo, todas as lâminas foram submetidas à lavagem abundante, em água corrente, em seguida, as lâminas foram inseridas na solução de corante de picro-sirius red $0,1 \%$ por 1 hora, aproximadamente. Logo em seguida foi realizada outra lavagem abundante em água corrente. Posteriormente, foi dado o banho nas lâminas em uma solução de $\mathrm{HCl}$ 0,01N, por 45 segundos e logo após, o material foi imerso novamente, em 3 soluções de álcool absoluto I, II e III (5 minutos cada). A última etapa da coloração foi realizar os 3 últimos banhos em 3 soluções de xilol I, II e III (5 minutos cada).

Feito isso, todas as lâminas foram sobrepostas com lamínulas, para posterior análise. Na Figura 7, é possível visualizar o resultado desta coloração realizada em uma lâmina do osso fêmur de uma das ratas do grupo C (Controle com ingestão de água). 
Figura 7. Fotomicrografia de uma lâmina de fêmur na porção distal, corado por picro-sirius red em objetiva com aumento real de 40x sob luz polarizada.

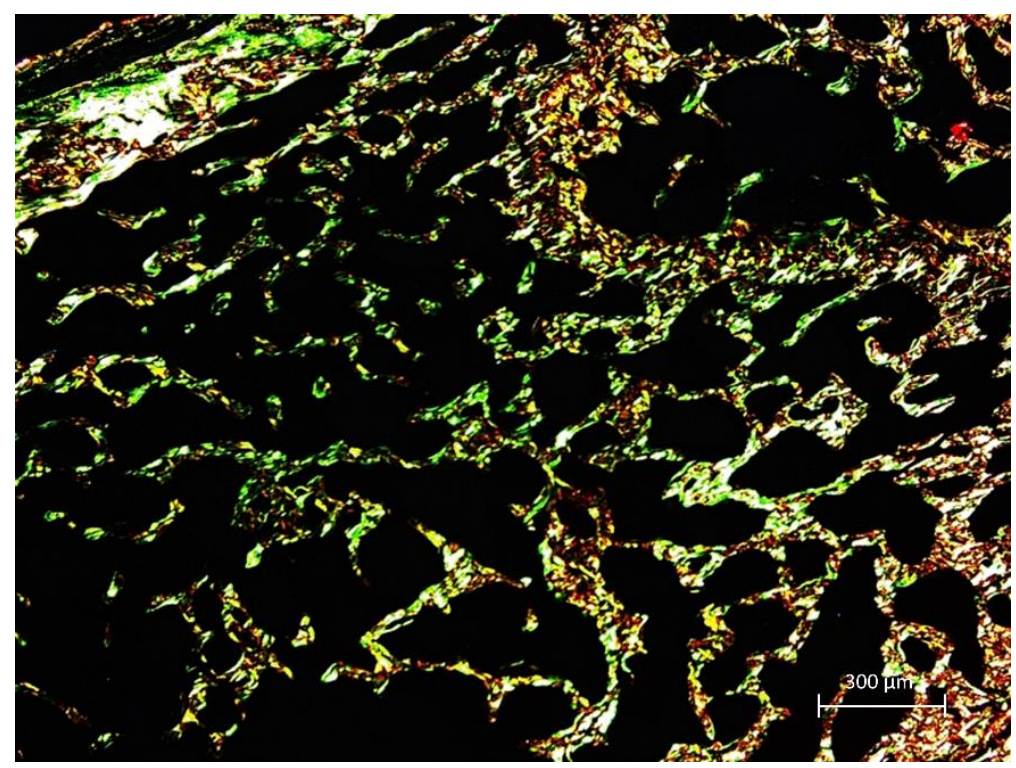

\subsubsection{Imuno-histoquímica por TRAP}

Para a análise imuno-histoquímica os cortes histológicos foram desparafinizados em xilol e hidratados em série decrescente de etanol (100 - 100- $\left.100^{\circ}-90^{\circ}-70^{\circ} \mathrm{GL}\right)$. A recuperação antigênica foi realizada através da imersão das lâminas histológicas em tampão citrato (Spring Bioscience, Pleasanton, CA, EUA), em câmara pressurizada (Decloaking chamber ${ }^{\circledR}$, Biocare Medical, Concord, CA, EUA) a $95^{\circ} \mathrm{C}$, por 20 minutos. No final de cada etapa da reação imuno-histoquímica, as lâminas histológicas foram lavadas em PBS 0,1 M, pH 7,4. Posteriormente, as lâminas foram imersas em 3\% de peróxido de hidrogênio por 1 hora e $1 \%$ de soro albumina bovino por 12 horas para bloqueio da peroxidase endógena e bloqueio dos sítios inespecíficos, respectivamente. As lâminas contendo amostras de cada grupo experimental foram incubadas com anticorpo primário anti-TRAP do rato gerado em cabra (SC-30833, Santa Cruz Biotechnology®). Em seguida os cortes foram incubados com anticorpo secundário biotinilado por 2 horas e subsequentemente tratados com estreptavidina conjugada com a peroxidase da raiz forte - HRP por 1 hora (Universal Dako Labeled HRP Streptavidin-Biotin Kit®, Dako Laboratories, CA, EUA). A revelação foi realizada utilizando como cromógeno o 3,3'- tetracloridrato de diaminobenzidina (DAB chromogen Kit®, Dako 
Laboratories, CA, EUA). Foi realizada a contracoloração com Hematoxilina de Harris e em seguida a desidratação em etanol, diafanização em xilol e, recobrimento com meio de montagem (Permount, Fisher Scientific, San Diego, CA, USA) e lamínulas de vidro. Como controle negativo, os espécimes foram submetidos aos procedimentos descritos anteriormente suprimindo-se a utilização do anticorpo primário.

A análise imuno-histoquímica foi realizada por um histologista experiente e cego aos tratamentos realizados (EE). Foi efetuada uma análise semi-quantitativa utilizando-se de uma secção histológica de cada animal, no aumento original de 200x. Ao padrão de imunomarcação foi atribuído um escore. O critério adotado para o estabelecimento dos escores foi baseado e modificados daqueles estabelecidos por Faria et al. (2008) (FARIA et al., 2008), onde: ESCORE 0 = ausência de imunomarcação; ESCORE 1 = baixo padrão de imunomarcação; ESCORE 2 = moderado padrão de imunomarcação; ESCORE 3 = alto padrão de imunomarcação.

\subsubsection{Análise por microscopia de luz}

Análise qualitativa das lâminas permitiu avaliar a organização óssea na área de epífise proximal e distal por coloração de tricromo de Masson, nos grupos experimentais. Também foi empregada a coloração de picro-sirius red para quantificação de colágeno total. Foi utilizado um microscópio de luz acoplado a uma câmera digital, Axioimager Z2 Zeiss (Alemanha) auxiliado por uma Estação de trabalho DELL Precision T3500 (DELL, São Paulo, Brasil) já instalados na Faculdade de Odontologia de Ribeirão Preto. As imagens digitais obtidas a partir da coloração de Tricromo de Masson foram analisadas pelo software AxioVision 4.8 (Carl Zeiss, Oberkochen, Alemanha) e a quantificação óssea foi executada com objetivas com 2,5x de aumento. Já as imagens de quantificação de colágeno total foram obtidas a partir da coloração de picro-sirius red em objetivas de aumento de 4x e foi analisado com o programa Image J (NIH, EUA), utilizando os plugins necessários para este feito. Para análises quantitativas foram focados os trabeculados ósseos nas porções epifisárias, uma 
distal e outra proximal (ou seja, 2 pontos). As pranchas histológicas foram obtidas para uma análise comparativa e qualitativa entre os grupos e serão discutidas a seguir na Seção 5.

Para análises qualitativas das amostras, as lâminas mais relevantes foram focalizadas no equipamento microscópio Leica DMRB sob três objetivas $(1,6 x ; 2,5 x ; 5 x)$ com o programa Leica LAS (Buffalo Grove, USA).

\subsection{Análise estatística}

O software usado para análise estatística foi o SPSS 20.0 (IBM, New York, NY, EUA), as amostras foram submetidas ao modelo geral linear multivariado e todas as comparações foram submetidas ao ajuste de Bonferroni. Análises da enzima TRAP foram submetidas a teste de normalidade e em seguida ao teste não paramétrico de Kurskal Wallis como análise de variância. Na ocorrência de diferenças significantes, o post-test de Dunn foi empregado para especificar estas diferenças. Os gráficos ilustrativos das diferenças foram obtidos a partir do programa Graphprism (Graphpad, San Diego, CA, EUA) e colocados como Figura 8. Os resultados foram considerados diferentes quando $p \leq 0,05$. 
Figura 8: Gráficos obtidos a partir do Graphprism 5.0 com os resultados de cada um dos experimentos executados nessa tese ilustrados. É importante salientar que as diferenças apresentadas podem não ter alcançado o valor de p mínimo para ser diferente estatisticamente.
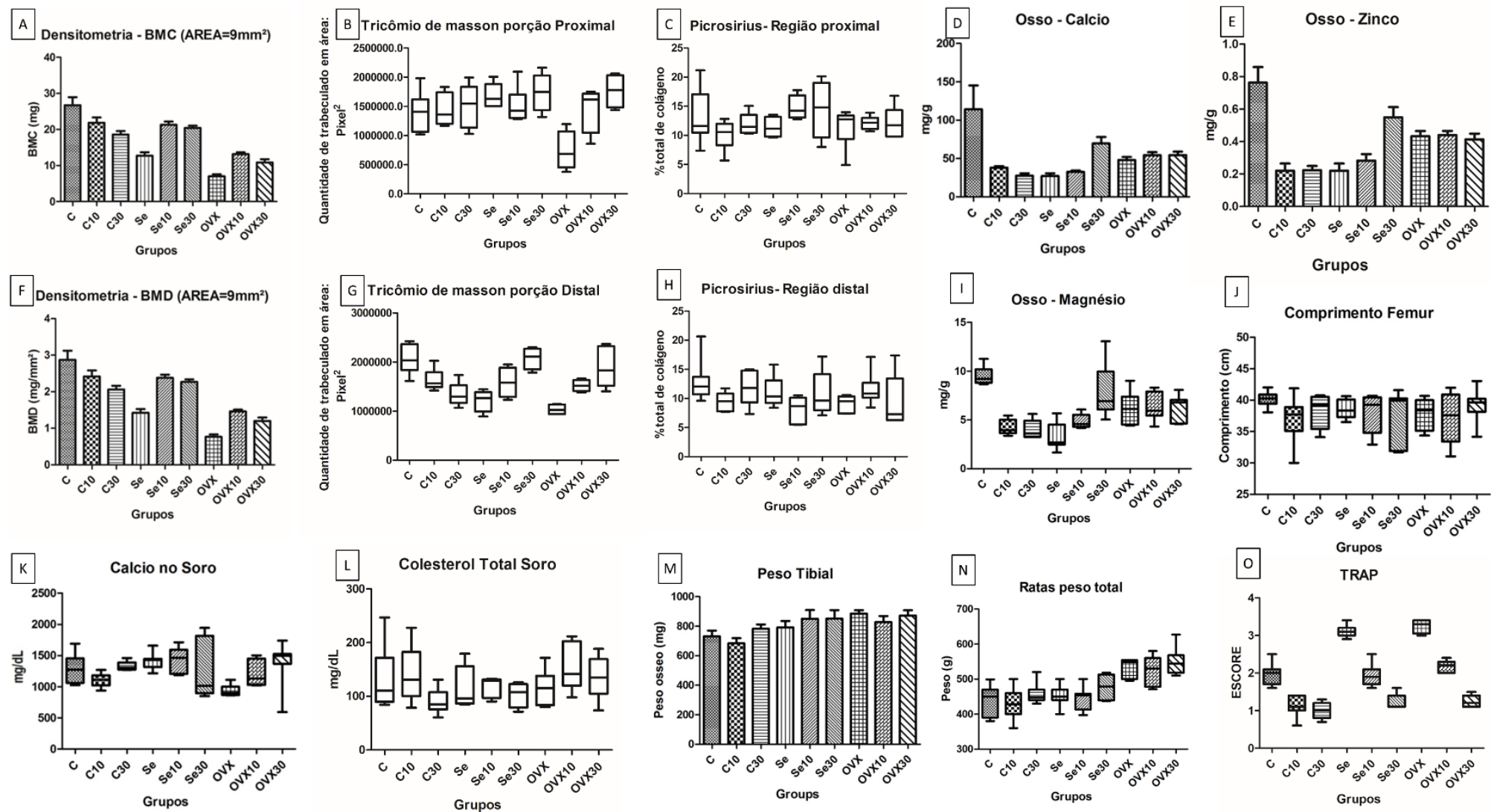

\section{RESULTADOS}

\subsection{Análises macroscópicas das amostras e comportamento das ratas}

As ratas do grupo Se, por estarem isoladas em gaiolas individuais, apresentaram erupções, decorrente da ausência de higiene em animais, motivada pela ausência de contato com outro animal da mesma espécie. Devido a isto, realizamos o tratamento diário com rifamicina (Rifocina Spray, Sanovi Aventis, São Paulo, Brasil) até a indução da morte e garantimos que o uso desse medicamento não influenciou nos resultados do presente estudo, de acordo com estudos de reparos ósseos onde se procura evitar infecções da região cirúrgica (FREITAS et al., 2014).

Após a remoção cirúrgica dos fêmures, observou-se macroscopicamente diferenças anatômicas nos fêmures esquerdos de cada animal dos grupos expostos a doxiciclina. Isso 
se deve ao fato de que os animais foram submetidos ao medicamento doxiciclina gerando como consequência um efeito na remodelação óssea fisiológica, como mostrado na Figura 3 do grupo C30 (Doxiciclina $30 \mathrm{mg} / \mathrm{kg}$ induzidos). Nesta Figura pode-se visualizar os ossos apontados pela seta branca com diferenças anatômicas em relação aos outros ossos. Isso é atribuído à inibição das MMPs do tipo 9 e 13, algo que foi presente em todos os grupos de ratas expostas ao medicamento (C10, C30, Se10, Se30, OVX10 e OVX30) (HOLMBECK et al., 1999; ULICl et al., 2009; VU et al., 1998). Conforme será discutido na Seção 6, os ossos destas ratas apresentaram variações anatômicas condizentes com nanismo em 28\% das amostras nos grupos expostos à doxiciclina, pois estes ossos apresentaram $3 / 4$ do comprimento total, porém vale salientar que não houve diferenças estatisticamente significantes ( $p=1)$ para esta modificação (Tabela 2, 3 e 4 - Comprimento do osso fêmur).

\subsection{Apresentação dos resultados para cada análise}

Os resultados de cada uma das tabelas são discursados em grupos versus grupos, sendo versus abreviado como vs.

Os resultados da densitometria foram demonstrados em miligramas por milímetros quadrados $\left(\mathrm{mg} / \mathrm{mm}^{2}\right)$ para BMD e miligrama $(\mathrm{mg})$ para BMC com os raios incidindo em $9 \mathrm{~mm}^{2}$. Os dados de quantificação de cálcio, magnésio e zinco foram expressos em miligrama por grama (mg/g). A medida de peso total do animal foi expresso em grama (g). O comprimento do osso fêmur foi demonstrado em centímetros $(\mathrm{cm})$ e o peso do osso fêmur foi demonstrado em miligramas $(\mathrm{mg})$. As amostras de soro foram submetidos às medidas de quantidades de cálcio e colesterol total que por sua vez foram expressos em miligrama por decilitro ( $\mathrm{mg} / \mathrm{dL})$.

A quantificação de trabeculado ósseo por Tricromo de Masson foi expresso em Pixel$^{2}$ (ISSA et al., 2015; MONTEIRO et al., 2016), a quantificação por picro-sirius red foi expresso em porcentagem de colágeno total (\%) (PEREIRA, B. F. et al., 2014) e a imunomarcação por TRAP foi expresso em Escores (SHIMANO, R. C. et al., 2014). 
A partir dos resultados de cada um dos grupos experimentais, foi demonstrada uma ideia do benefício da doxiciclina para os grupos que foram induzidas as osteopenias (Se e OVX) e o malefício gerado nos grupos controle sem indução (C).

\subsection{Padrão de imunomarcação por TRAP}

A técnica imuno-histoquímica empregada para a detecção de TRAP (Fosfatase Ácida Tartarato Resistente) mostrou alta especificidade na detecção de tal proteína que indica uma imunomarcação de atividade osteoclástica (HABERMANN et al., 2007), a qual foi comprovada pela ausência total de marcação no controle negativo da reação. As células imunorreativas apresentaram uma coloração marrom escura confinada exclusivamente ao citoplasma. Obteve-se como diferenças Se vs. Se30 e OVX vs. OVX30 com $p<0,00001$ conforme Tabela 1.

Tabela 1: Padrão de imunomarcação para TRAP. A-I: fotomicrograficas evidenciando o padrão de imunomarcação para TRAP nos grupos C (A), C10 (B), C30 (C), OVX (D), OVX10 (E), OVX30 (F), SE (G), SE10 (H), SE30 (I). ${ }^{a} e^{\text {b }}$ são diferentes entre si com p<0,00001.

\begin{tabular}{|c|c|c|}
\hline \multicolumn{3}{|c|}{ TRAP (ESCORE - MEDIANA) } \\
\hline C & ESCORE 2 & MODERADA IMUNOMARCAÇÃO \\
\hline C10 & ESCORE 1 & BAIXA IMUNOMARCAÇÃO \\
\hline C30 & ESCORE 1 & BAIXA IMUNOMARCAÇÃO \\
\hline OVX & ESCORE $3^{\text {a }}$ & ALTA IMUNOMARCAÇÃO \\
\hline OVX10 & ESCORE 2 & MODERADA IMUNOMARCAÇÃO \\
\hline OVX30 & ESCORE $1^{\text {a }}$ & BAIXA IMUNOMARCAÇÃO \\
\hline SE & ESCORE $3^{b}$ & ALTA IMUNOMARCAÇÃO \\
\hline SE10 & ESCORE 2 & MODERADA IMUNOMARCAÇÃO \\
\hline SE30 & ESCORE $1^{\mathrm{b}}$ & BAIXA IMUNOMARCAÇÃO \\
\hline
\end{tabular}

\subsection{Comparação entre as induções de osteopenia}

Na Tabela 2 é demonstrado o resultado de "p" somente quando significante em comparação com os grandes grupos de indução. 
Tabela 2: Comparação entre os grandes grupos de indução de osteopenia com o valor de $p$ demonstrado somente em caso de diferenças estatisticamente significantes ( $p \leq 0,05)$. Quando não há o valor de "p" é porque não foi estatisticamente diferente.

\begin{tabular}{|c|c|c|c|c|}
\hline & & $\begin{array}{l}\text { Média (desı } \\
\text { grandes gru }\end{array}$ & ăo) - Con & Jes entre os \\
\hline & $\mathrm{C}$ & $\mathrm{Se}$ & ovx & Valor de $p$ \\
\hline $\mathrm{BMC}(\mathrm{mg})$ & $22,5(1,8)^{\mathrm{a}}$ & $17,2(1,5)^{\mathrm{a}}$ & $10(1,4)^{\mathrm{a}}$ & a $\mathrm{p}<0,001$ \\
\hline BMD $\left(\mathrm{mg} / \mathrm{mm}^{2}\right)$ & $2,4(0,2)^{\mathrm{a}}$ & $1,9(0,1)^{\mathrm{a}}$ & $1,1(0,1)^{\mathrm{a}}$ & a $p<0,001$ \\
\hline $\begin{array}{l}\text { Cálcio Biópsia } \\
\text { óssea -mg/g }\end{array}$ & $59,3(5)^{\mathrm{a}}$ & $31,2(4)^{\mathrm{a}, \mathrm{b}}$ & $49,9(4)^{b}$ & $\begin{array}{l}\text { a p }=0,002 \\
\text { b } p=0,021\end{array}$ \\
\hline $\begin{array}{l}\text { Magnésio Biópsia } \\
\text { óssea - mg/g }\end{array}$ & $6,7(0,9)$ & $5,4(0,7)$ & $6,2(0,7)$ & \\
\hline $\begin{array}{l}\text { Zinco Biópsia } \\
\text { óssea -mg/g }\end{array}$ & $0,4(0,05)$ & $0,2(0,05)$ & $0,4(0,04)$ & \\
\hline $\begin{array}{l}\text { Cálcio em soro - } \\
\mathrm{mg} / \mathrm{dL}\end{array}$ & 1304(128) & 1399(107) & $1098(103)$ & \\
\hline $\begin{array}{l}\text { Colesterol Total } \\
\text { em soro }-\mathrm{mg} / \mathrm{dL}\end{array}$ & $85(14)^{\mathrm{a}}$ & $119(12)$ & $121(11)^{\mathrm{a}}$ & a $\mathrm{p}=0,014$ \\
\hline $\begin{array}{l}\text { Colágeno total na } \\
\text { porção proximal } \\
\text { do fêmur (\%) }\end{array}$ & $10,6(1,4)$ & $13(1,2)$ & $12,9(1,1)$ & \\
\hline $\begin{array}{l}\text { Colágeno total na } \\
\text { porção distal do } \\
\text { fêmur (\%) }\end{array}$ & $11,7(1,3)$ & $10,6(1,1)$ & $11,7(1)$ & \\
\hline $\begin{array}{l}\text { Quantificação de } \\
\text { trabeculado } \\
\text { ósseo na porção } \\
\text { proximal do } \\
\text { fêmur }\left(10^{-5}\right) \\
\text { Pixel }\end{array}$ & $12,6(1,4)$ & $16,5(1,2)$ & $12,4(1,1)$ & \\
\hline $\begin{array}{l}\text { Quantificação de } \\
\text { trabeculado } \\
\text { ósseo na porção } \\
\text { distal do fêmur } \\
\left(10^{-5}\right) \\
\text { Pixel }\end{array}$ & $17,5(1,1)^{\mathrm{a}}$ & $14,2(0,9)$ & $13,1(0,9)^{\mathrm{a}}$ & a $\mathrm{p}=0,024$ \\
\hline $\begin{array}{l}\text { Comprimento do } \\
\text { osso fêmur }\end{array}$ & $36(1,2)$ & $36,5(1)$ & $38,3(1)$ & \\
\hline Peso Total - $\mathbf{g}$ & $451(14)^{\mathrm{a}}$ & $456(12)^{b}$ & $527(11)^{\mathrm{a}, \mathrm{b}}$ & $\mathrm{a}, \mathrm{b} \mathrm{p}<0,0001$ \\
\hline $\begin{array}{l}\text { Peso do osso } \\
\text { fêmur- mg }\end{array}$ & $766,8(36)^{\mathrm{a}}$ & $850(30)$ & $870(29)^{\mathrm{a}}$ & a $p<0,0001$ \\
\hline
\end{tabular}


Para BMC e BMD, os grupos Controles (C), Sedentários (Se) e Ovariectomizados (OVX) são diferentes entre si com $p<0,001$.

Para massa total das ratas antes da indução de morte, observam-se diferenças estatisticamente significantes entre OVX vs. C e OVX vs. Se com $p<0,0001$.

Para massa seca dos fêmures, tem-se que os grupos C vs. OVX são diferentes entre si com $p<0,0001$

Para a quantificação de Colesterol tem-se que C vs. OVX são diferentes entre si com $p=0,014$. Para a quantificação do trabeculado por Tricromo de Masson na porção distal do osso, temse que $C$ vs. OVX possuem diferenças estatisticamente significantes com $p=0,02$. Já as biópsias ósseas para a medição de Ca (Cálcio) se observam que C vs. Se são diferentes entre si com $p=0,002$ e Se vs. OVX são diferentes entre si com $p=0,021$.

O restante das análises, quantificações Mg (Magnésio), Zn (Zinco) e Ca (Cálcio) no soro, comprimento dos fêmures, quantificação de colágeno total e quantificação do trabeculado ósseo por Tricromo de Masson, não apresentaram diferenças estatisticamente significantes entre si, quando comparamos os grandes grupos de indução ( $p>0,05$, ou seja não significante).

\subsection{Comparando-se os grupos de indução a osteopenia com as doses de} medicamentos

$\mathrm{Na}$ Tabela 3 são demonstrados os valores das médias com os seus respectivos desvios padrões entre parênteses, seguido do valor de "p" quando houver diferenças estatisticamente significante, demonstrando uma comparação entre os grupos. Na Figura 8 tem-se a ilustração das diferenças encontradas entre todos os grupos em todas as análises realizadas, esta Figura foi disponibilizada para simples conferência. Na Figura 8 são observadas as letras A até $\mathrm{N}$ com as análises ilustrativas referentes a cada uma das análises realizadas. 
Tabela 3: Comparação entre os grupos de indução com suas respectivas doses, verificando se há diferenças estatisticamente significantes ( $p$ $\leq 0,05)$. Quando não há o valor de "p" é porque não foi estatisticamente diferente.

\begin{tabular}{|c|c|c|c|c|c|c|c|c|c|c|c|c|}
\hline & \multicolumn{10}{|c|}{ Valores: Média (Desvio Padrão) Comparação entre os grupos experimentais } & \multicolumn{2}{|c|}{$-\quad p \leq 0,05$} \\
\hline & C & C10 & C30 & $\begin{array}{l}\text { Valor de } \\
\qquad p\end{array}$ & Se & Se10 & Se30 & $\begin{array}{l}\text { Valor de } \\
\qquad p\end{array}$ & OVX & 0X10 & OVX30 & $\begin{array}{l}\text { Valor } \\
\text { de } p\end{array}$ \\
\hline BMC (mg) & $26,7(5,9)^{\mathrm{a}, \mathrm{b}}$ & $21,8(3,9)^{\mathrm{a}}$ & $18,6(2,5)^{\mathrm{b}}$ & $\begin{array}{l}\text { a } p=0,018 \\
\text { b } p<0,0001\end{array}$ & $12,7(2,5)^{\mathrm{q}, \mathrm{b}}$ & $21,3(2,3)^{\mathrm{a}}$ & $20,4(1,6)^{\mathrm{b}}$ & $\begin{array}{l}\text { a p }<0,0001 \\
\text { b } p<0,001\end{array}$ & $8,8(3,4)^{\mathrm{a}}$ & $13,1(1,3)^{\mathrm{a}}$ & $10,8(2,3)$ & a $\mathrm{p}=0,044$ \\
\hline BMD $\left(\mathrm{mg} / \mathrm{mm}^{2}\right)$ & $2,8(0,6)$ & $2,4(0,4)$ & $2(0,2)$ & & $1,4(0,2)^{\mathrm{a}, \mathrm{b}}$ & $2,3(0,2)^{\mathrm{a}}$ & $2,2(0,2)^{\mathrm{b}}$ & $\begin{array}{l}\text { a p }<0,001 \\
\text { b p }<0,001\end{array}$ & $0,9(0,4)^{\mathrm{a}}$ & $1,4(0,1)^{\mathrm{a}}$ & $1,2(0,2)$ & a $\mathrm{p}=0,031$ \\
\hline $\begin{array}{l}\text { Cálcio Biópsia óssea - } \\
\mathrm{mg} / \mathrm{g}\end{array}$ & $114,2(8,2)^{\mathrm{a}, \mathrm{b}}$ & $38(5,5)^{\mathrm{a}}$ & $27(8,5)^{\mathrm{b}}$ & $\begin{array}{l}\text { a } p<0,001 \\
\text { b p }<0,001\end{array}$ & $27,1(9,2)$ & $32,5(4,3)$ & $32,9(6,9)$ & & $48(9,9)$ & $54,2(10,5)$ & $54,3(12,2)$ & \\
\hline $\begin{array}{l}\text { Magnésio Biópsia óssea } \\
-\mathrm{mg} / \mathrm{g}\end{array}$ & $10,5(2,8)^{\mathrm{a}, \mathrm{b}}$ & $4,2(0,7)^{\mathrm{a}}$ & $4(0,9)^{b}$ & $\begin{array}{l}\text { a p }<0,001 \\
\text { b p }<0,001\end{array}$ & $3,4(1,4)^{\mathrm{a}}$ & $4,9(0,7)^{\mathrm{b}}$ & $7,8(2,7)^{\mathrm{a}, \mathrm{b}}$ & $\begin{array}{l}\text { a p }<0,001 \\
\text { b p }=0,007\end{array}$ & $6,2(1,6)$ & $6,3(1,4)$ & $6,3(1,3)$ & \\
\hline $\begin{array}{l}\text { Zinco Biópsia óssea - } \\
\mathrm{mg} / \mathrm{g}\end{array}$ & $0,7(0,2)^{\mathrm{a}, \mathrm{b}}$ & $0,2(0,1)^{\mathrm{a}}$ & $0,2(0,06)^{b}$ & $\begin{array}{l}\text { a p }<0,001 \\
\text { b } p<0,001\end{array}$ & $0,2(0,1)$ & $0,3(0,1)$ & $0,5(0,1)$ & & $0,4(0,08)$ & $0,4(0,06)$ & $0,4(0,1)$ & \\
\hline Cálcio em soro - mg/dL & $1287(23,5)$ & $1109(11,1)$ & $1184(38,6)$ & & $1404(13,9)$ & $1414(20,3)$ & $1310(47,3)$ & & $936(89)^{\mathrm{a}}$ & $1222(21,6)$ & $1375(36,5)^{\mathrm{a}}$ & a $\mathrm{p}=0,013$ \\
\hline $\begin{array}{l}\text { Colesterol Total em soro } \\
-\mathrm{mg} / \mathrm{dL}\end{array}$ & $100(14,5)$ & $103(15,5)$ & $88(15,5)$ & & $115(17,7)$ & $110(15,8)$ & $94,7(15)$ & & $122,7(15,8)$ & 164(17) & $126(17)$ & \\
\hline $\begin{array}{l}\text { Colágeno total na } \\
\text { porção proximal do } \\
\text { fêmur (\%) }\end{array}$ & $13,4(3,9)$ & $16,6(4,2)$ & $16,6(4,1)$ & & $21,9(4,2)$ & $14,8(4,2)$ & $20,9(4,3)$ & & $12,7(4,3)$ & $12,2(4,7)$ & $13,3(4,8)$ & \\
\hline $\begin{array}{l}\text { Colágeno total na } \\
\text { porção distal do fêmur } \\
\text { (\%) }\end{array}$ & $13,3(3,4)$ & $9,6(3,7)$ & $11,7(3,7)$ & & $11,6(4,2)$ & $15,3(3,7)$ & $11,1(3,3)$ & & $9(3,7)$ & $12,2(4,2)$ & $19,4(4,1)$ & \\
\hline $\begin{array}{l}\text { Quantificação de } \\
\text { trabeculado ósseo na } \\
\text { porção proximal do } \\
\text { fêmur }\left(10^{-5}\right) \text { Pixel }^{2}\end{array}$ & $15,5(1,6)$ & $14,9(1,8)$ & $19,6(1,7)$ & & $15,9(2)$ & $15(1,8)$ & $16,9(1,6)$ & & $8,7(1,8)^{\mathrm{a}, \mathrm{b}}$ & $11,7(2)^{\mathrm{a}}$ & $17,6(2)^{b}$ & $\begin{array}{l}\text { a p }=0,04 \\
\text { b p }=0,05\end{array}$ \\
\hline $\begin{array}{l}\text { Quantificação de } \\
\text { trabeculado ósseo na } \\
\text { porção distal do fêmur } \\
\left(10^{-5}\right) \\
\text { Pixel }^{2}\end{array}$ & $20,3(1,3)^{\mathrm{a}}$ & $16,1(1,5)$ & $13,9(1,4)^{\mathrm{a}}$ & a $\mathrm{p}=0,036$ & $9,4(1,7)^{\mathrm{a}, \mathrm{b}}$ & $14,7(1,5)^{\mathrm{a}}$ & $17,4(1)^{b}$ & $\begin{array}{l}\text { a } p=0,05 \\
\text { b p }=0,02\end{array}$ & $9,2(1,5)^{\mathrm{a}, \mathrm{b}}$ & $15,1(1,7)^{\mathrm{a}}$ & $18,0(1,5)^{b}$ & $\begin{array}{l}\text { a } p<0,01 \\
\text { b p }=0,03\end{array}$ \\
\hline $\begin{array}{l}\text { Comprimento do osso } \\
\text { fêmur }\end{array}$ & $40,1(1,2)$ & $36,9(3,6)$ & $38,4(2,9)$ & & $38,6(1,6)$ & $37,6(3)$ & $37,2(4,2)$ & & $37,9(2,4)$ & $36,9(4,2)$ & $39,1(2,6)$ & \\
\hline Peso Total - $\mathrm{g}$ & $438,4(43,5)$ & $428(44,1)$ & $\begin{array}{l}460,4 \\
(30,1)\end{array}$ & & $451,430,2)$ & $444(34)$ & $478(33,2)$ & & $535(26)$ & $523,1(41,1)$ & $550,1(39,1)$ & \\
\hline Peso do osso fêmur- mg & $731,2(102,6)$ & $684(92,2)$ & $\begin{array}{l}782,7 \\
(76,9)\end{array}$ & & $\begin{array}{c}791,8 \\
(155,5)\end{array}$ & $\begin{array}{c}850,7 \\
(161,1)\end{array}$ & $\begin{array}{c}851,1 \\
(152,5)\end{array}$ & & $885,4(61)$ & $\begin{array}{c}827,8 \\
(108,3)\end{array}$ & $872,1(95,4)$ & \\
\hline
\end{tabular}


Para BMC tem-se que o controle C vs. $C 10(p=0,018)$ e $C$ vs. $C 30(p<0,0001)$ possuem diferenças estatisticamente significantes. No grupo OVX é visto que OVX vs. OVX10 $(p=0,044)$ possuem diferenças estatisticamente significantes.

No grupo Se é visto que Se vs. Se10 $(p<0,0001)$ e Se vs. Se30 $(p<0,001)$ possuem diferenças estatisticamente significantes.

Com BMD tem-se para o grupo OVX que OVX vs. OVX10 $(p=0,031)$ possuem diferenças estatisticamente significantes.

Já para o Grupo Se tem-se que Se vs. Se10 $(p<0,001)$ e Se vs. Se30 $(p<0,001)$ possuem diferenças estatisticamente significantes.

No grupo controle, não foram encontradas diferenças estatisticamente significantes.

Para dosagem de cálcio tem-se que no grupo controle são observados que C vs. C10 $(p<0,001)$ e C vs. C30 ( $p<0,001)$ possuem diferenças estatisticamente significantes.

Nos grupos OVX e Se não foram obtidas diferenças estatisticamente significantes.

Para dosagem de magnésio e zinco no grupo Controle tem-se que $C$ vs. $C 10(p<0,001)$ e $C$ vs. C30 ( $p<0,001)$ possuem diferenças estatisticamente significantes.

No grupo OVX não foram obtidas diferenças estatisticamente significantes.

No grupo Se obteve-se diferenças somente para quantificação de magnésio Se vs. Se30 $(p<0,001)$ e Se10 vs. Se30 ( $p=0,007)$ possuem diferenças estatisticamente significantes.

Na quantificação de Ca em Soro tem-se que para os grupos Controle e Se não foram obtidas diferenças estatisticamente significantes.

Para o grupo OVX obteve-se que OVX vs. OVX30 $(\mathrm{p}=0,013)$ possuem diferenças estatisticamente significantes.

Na quantificação de trabeculado ósseo por tricromo de Masson na região proximal do osso fêmur tem-se que para o grupo OVX que OVX vs. OVX10 $(p=0,04)$ e OVX vs. OVX30 $(p=0,05)$ possuem diferenças estatisticamente significantes. Por outro lado, para os grupos Controle e Sedentarismo não se obteve diferenças. 
Na quantificação de trabeculado ósseo por tricromo de Masson na região distal do osso fêmur tem-se para o grupo controle que C vs. $C 30(p=0,036)$ possuem diferenças estatisticamente significantes.

Para o grupo OVX tem-se que OVX vs. OVX10 $(p<0,01)$ e OVX vs. OVX30 $(p=0,03)$ possuem diferenças estatisticamente significantes. Por outro lado, para o grupo Se se tem que Se vs. Se10 $(p=0,05)$ e Se vs. Se30 $(p=0,02)$ possuem diferenças estatisticamente significantes. Quanto ao peso total das ratas antes da indução de morte, colesterol total, quantificações de colágeno por picro-sirius red, comprimento total dos fêmures e peso dos fêmures não foram encontradas diferenças estatisticamente significantes.

\subsection{Comparando-se as doses de medicamentos com os grupos de indução à} osteopenia.

Na Tabela 4 são demonstradas as comparações entre os grupos de indução, demonstrando a significância dos medicamentos nos diferentes modelos experimentais. 
Tabela 4: Tabela demonstrativa da significância dos medicamentos em cada modelo de indução de osteopenia. Valores de "p" demonstrados somente $p \leq 0,05$. *Valor de P próximo ao patamar máximo de diferença. Quando não há o valor de "p" é porque não foi estatisticamente diferente.

Valores: Média (Desvio Padrão) - Tabela de comparação entre as doses e os grupos de indução - p $\leq 0,05$

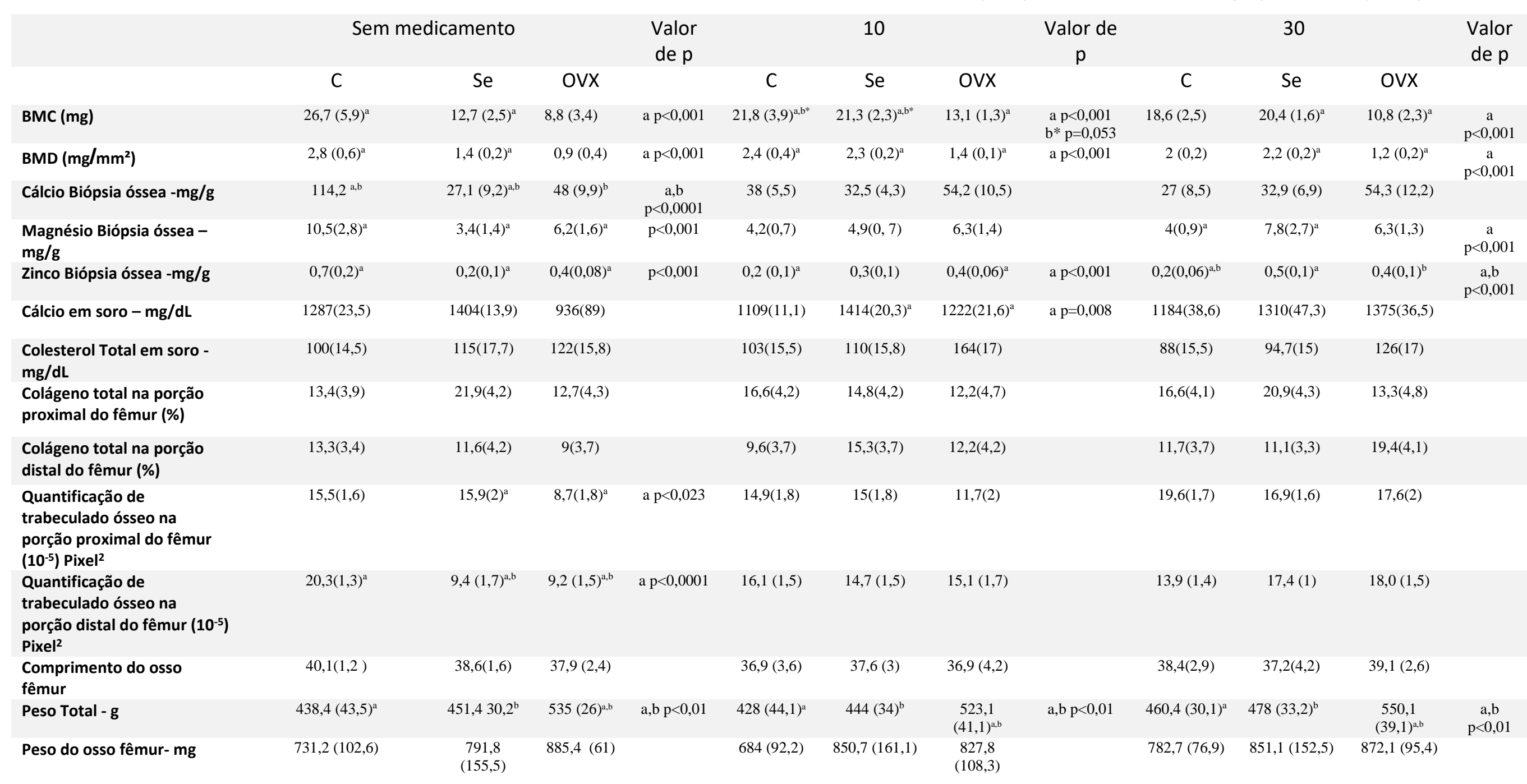


Para BMC e BMD observam-se diferenças entre todos os modelos de indução com $p<0,001$, com exceção do grupo Controle (sem medicamento) quando se compara OVX vs. Se. Também não nota-se diferenças quando se compara para a concentração de doxiciclina 10, $C$ vs. Se (porém com uma ressalva para o BMD que foi apresentado um $p=0,053$, valor de $p$ muito próximo ao ideal) e para doxiciclina 30, comparando-se C vs. Se.

Na quantificação de cálcio tem-se diferenças para os controles sem medicamento com C vs. OVX e C vs. Se com $p<0,0001$. O restante das análises não demonstraram diferenças estatisticamente significantes.

Para quantificação de $\mathrm{Mg}$ tem-se diferenças entre todos os grupos com $\mathrm{p}<0,01$, com exceção do grupo Doxiciclina 10 e Doxiciclina 30 com OVX vs. Se.

Para quantificação de $\mathrm{Zn}$ tem-se diferenças entre todos os grupos no controle sem medicamento. No grupo doxiciclina 10 tem-se diferença estatisticamente significante C vs. OVX com $p<0,01$ e no grupo doxiciclina 30 tem-se diferenças entre C vs. Se e Se vs. OVX $p<0,01$.

Para quantificação de $\mathrm{Ca}$ no soro é demonstrado que somente para a concentração doxiciclina 10 obteve-se diferenças entre OVX vs. Se com $p=0,008$.

Para massa total das ratas antes da indução de morte, é demonstrado que todos os grupos são diferentes entre si para Controle sem medicamento, Doxiciclina 10 e Doxiciclina 30, com exceção de C vs. Se.

Para o comprimento dos fêmures não se obteve diferenças estatisticamente significantes $(p=1)$.

Para massa total seca dos fêmures tem-se diferenças no grupo sem medicamento C vs. OVX com $p=0,03$. Para doxiciclina 10 ocorreram diferenças entre $C$ vs. OVX e $C$ vs. Se. Não obteve-se diferenças para o grupo Doxiciclina 30.

Quanto as quantificações de trabeculado ósseo por tricromo de Masson na porção proximal obervando o controle sem medicamento, tem-se que Se vs. OVX são diferentes 
estatisticamente com $p=0,023$. Já na porção distal, tem-se que controle sem medicamento $C$ vs. Se e C vs. OVX possuem diferenças estatisticamente significantes com $p<0,0001$.

Para as quantificações de colágeno total por picro-sirius red e colesterol total não foram obtidas diferenças estatisticamente significantes.

\subsection{Análise qualitativa das lâminas histológicas coradas por tricromo de Masson verde- luz, picro-sirius red e imunomarcação por TRAP}

\subsubsection{Tricromo de Masson verde-luz}

As amostras foram coradas por tricromo de Masson e o intuito principal foi facilitar análise do trabeculado ósseo de acordo com a metodologia discutida anteriormente. Houve diferenças estatisticamente significantes conforme os resultados já discursados.

Nas figuras a seguir são observados os seguintes itens: osso trabecular (OT), placa de crescimento (PC) e osso cortical (OC).

Verifica-se nas figuras a seguir as pranchas de cortes histológicos corados por tricromo de Masson porção distal (Figura 9) e porção proximal (Figura 10). Além da Figura 11 com cortes corados com picro-sirius red na porção distal do fêmur, tem-se a Figura 12 com cortes corados em picro-sirius red na porção proximal. 
As letras no canto superior esquerdo são referências aos grupos experimentais do presente trabalho e são distribuídos da seguinte maneira:
A - Grupo C: Controle sem doxiciclina ou quaisquer tratamentos
B- Grupo C10: Doxiciclina 10mg/kg induzidos
C- Grupo C30: Doxiciclina 30mg/kg induzidos
D- Grupo Se: Sedentarismo controle
E- Grupo Se10: Sedentarismo 10mg/kg/dia
F- Grupo Se30: Sedentarismo 30mg/kg/dia
G- Grupo OVX: Ovariectomia controle
H- Grupo OVX10: Ovariectomia 10mg/kg/dia
I- Grupo OVX30: Ovariectomia 30mg/kg/dia

$\mathrm{Na}$ Figura 9A tem-se a presença de um tecido ósseo mineralizado normal com trabeculado ósseo distribuído de modo uniforme (OT) e a placa de crescimento presente atravessando a porção distal do osso de modo normal e uniforme (PC). Na Figura 9B tem-se um tecido ósseo mineralizado com as mesmas distribuições, porém em menor quantidade de trabeculados se comparado ao tecido ósseo da Figura 9A (Controle), pois o osso trabecular (OT) aparece ligeiramente mais espaçado. A placa de crescimento (PC) aparenta normalidade neste corte. Na Figura 9C é demosntrada a presença de um corte de tecido ósseo mineralizado com ligeira piora em sua qualidade, pois os ossos trabeculares (OT) apresentam maior espaçamento se compararmos com o controle (Figura 7A).

Na Figura 9D tem-se a presença de um tecido ósseo acometido por uma doença degenerativa provocada pelo sedentarismo induzido em ratas Wistar fêmeas. Osso trabecular (OT) apresenta um grande espaçamento entre si e a placa de crescimento (PC) apresenta leve alteração em sua espessura. Já na Figura 9E observa-se uma grande melhora do tecido ósseo trabecular (OT) aliado a uma irregularidade presente na placa de crescimento (PC) demonstrando um indicativo de que a doxiciclina provoca alterações na placa de crescimento. 
Na Figura 9F é encontrado uma maior presença de trabeculado ósseo (OT) e uma alteração mais evidente na placa de crescimento (PC).

Para a Figura 9G tem-se a presença de um tecido ósseo acometido por uma doença degenerativa provocada pela ovariectomia bilateral em ratas Wistar fêmeas, com espaçamento de trabeculado ósseo (OT) e placa de crescimento espessa (PC) (YAO et al., 2006). Nas Figuras 9H e $9 \mathrm{I}$ têm-se um aumento no número de trabeculado ósseo e uma diminuição nas alterações na espessura da placa de crescimento (PC). 
Figura 9: Fotomicrografia de um corte histológico do osso fêmur porção distal, demonstrando o osso trabecular (OT) e a placa de crescimento (PC). As figuras demonstram que se obteve para o grupo Controle que A vs. C (C vs. C30) $p=0,036$, para o grupo OVX que G vs. H (OVX vs. OVX10) $p<0,01$ e G vs. I (OVX vs. OVX30) $p=0,03$ e para o grupo Se que D vs. G (Se vs Se10) $p=0,05$ e $D$ vs. $F$ (Se vs. Se30) $p=0,02$ possuem diferenças estatisticamente significantes. As letras superiores-esquerda indicam os grupos de estudo: $A=C ; B=C 10$; $\mathrm{C}=\mathrm{C} 30 ; \mathrm{D}=\mathrm{Se}$; E=Se10; $\mathrm{F}=\mathrm{Se} 30 ; \mathrm{G}=\mathrm{OVX} ; \mathrm{H}=\mathrm{OVX10}$ e; I=OVX30. Coloração: Tricromo de Masson, 25x de aumento real.
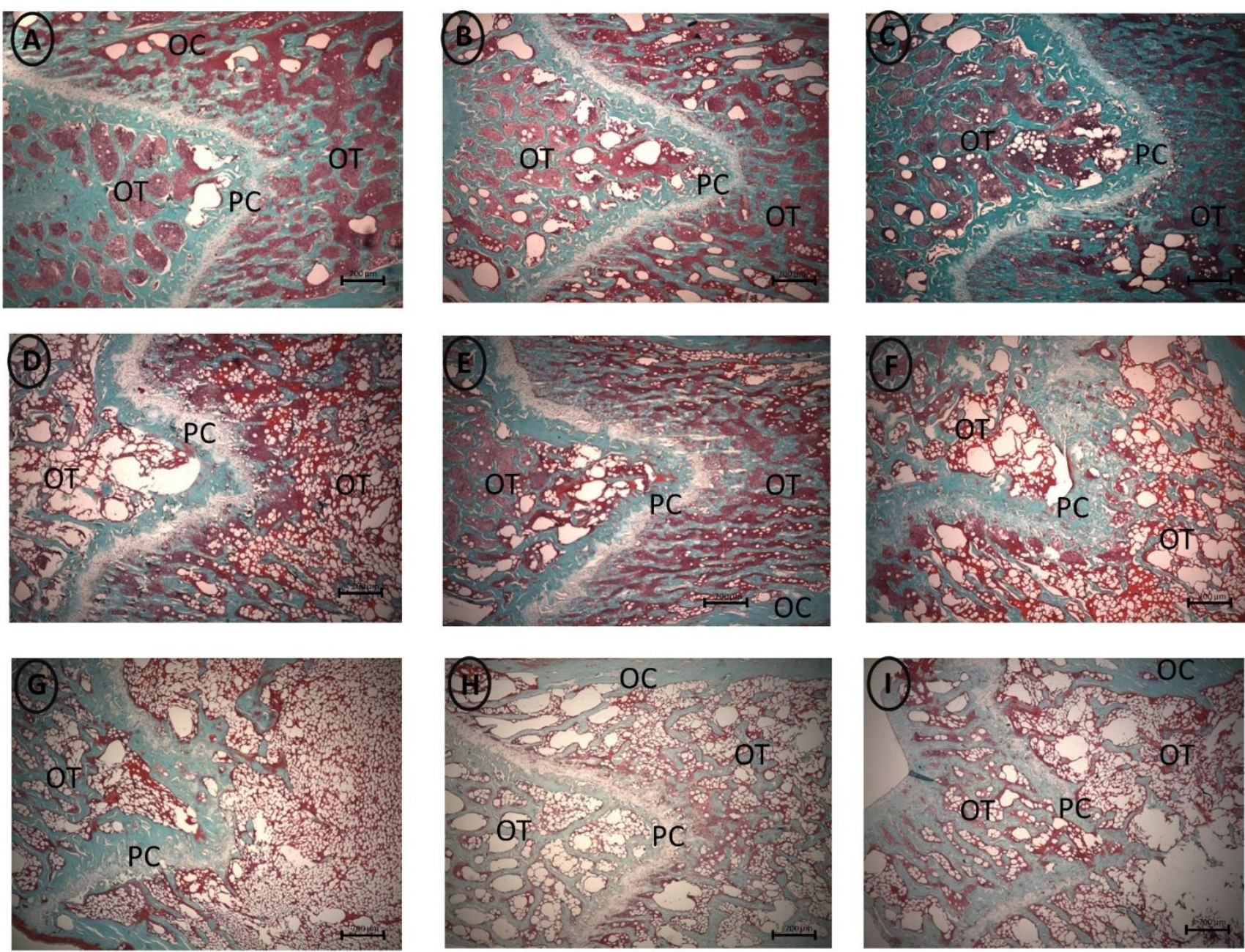
Na Figura 10 (região proximal do fêmur) não houve grandes diferenças no trabeculado ósseo (OT), com exceção do grupo OVX. Se pode visualizar que ocorrem alterações evidentes na placa de crescimento (PC) de amostras de ratas expostas à doxiciclina por 60 dias (Figuras 10B, 10C, 10E, 10F e 10l e estando esta placa de crescimento ausente completamente na Figura 10H). Conforme as diferenças estatísticas encontradas na Tabela 3, obteve-se que G vs. $H(O V X$ vs. OVX10) $p=0,04$ e $G$ vs. I (OVX vs. OVX30) p=0,05 possuem diferenças estatisticamente significantes. 
Figura 10: Fotomicrografia de um corte histológico do osso fêmur porção proximal, demonstrando o osso trabecular (OT) e a placa de crescimento (PC). As figuras demonstram que se obteve que G vs. H (OVX vs. OVX10) $p=0,04$ e G vs. I (OVX vs. OVX30) $p=0,05$ possuem diferenças estatisticamente significantes. As letras superiores-esquerda indicam os grupos de estudo: $A=C ; B=C 10 ; C=C 30 ; D=S e ; E=S e 10 ; F=S e 30 ; G=O V X ; H=O V X 10$ e; I=OVX30. Coloração: Tricromo de Masson, aumento real de 25x.
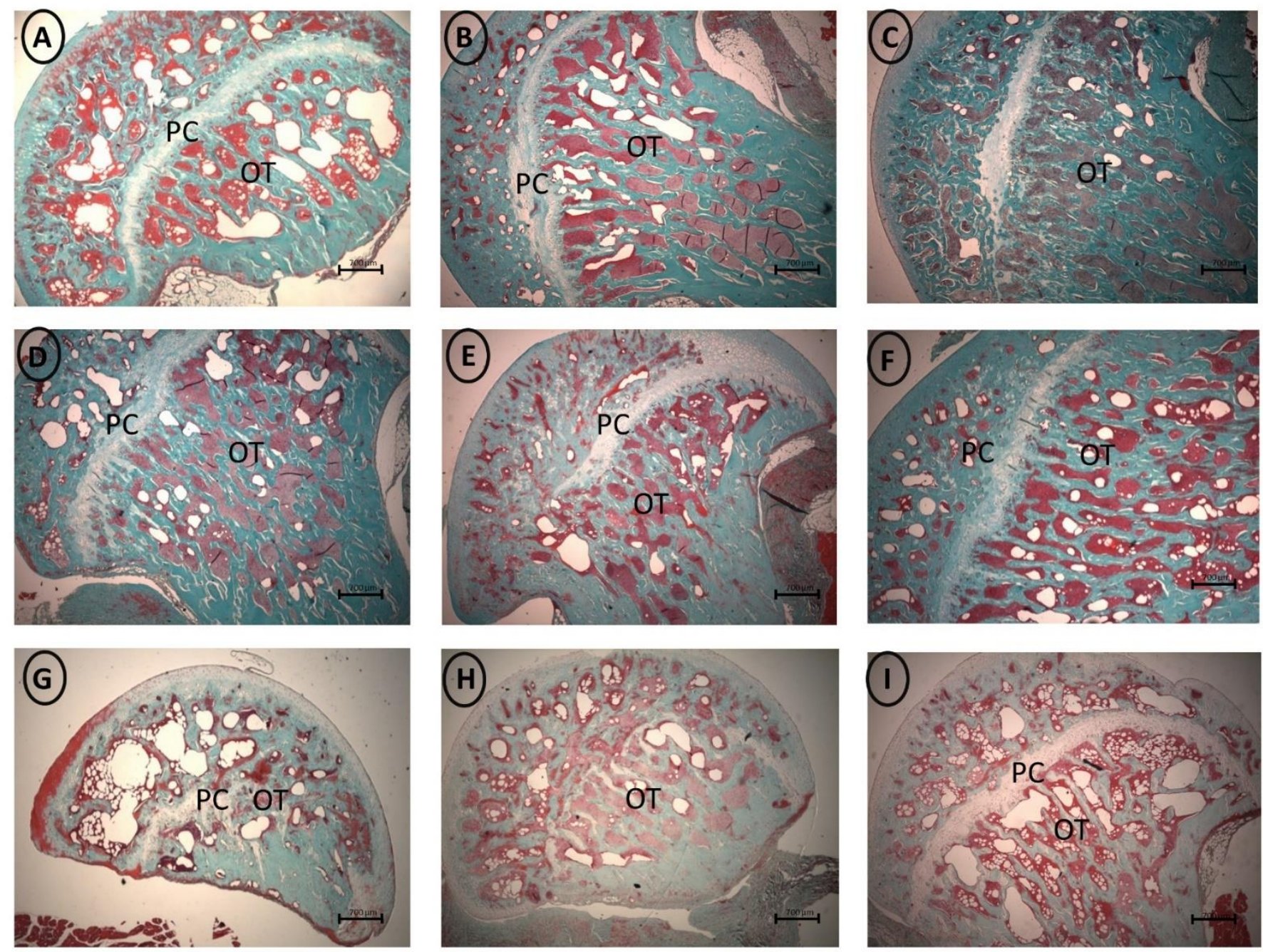


\subsubsection{Pricro-sirius}

Para as amostras submetidas à coloração de picro-sirius red (Figuras 11 e 12), temse que não houve diferenças evidentes na quantidade colágeno total. A inibição de colagenase, uma das ações da doxiciclina, não resultou em alterações na quantificação de colágeno total. 
Figura 11: Fotomicrografia de um corte histológico do osso fêmur porção proximal, demonstrando colágeno total refrigente à luz polarizada. Não ocorreram diferenças estatisticamente significantes. As letras superiores-esquerda indicam os grupos de estudo: $\mathrm{A}=\mathrm{C} ; \mathrm{B}=\mathrm{C} 10 ; \mathrm{C}=\mathrm{C} 30 ; \mathrm{D}=\mathrm{Se}$; $\mathrm{E}=\mathrm{Se} 10 ; \mathrm{F}=\mathrm{Se} 30 ; \mathrm{G}=\mathrm{OVX}$; H=OVX10 e; I=OVX30. Coloração: Picro-sirius red, aumento real de 40x.
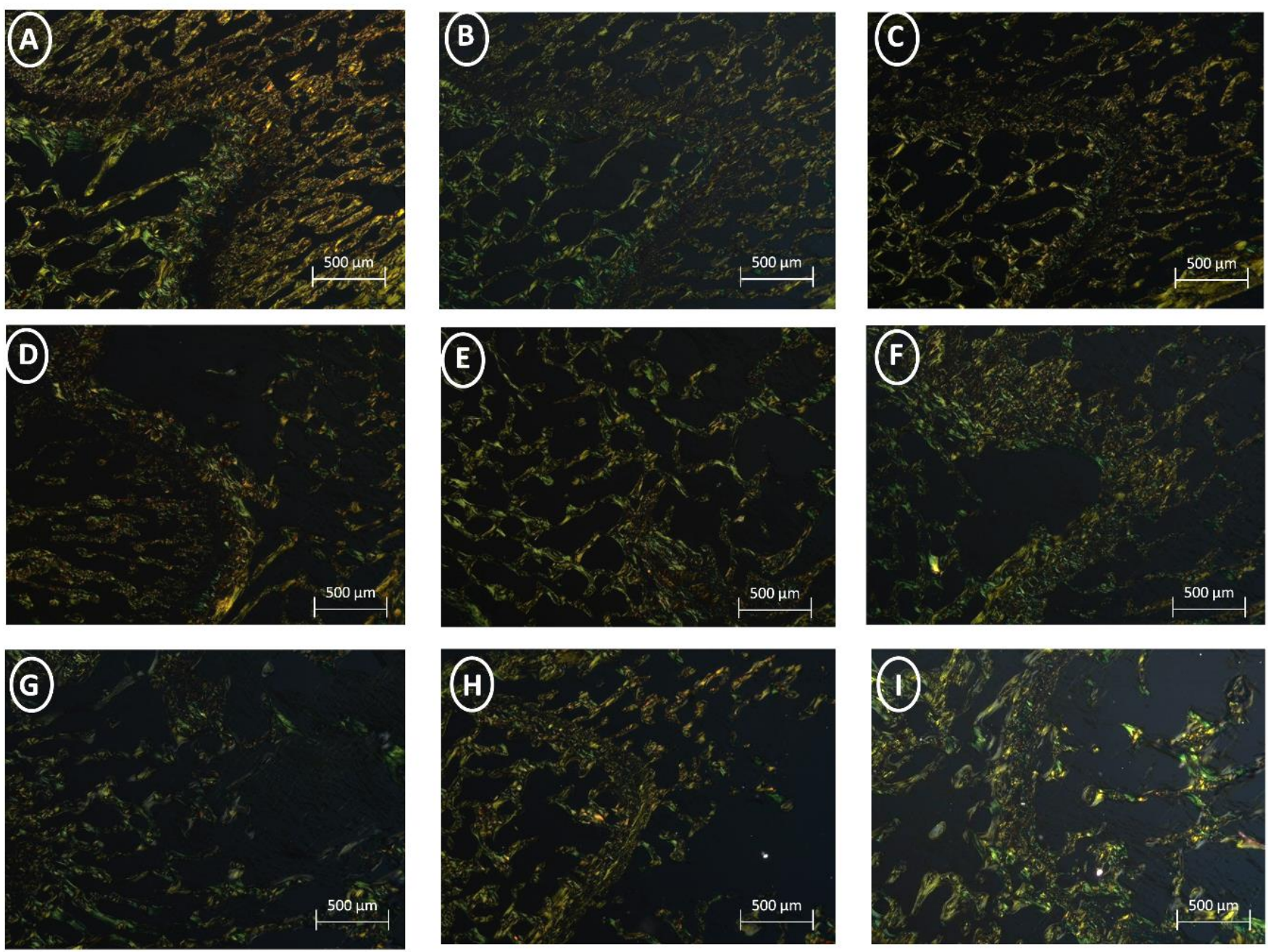
Figura 12: Fotomicrografia de um corte histológico do osso fêmur porção distal, demonstrando colágeno total refrigente à luz polarizada. Não ocorreram diferenças estatisticamente significantes. As letras superiores-esquerda indicam os grupos de estudo: $\mathrm{A}=\mathrm{C} ; \mathrm{B}=\mathrm{C} 10 ; \mathrm{C}=\mathrm{C} 30 ; \mathrm{D}=\mathrm{Se}$; $\mathrm{E}=\mathrm{Se} 10 ; \mathrm{F}=\mathrm{Se} 30 ; \mathrm{G}=\mathrm{OVX}$; H=OVX10 e; I=OVX30. Coloração: Picro-sirius red, aumento real de 40x.
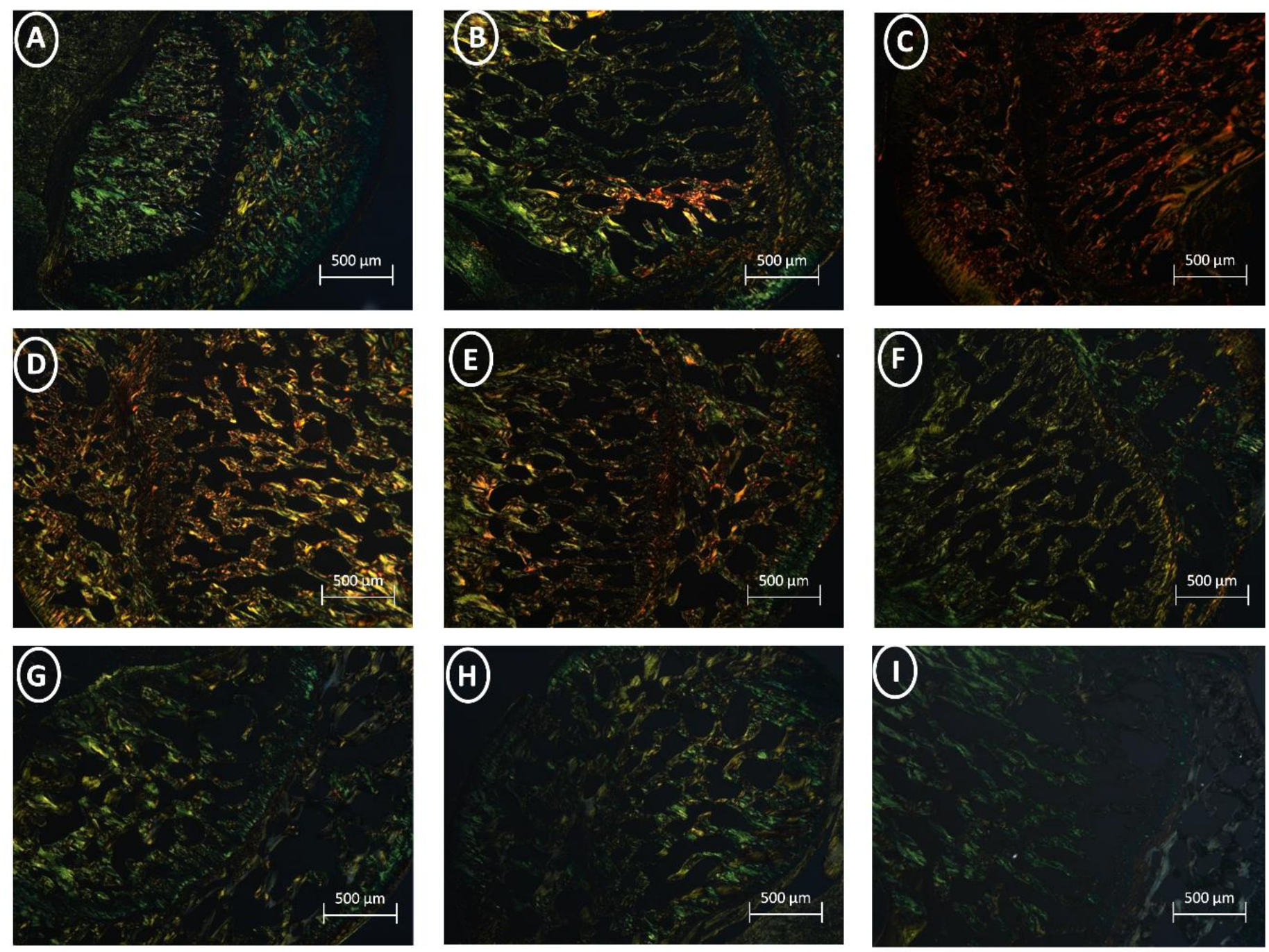


\subsubsection{Análise qualitativa das lâminas coradas por Tricromo de Masson}

Foram feitas análises qualitativas em 3 aumentos para ilustrar as diferenças encontradas nos ossos. A seguir, são demonstradas as figuras (Figuras 13 até 21) com o grupo indicado no canto superior esquerdo. Para cada figura tem-se que as três figuras superiores são cortes da região distal do osso fêmur e as três inferiores são cortes da região proximal.

Quanto a nomenclatura das figuras, no canto superior esquerdo apresenta um quadrado com a sigla do grupo e isso quer dizer que:

C: Controle sem doxiciclina ou quaisquer tratamentos

C10: Doxiciclina $10 \mathrm{mg} / \mathrm{kg}$ induzidos

C30: Doxiciclina 30mg/kg induzidos

OVX: Ovariectomia controle

OVX10: Ovariectomia 10mg/kg/dia

OVX30: Ovariectomia 30mg/kg/dia

Se: Sedentarismo controle

Se10: Sedentarismo $10 \mathrm{mg} / \mathrm{kg} / \mathrm{dia}$

Se30: Sedentarismo 30mg/kg/dia

Cada uma das Figuras (11 até 19) possuem 3 aumentos indicados com as figuras na horizontal, com aumentos finais de 16x (I), 25x (II) e 40x(III)

Em referência aos achados estatísticos, não se obteve diferenças na distribuição do trabeculado ósseo na região proximal e vale salientar que somente em ratas submetidas ao tratamento com doxiciclina em doses subantimicrobiana, encontramos alterações sensíveis na placa de crescimento. 
Pode-se visualizar uma tendência na modificação das placas de crescimento (PC) quando se tem a exposição à doxiciclina $10 \mathrm{mg} / \mathrm{kg} / \mathrm{dia}$ e $30 \mathrm{mg} / \mathrm{kg} / \mathrm{dia}$. Nota-se que nos grupos com osteopenia induzida (Se e OVS) tem-se um restabelecimento do trabeculado ósseo (OT) quando tratado com doxiciclina. As fotomicrografias das Figuras 13-21 demonstram estes achados.

Figura 13: Apresentação do corte histológico de um osso corado por Tricromo de Masson em condições normais inerentes ao grupo controle $(C)$, demonstrando uma distribuição normal do trabeculado ósseo (OT) e presença normal da placa de crescimento (PC) nos 3 aumentos (I, II e III). Coloração: Tricromo de Masson, aumento real: 16x ( I ), 25x (II) e 40x (III).
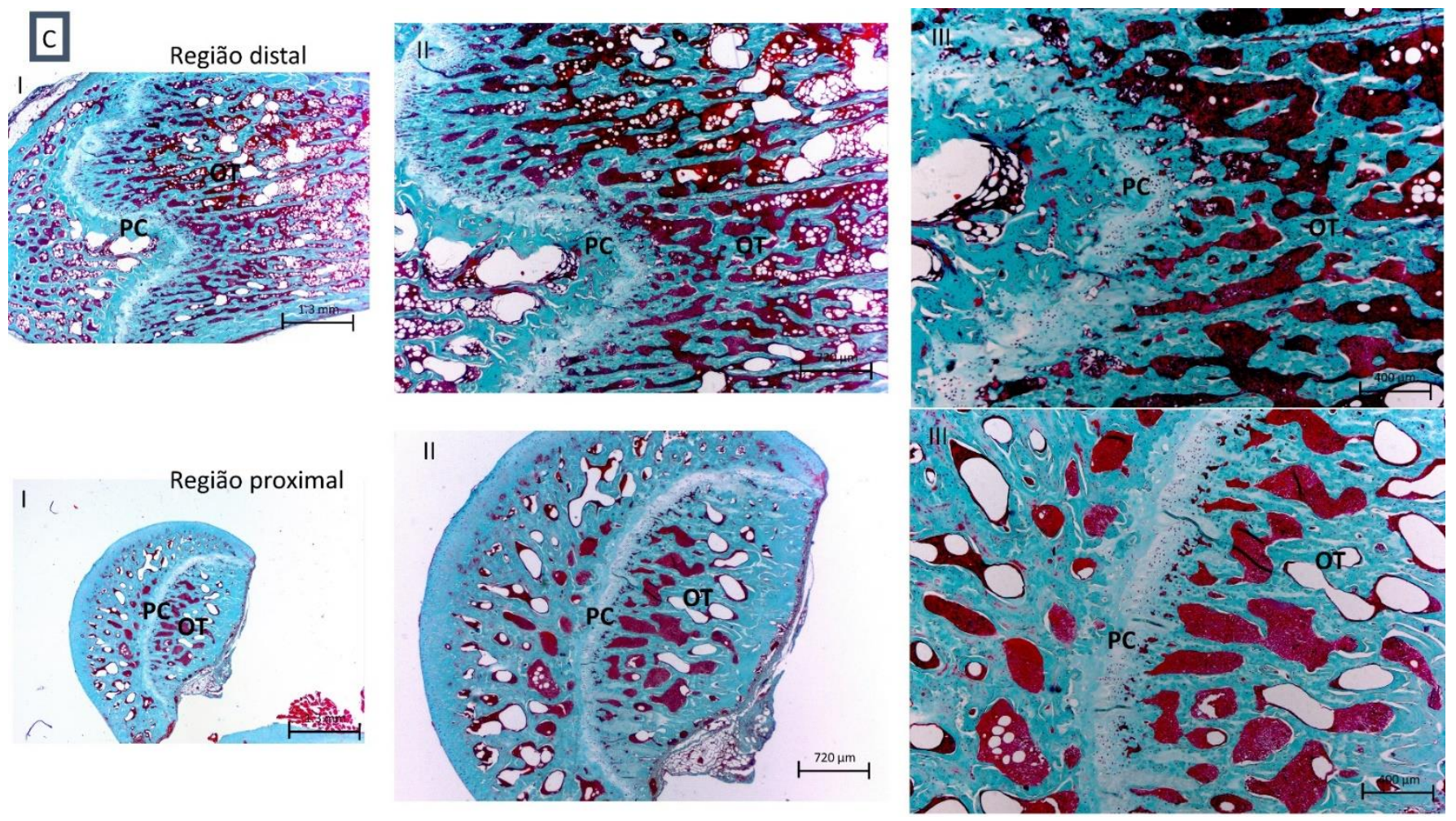
Figura 14: Apresentação do trabeculado ósseo com indicativos de prejuízo provocado pela doxiciclina em dose de $10 \mathrm{mg} / \mathrm{kg} / \mathrm{dia}(\mathrm{C} 10)$ na região distal, com um trabeculado ósseo (OT) sensivelmente mais espaçado e uma placa de crescimento mais espessa (PC). A região proximal não se tem essa diferença. Coloração: Tricromo de Masson, aumento real: 16x (I), $25 x$ (II) e $40 x$ (III).
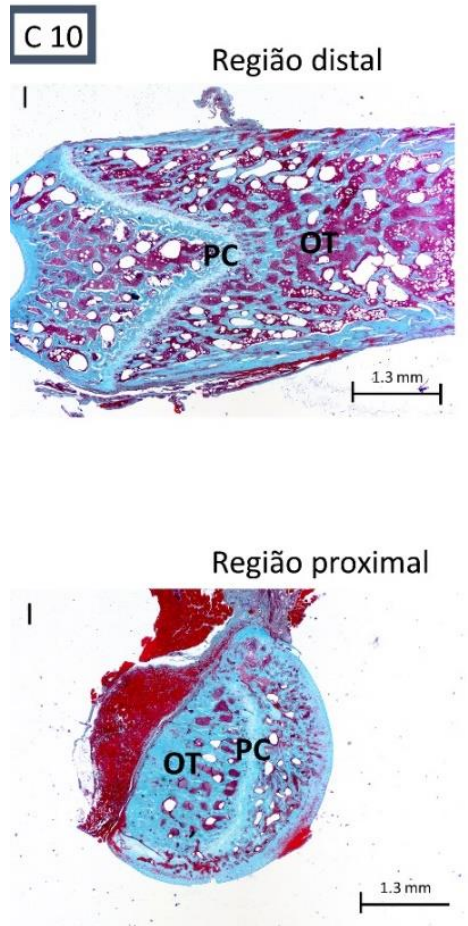
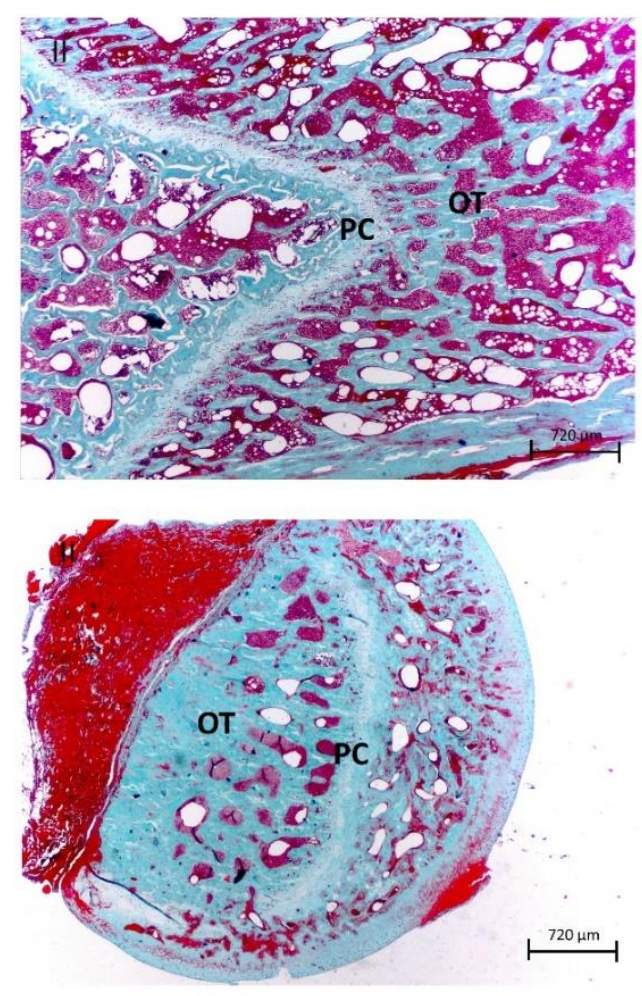

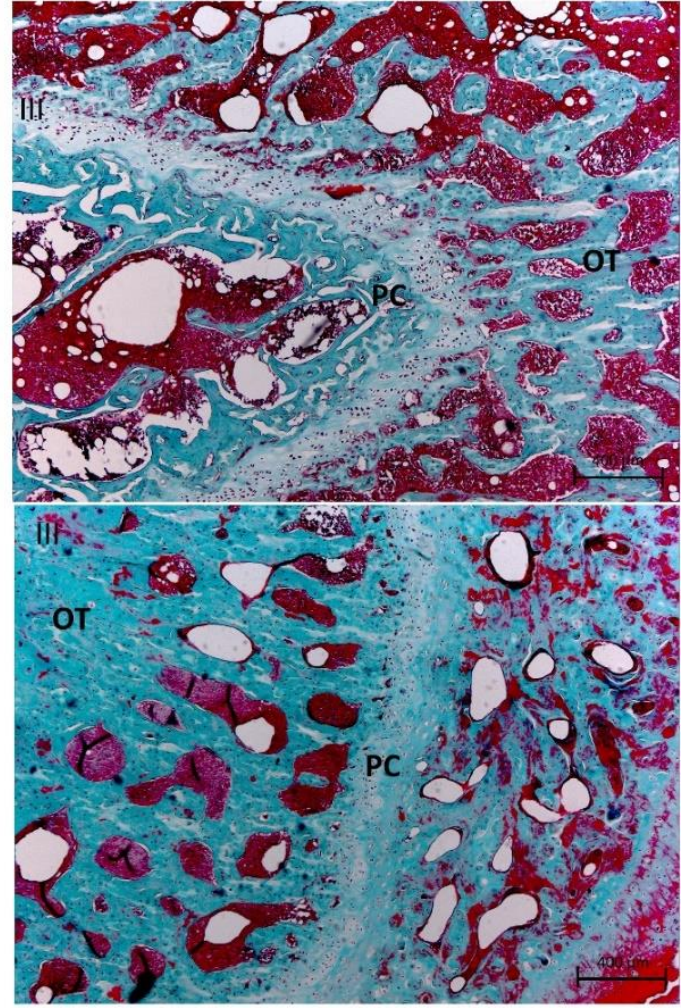


Figura 15: Fotomicrografia de uma amostra submetida a doxiciclina de $30 \mathrm{mg} / \mathrm{kg} / \mathrm{dia}$ (C30) com anomalia na placa de crescimento (PC) indicado pelas setas escuras, tanto nas amostras distais quanto proximais. Na região distal de maior aumento (III), tem-se a presença de um tecido ósseo hipomineralizado difuso em região de trabeculado ósseo (OT) indicado com o círculo vermelho e setas vermelhas (III - Seta vermelha). Na região proximal tem-se a presença da placa de crescimento (PC) mais espessa e anômala (indicada pela seta escura em I, II e III). Coloração: Tricromo de Masson, aumento real: 16x ( I ), 25x (II) e 40x (III).

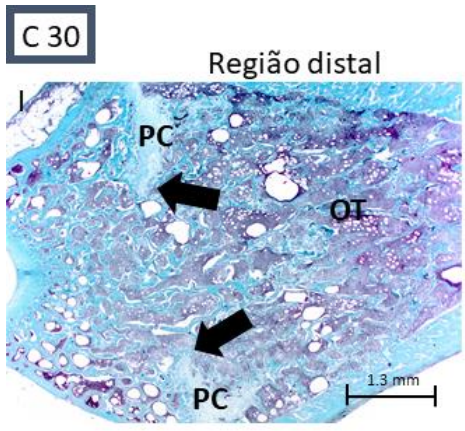

Região proximal

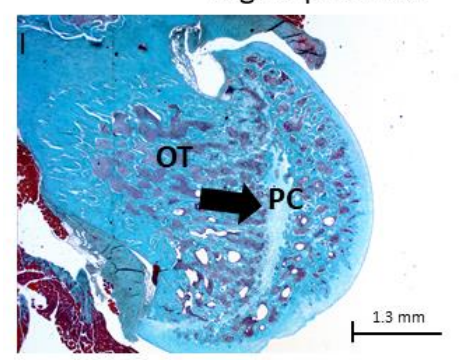

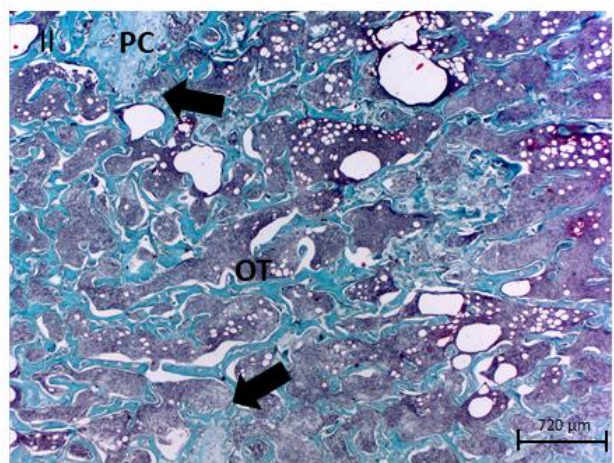

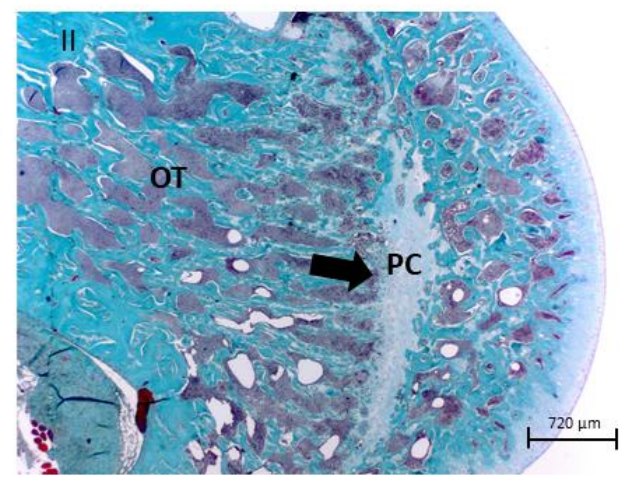

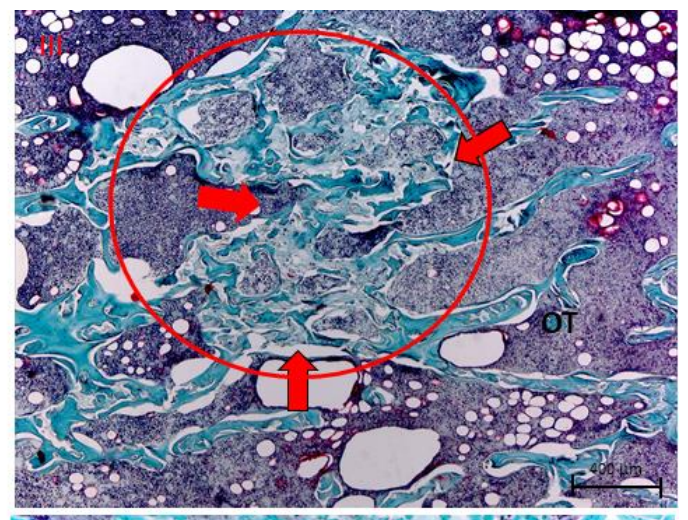

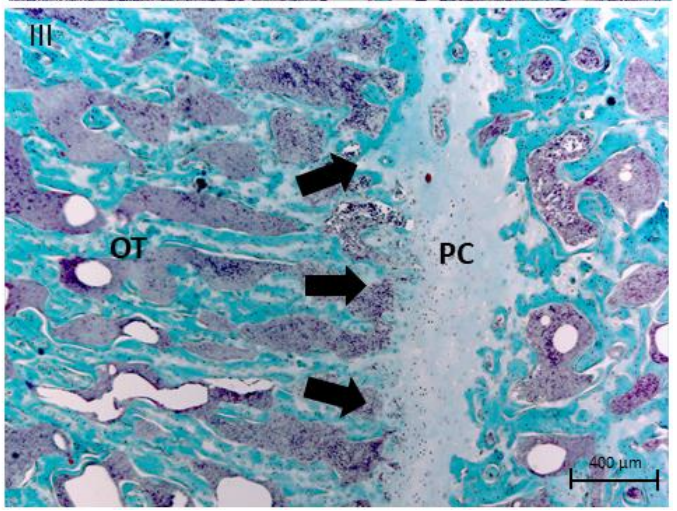


Figura 16: Apresentação do osso osteopênico acometido pelo sedentarismo (Se) induzido em ratas wistar. Com os trabeculados mais espaçados (OT), tem-se nesta Figura as placas de crescimento (PC) presente de maneira normal tanto na região proximal quanto distal. Coloração: Tricromo de Masson, aumento real: 16x (I), 25x (II) e 40x (III).
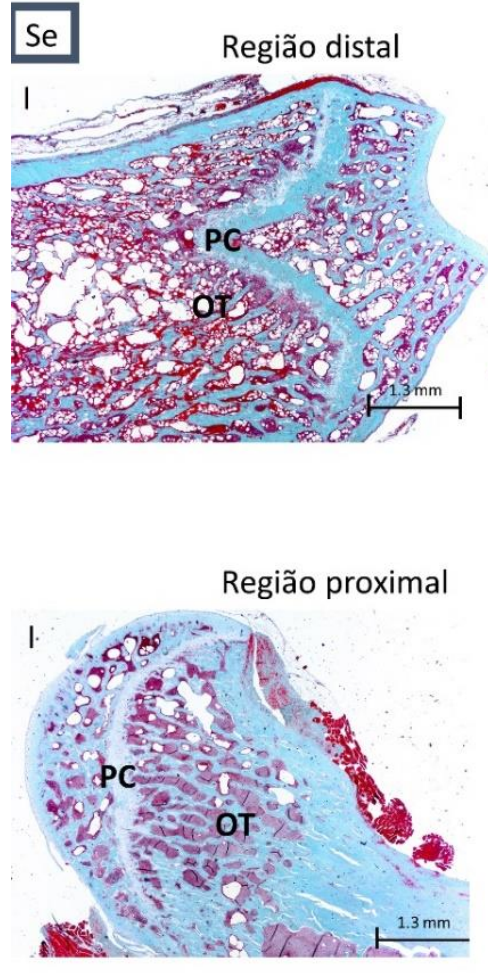
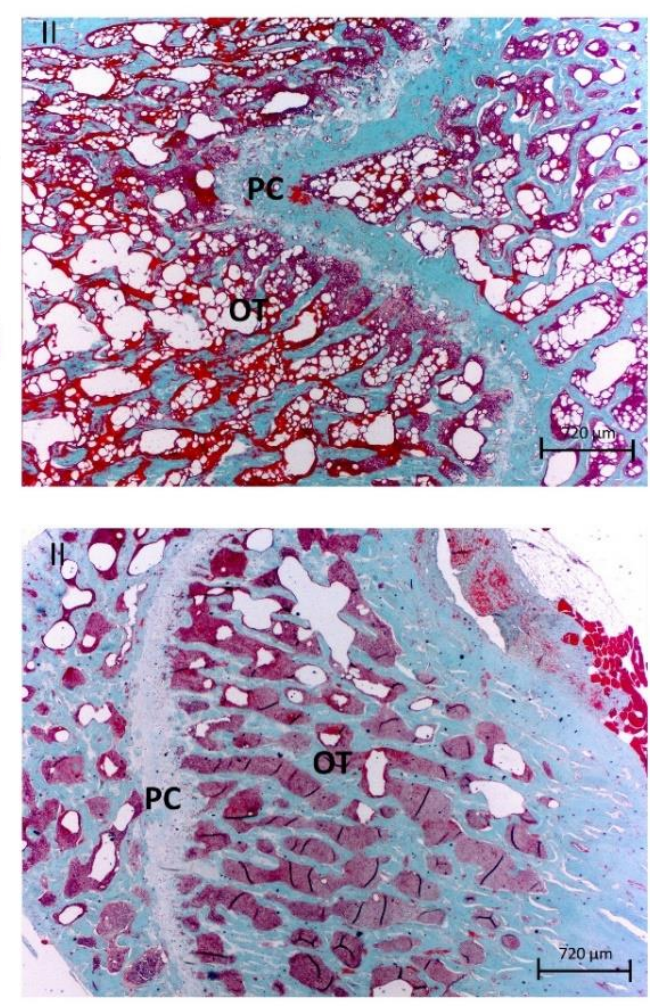

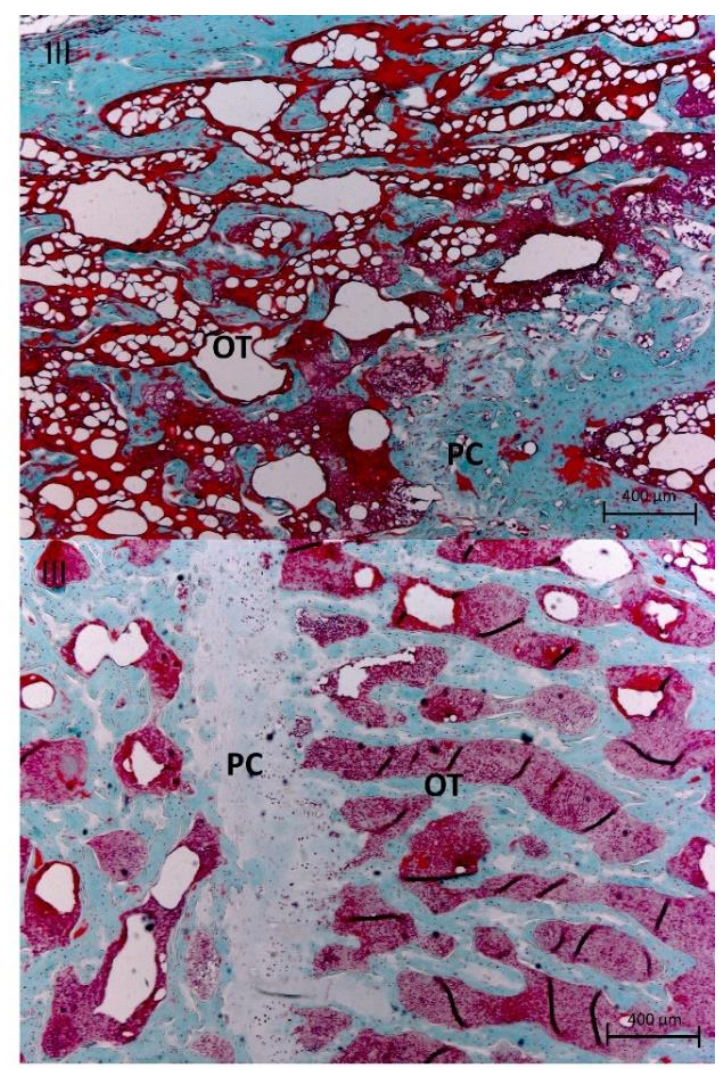


Figura 17: Fotomicrografia de um osso acometido pela osteopenia induzida por sedentarismo tratado com doxiciclina na dose $10 \mathrm{mg} / \mathrm{kg} / \mathrm{dia}$ (Grupo Se10) demonstrando uma melhora na região distal (quando se compara com a Figura 14, na mesma região) com um trabeculado ósseo menos espaçado (OT), porém se observa a presença de uma placa de crescimento mais espessa (PC). Na região proximal é observado uma maior espessura na placa de crescimento (PC). Coloração: Tricromo de Masson, aumento real: 16x (I), 25x (II) e 40x (III).
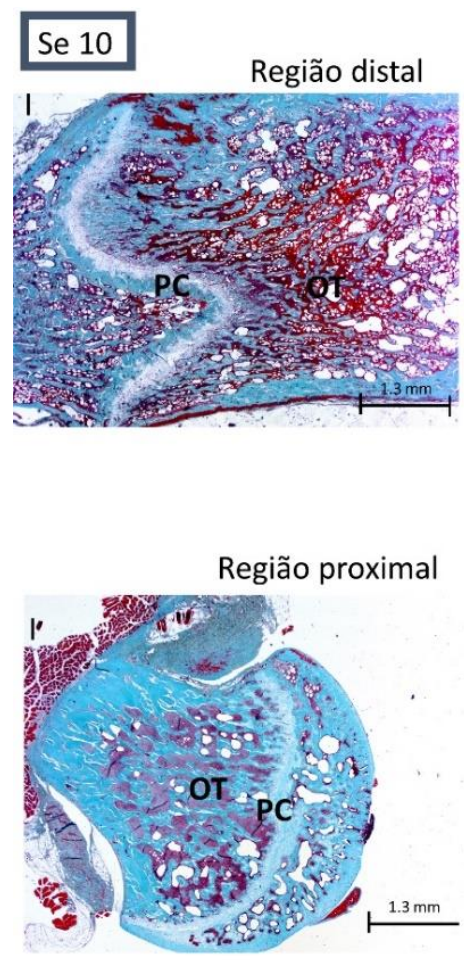
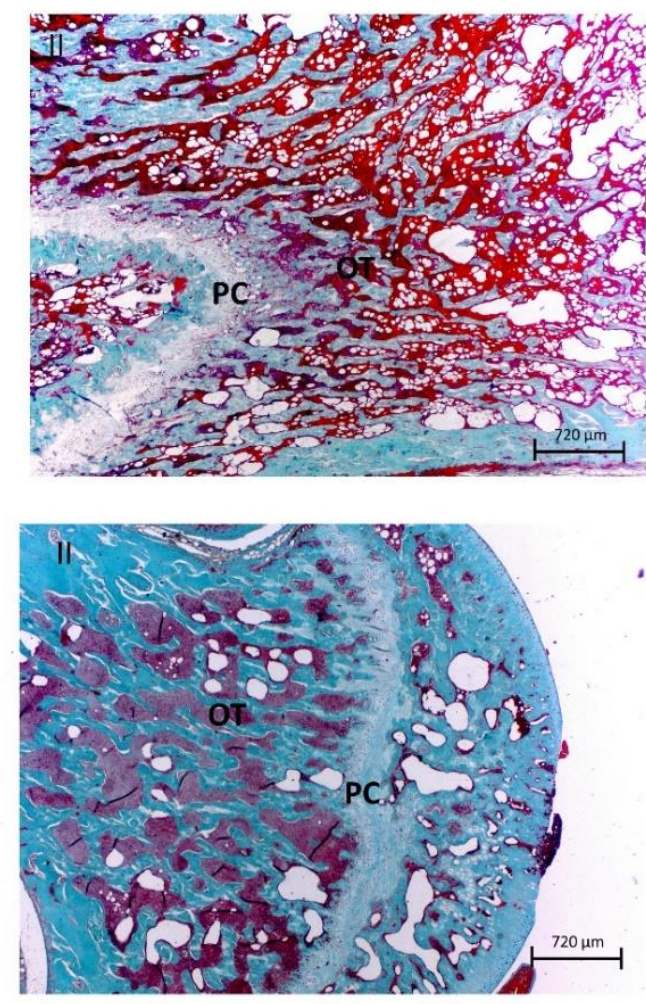

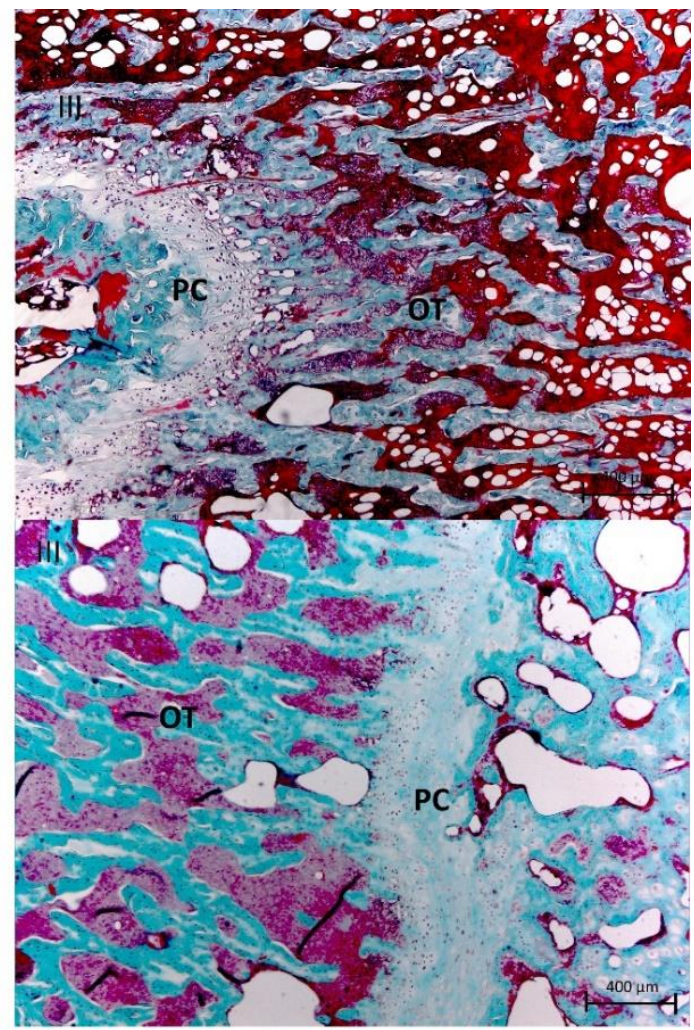


Figura 18: Nesta Fotomicrografia de um osso acometido pela osteopenia induzida por sedentarismo tratado com doxiciclina na dose 30mg/kg/dia (Grupo Se30) demonstrando uma melhora na região distal (quando se compara com a Figura 14, na mesma região). Observase um trabeculado ósseo menos espaçado (OT) e se observa a presença de uma placa de crescimento mais espessa (PC). Na região proximal é observado uma maior espessura na placa de crescimento (PC). Coloração: Tricromo de Masson, aumento real: 16x (I), 25x (II) e 40x (III).
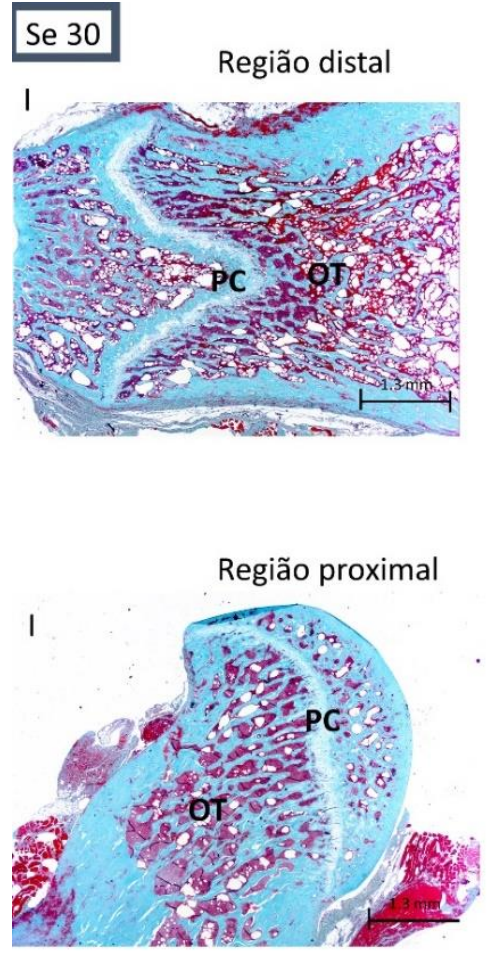
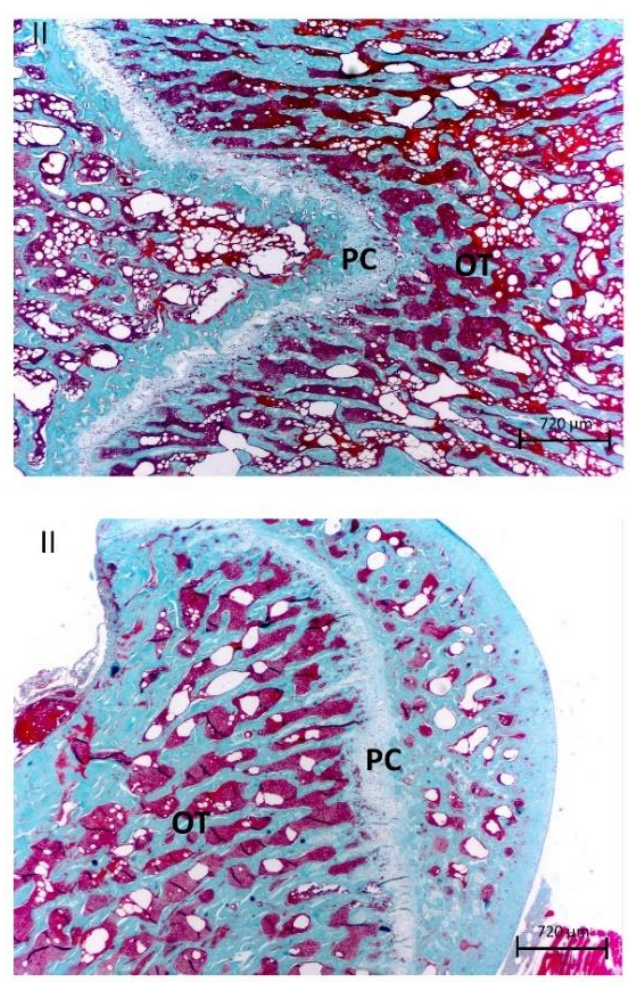

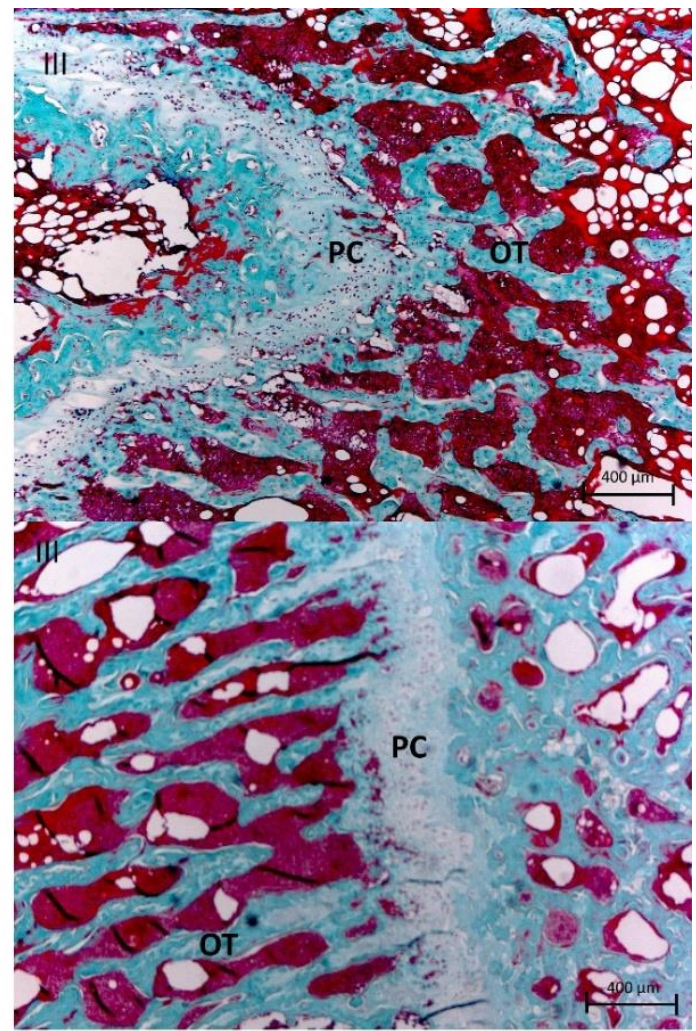


Figura 19: Fotomicrografia demonstrando um osso acometido pela osteopenia induzida por ovariectomia bilateral em ratas Wistar (OVX). Na região distal, se observa o trabeculado ósseo (OT) quase que inexistente e uma placa de crescimento bem disforme (PC). Na região proximal, não se observa este problema tão evidente, apesar de termos um osso trabecular (OT) mais espaçado se compararmos com os grupos controle (C Figura 11). Coloração: Tricromo de Masson, aumento real: 16x (I), 25x (II) e 40x (III).
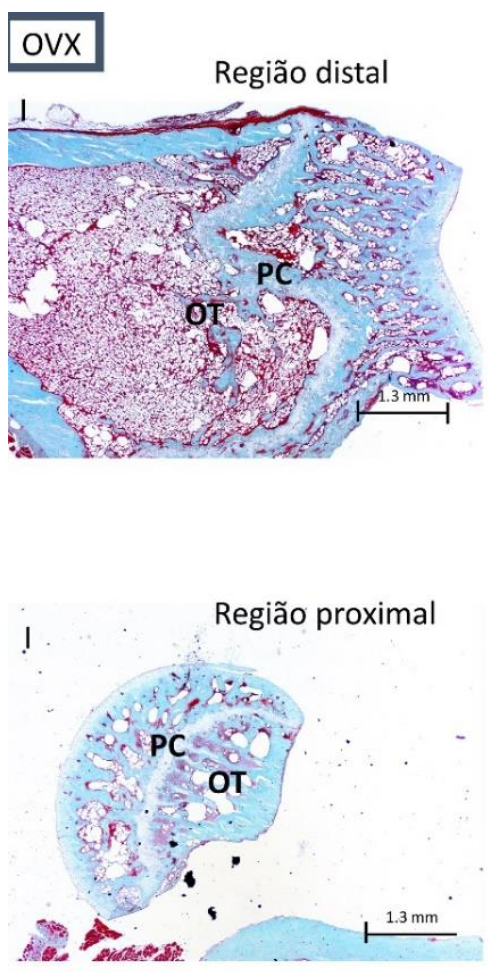
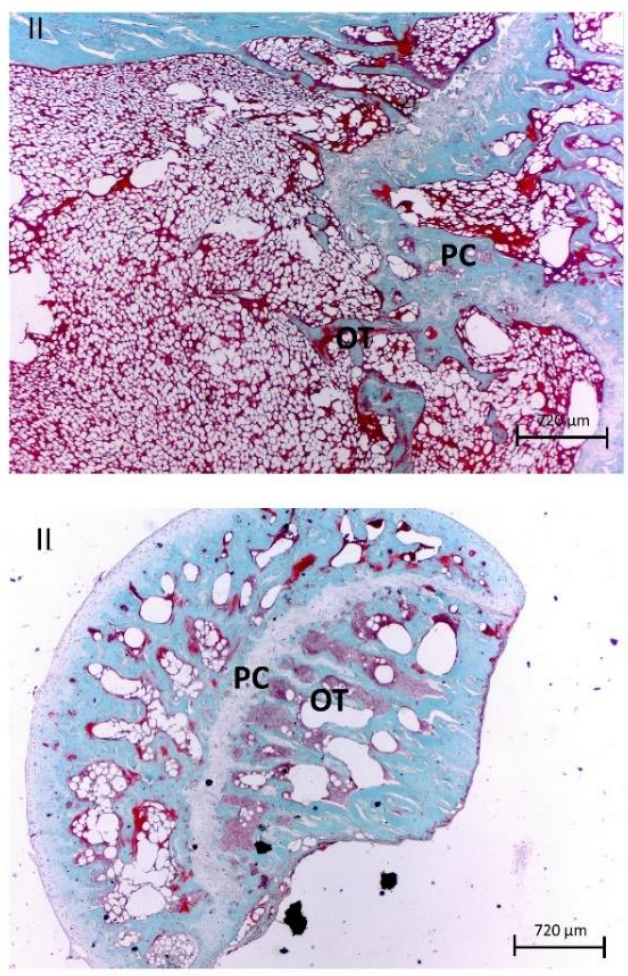

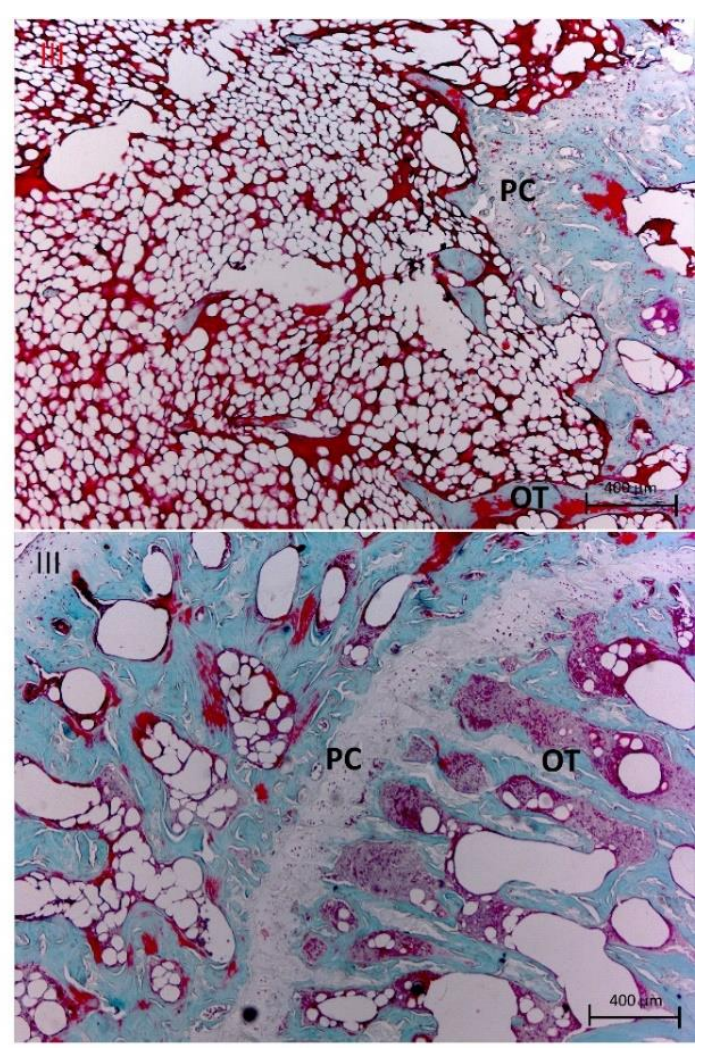


Figura 20: Quando se analisa a região distal tem-se uma sensível melhora do quadro (OVX10), se comparado com a Figura 17. Há a ocorrência de um osso trabecular (OT) na região onde havia a placa de crescimento $(\mathrm{PC})$, porém se vê uma anormalidade na placa de crescimento. Na seta escura tem-se a placa de crescimento (PC) interrompida na região sagital do corte histológico. Olhando na região proximal, nota-se uma placa de crescimento sensivelmente mais espessa (PC). Coloração: Tricromo de Masson, aumento real: 16x (I), $25 x$ (II) e 40x (III).
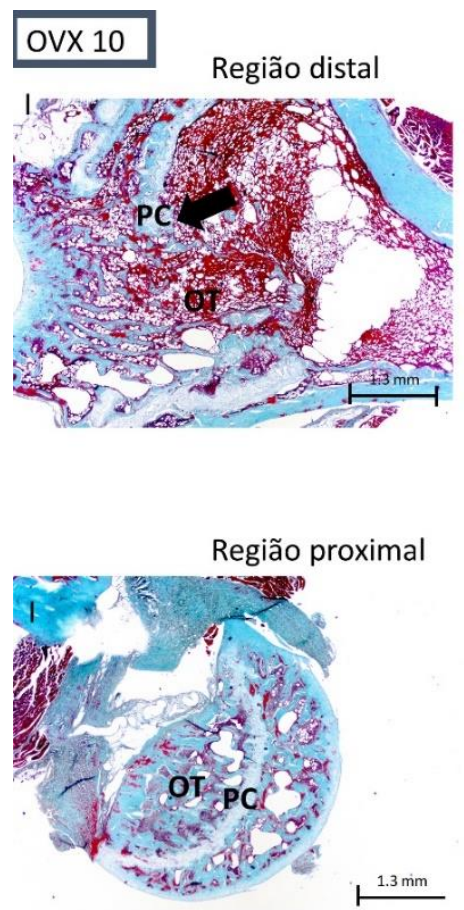
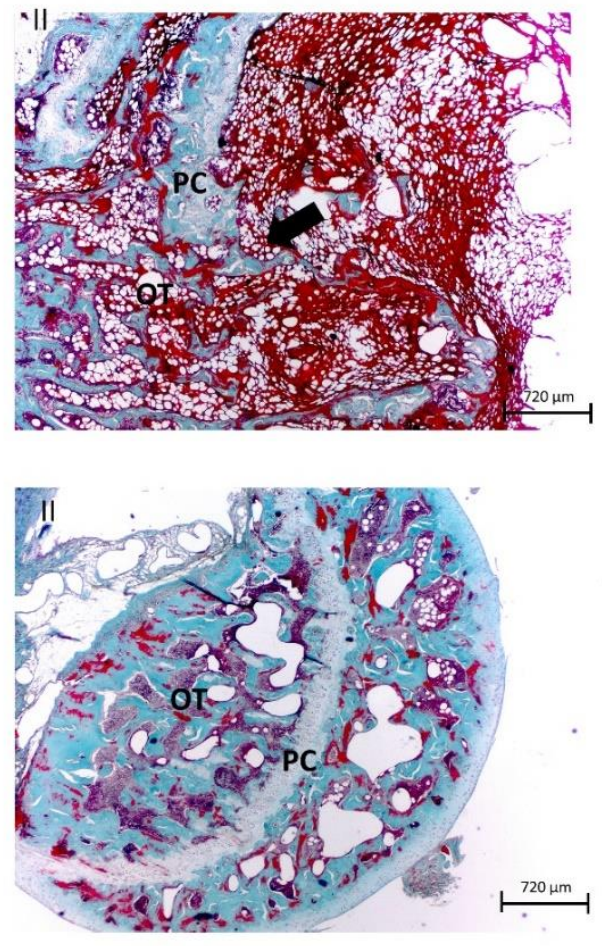
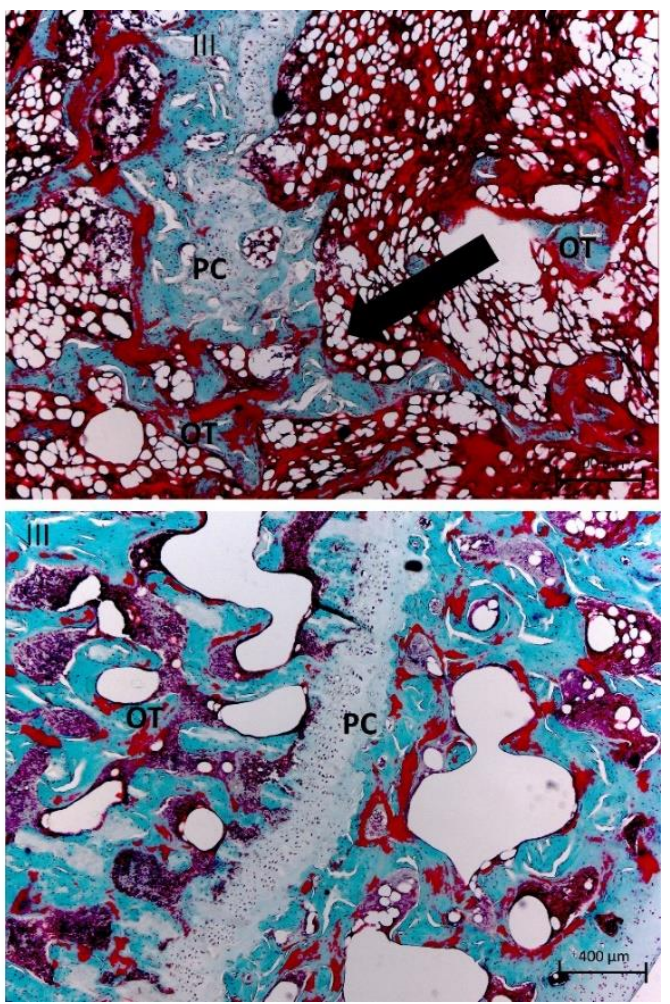
Figura 21: Na região distal é apresentado um osso osteopênico tratado por doxiciclina $30 \mathrm{mg} / \mathrm{kg} / \mathrm{dia}$ (OVX30) com uma melhora real no trabeculado ósseo (OT) se compararmos com a Figura 18. Na seta escura tem-se a placa de crescimento apresentando uma anomalia morfológica. Na região proximal, não se atesta grandes diferenças. Coloração: Tricromo de Masson, aumento real: 16x (I), 25x (II) e 40x (III).

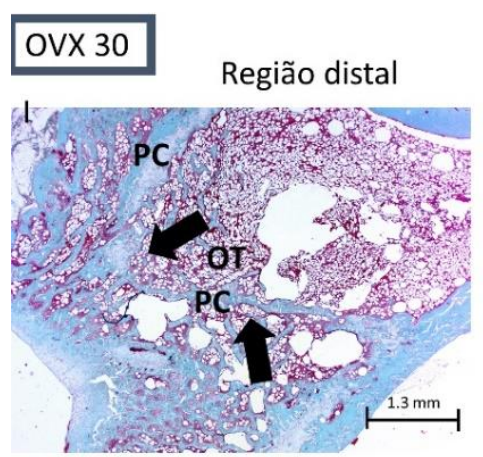

Região proximal

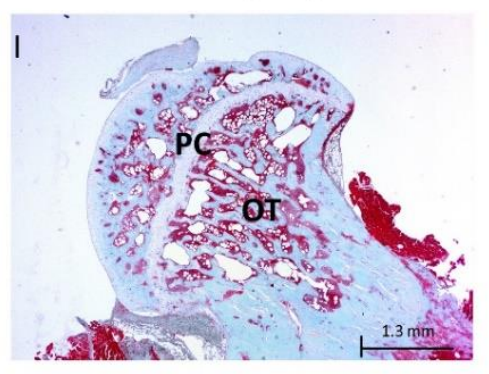

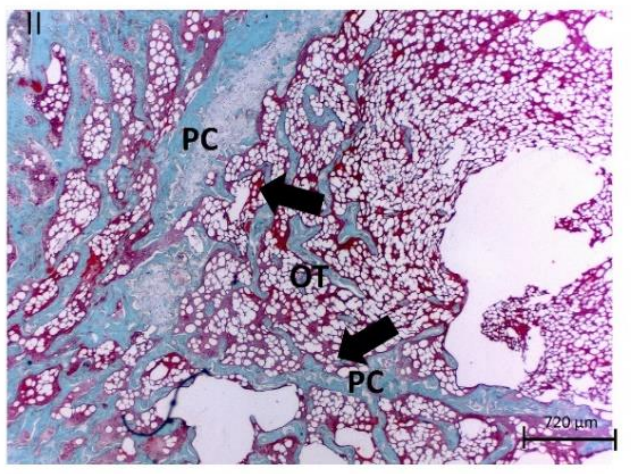

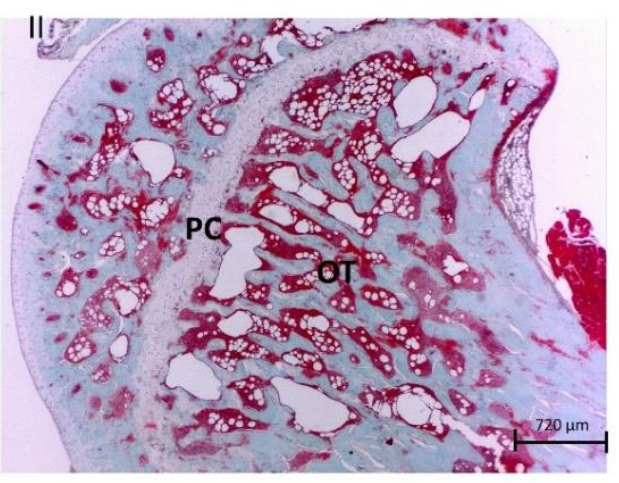

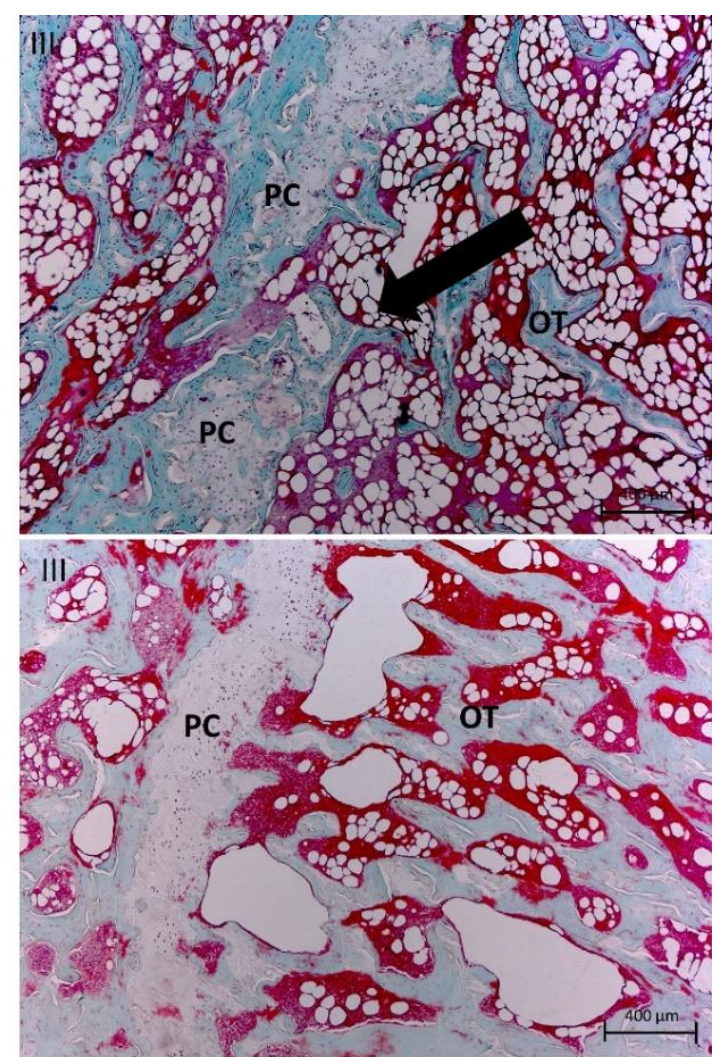




\subsubsection{Imunomarcação por TRAP}

A imunomarcação demonstrada pela Tabela 1 é correspondente com as fotomicrografias demonstradas pela Figura 20 onde ocorre uma tendência a diminuição da imunomarcação quando os grupos são expostos à doxiciclina $10 \mathrm{mg} / \mathrm{kg} / \mathrm{dia}$ e $30 \mathrm{mg} / \mathrm{kg} / \mathrm{dia}$. Quando se observa os grupos induzidos Se, OVX 10 e 30 , é visto uma tendência de diminuição da imunomarcação quando se aumenta a dose. Essa tendência é comprovada quando se atesta que Se vs. Se30 e OVX vs. OVX30 são estatisticamente diferentes entre si. Na Figura 8 tem-se a ilustração dessa diferença.

É demonstrado nos 2 aumentos apresentados que os grupos controles, C (Figura 22A e D), grupo Se (Figura 22G e J) e OVX (Figura 22M e P) possuem maior imunomarcação quando comparamos com os grupos expostos ao medicamento $10 \mathrm{mg} / \mathrm{kg} / \mathrm{dia}$ e $30 \mathrm{mg} / \mathrm{kg} / \mathrm{dia}$ (Figura 22B, C, H, I, N, O, Q, R).

Pode-se ver que o grupo controle $\mathrm{C}$, controle sem nenhum tratamento, possui uma imunomarcação média (ESCORE2), mesmo "valor" dado as imunomarcações dos grupos Se10 e OVX10. Pode-se considerar que estes grupos sujeitos ao tratamento com doxiciclina possuem uma expressão óssea "basal" muito parecida com o controle. Já os grupos Se30 e OVX30 possuem as mesmas imunomarcações baixas (ESCORE 1) que os grupos C10 e C30, o que demonstra que existe uma inibição ao metabolismo ósseo nestes grupos. 
Figura 22: Padrão de imunomarcação para TRAP. A-R: fotomicrograficas evidenciando o padrão de imunomarcação para TRAP nos grupos $C(\mathbf{A}, \mathbf{D}), \mathrm{C} 10(\mathbf{B}, \mathbf{E}), \mathrm{C} 30(\mathbf{C}, \mathbf{F}), \mathrm{OVX}(\mathbf{G}$, J), OVX10 (H, K), OVX30 (I, L), SE (M, P), SE10 (N, Q), SE30 (O, R). Símbolos: setas vermelhas: células imunomarcadas e, retângulos: aumentos nas áreas indicadas. Contracoloração: Hematoxilina de Harris. Aumento: A-C, G-I, M-O: 400x; D-F, J-L, P-R: 1000x.
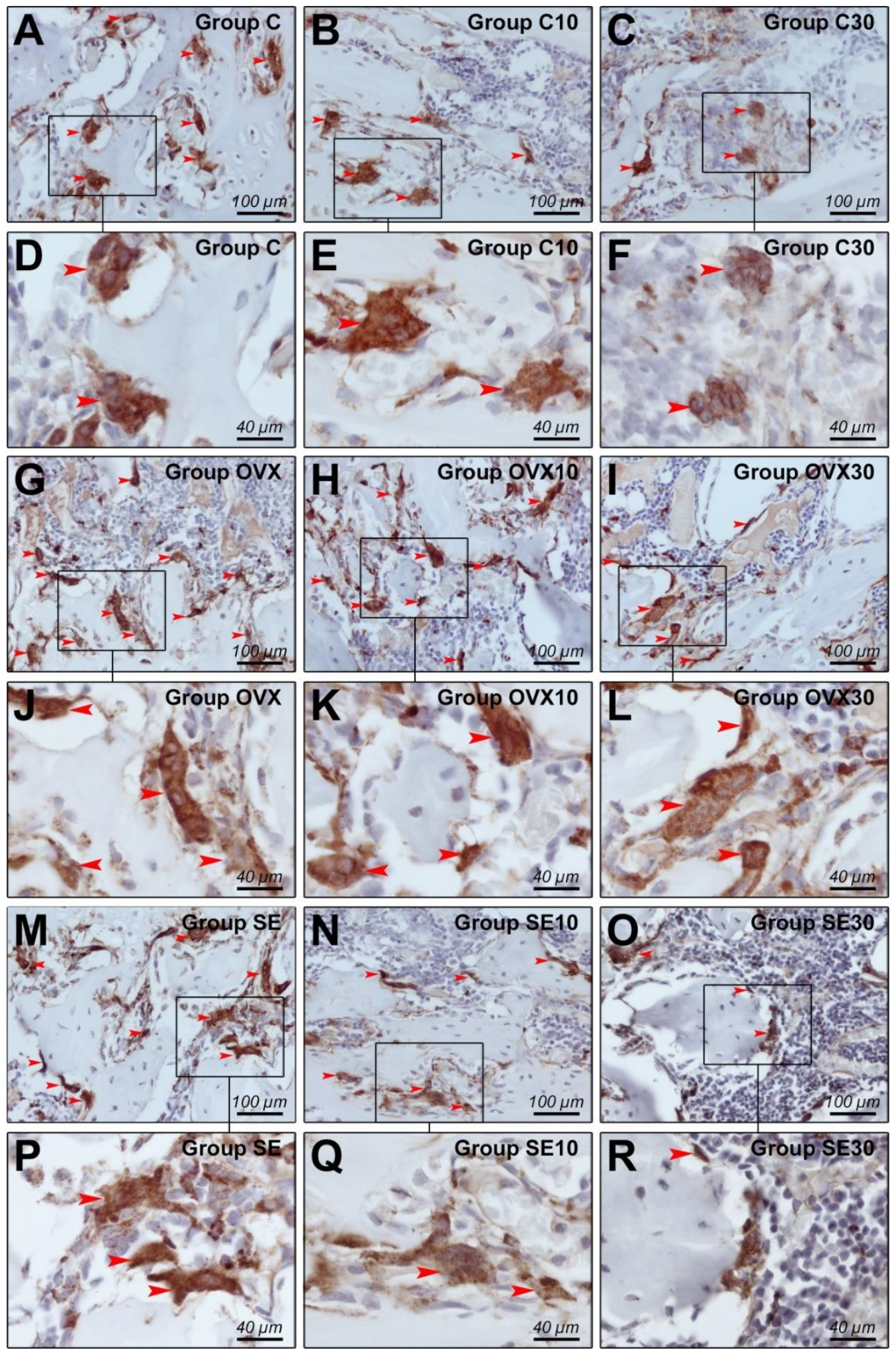


\section{DISCUSSÃO}

No presente trabalho, a doxiciclina modifica de modo positivo a remodelação óssea em ossos acometidos pela osteopenia, porém ela causa efeitos deletérios quando é utilizada em ossos não acometidos pela osteopenia.

Sabendo-se que as tetraciclinas são responsáveis pela inibição de reabsorção óssea (CHOWDHURY et al., 1993; GOLUB et al., 1998; GOMES, B. C.; GOLUB; RAMAMURTHY, 1984; GREENWALD et al., 1998; KLAPISZ-WOLIKOW; SAFFAR, 1996; SASAKI et al., 1999; WILLIAMS et al., 1998), pode-se concluir que de acordo com a metodologia empregada neste trabalho, a doxiciclina diminuiu os efeitos deletérios da osteopenia.

No presente estudo, foram comparadas duas técnicas clássicas de indução de osteopenia para garantir que a doxiciclina em doses subantimicrobianas seja o medicamento correto para melhoria da qualidade óssea. A procura por medicamentos capazes de inibir a reabsorção óssea em casos de osteopenia já é explorada pela literatura recente em um estudo pioneiro com o uso de um princípio ativo chamado "Kinsenoside". Este princípio ativo, advindo de uma planta muito usada pela medicina tradicional chinesa (HSIAO et al., 2013), tem efeitos de inibição de macrófagos e antiinflamatórios (HSIAO et al., 2011; WU et al., 2007). Os estudos de HSIAO, WU e colaboradores apresentam similaridades ao presente trabalho, uma vez que a doxiciclina além da conhecida inibição de metaloproteinases, também tem efeitos antiinflamatórios.

Para discutir os resultados do presente estudo é necessário discursar sobre os resultados obtidos. Considera-se nessa discussão as tabelas e os achados do presente trabalho.

$\mathrm{Na}$ Tabela 2 tem-se as comparações entre os grupos de indução de osteopenia desconsiderando os medicamentos usados. Nesta tabela estão embutidos o medicamento dentro de um grande grupo, ou seja, para o grupo $\mathrm{C}$ tem-se os resultados do grupo controle integrados com os grupos C, C10 e C30. Para o grupo Se, são integrados os grupos Se, Se10 e Se30. Para o grupo OVX, tem-se que os grupos OVX, OVX10 e 0VX30 estão integrados. Isso é importante para ver a influência do medicamento no grupo. Na Tabela 2 tem-se 
diferenças que demonstram que o grupo ovariectomizado (OVX) possui uma maior quantificação de colesterol total, seguido do grupo Se que possui uma maior quantidade de colesterol total em comparação ao controle (cerca de 50\% a mais que o grupo controle C). Isso demonstra que o medicamento não interferiu no colesterol total, pois o colesterol aumenta independente do tratamento com doxiciclina. Um estudo recente demonstrou que a doxiciclina em doses subantimicrobianas melhora as quantidades de HDL no organismo, promovendo uma proteção cardiovascular (SALMINEN et al., 2013) e, em doses antimicrobianas, de acordo com Bocker e colaboradores, ocorre uma deposição de gordura no fígado e uma queda na concentração de colesterol no soro. Isso faz evidenciar os dados de colesterol contidos na Tabela 3, onde para o grupo sedentário ocorreu uma tendência a diminuição de colesterol total, mas isso não ocorreu para o grupo OVX.

O peso total das ratas antes da indução de morte e o peso do fêmur também aumentaram nos grupos Se e OVX em comparação ao grupo controle, conforme a Tabela 2. Este ganho de peso das ratas já foi discutido com OVX vs. Controle em vários estudos (CHEN; HEIMAN, 2001; MACEDO et al., 2017) e Sedentários vs. Controle (MOCHIZUKI; HASEGAWA, 2005).

A queda na quantidade de cálcio em osso no grupo OVX, de acordo com a Tabela 2, está presente também em um estudo já publicado, onde foram feitas análises químicas de quantidade de cálcio em OVX vs. Controle (NORDSLETTEN et al., 1994), porém em nenhum destes estudos compararam os grandes grupos Controle vs. Sedentário vs. Ovariectomizados. Analisando os valores encontrados no presente estudo, pode-se constatar que a queda de minerais foi mais evidente no grupo Sedentário do que no grupo Ovariectomizado. Foi observado também diferenças evidentes na densitometria óssea (BMD e BMC) com um agravo na qualidade óssea dos ossos do grupo OVX em comparação aos grupos Se e Controle. Esta análise, no presente trabalho, mostra que apesar das melhoras da qualidade óssea dos grupos expostos à doxiciclina quando acometidos pela osteopenia, não chega a ser evidenciada quando agrupamos os grupos expostos ao medicamento e 
controle em um só grupo. Talvez o acometimento da doença osteopenia seja capaz de mascarar o resultado agrupado.

Na Tabela 4 tem-se a comparação da relevância dos medicamentos para cada grupo experimental. Com isso poode-se dizer que a indução de osteopenia por ovariectomia (grupo OVX) possui os maiores efeitos deletérios nos ossos (resultados demonstrados pela densitometria óssea, quantificação de cálcio e zinco, quantificação do trabeculado ósseo por tricromo de Masson, comprimento do osso). Além disso, pode-se ver neste trabalho que ocorreu um aumento de peso no grupo OVX em comparação ao grupo controle, dados já sedimentados em estudos publicados anteriormente (KIMURA et al., 2002; MITAZAKI et al., 2016). Para a quantificação de magnésio, observou-se uma menor quantidade de magnésio no grupo sedentário em comparação com os grupos Controle e OVX.

A Tabela 4 demonstra que não houve grandes melhorias no peso total das ratas dos grupos Se e OVX quando tratados com doxiciclina. Na verdade ocorreu um sensível aumento em seu peso, dados estes que corroboram com um estudo atual publicado por Mitazaki e colaboradores (MITAZAKI et al., 2016), porém pode-se perceber que o medicamento doxiciclina nas duas doses (10mg/kg/dia e $30 \mathrm{mg} / \mathrm{kg} / \mathrm{dia}$ ) possuem diferentes comportamentos de melhoria na qualidade óssea, sendo mais evidente a melhora quando observa-se os grupos Sedentários. Esta diferença se dá pelo fato da indução de osteopenia por sedentarismo ser menos invasiva à nível ósseo do que ovariectomia, uma vez que os dados contidos nas Tabelas 2, 3 e 4 (e ilustrado pela Figura 8) comprovam isso.

Pode-se ver que os dados de imunomarcação por TRAP (contidos na Tabela 1) possuem diferenças semi-quantitativas, mostrando que em ossos controle tem-se uma maior imunomarcação em comparação com os grupos expostos a doxiciclina $(10 \mathrm{mg} / \mathrm{kg} / \mathrm{dia}$ e $30 \mathrm{mg} / \mathrm{kg} / \mathrm{dia}$ ). Isso demonstra que a doxiciclina nestas duas doses inibiu a ação do osteoclasto em ossos fêmur de ratas Wistar, conforme descrito em estudos anteriores in vitro (ZHANG et al., 2007; ZHOU et al., 2010). Além disso, em um estudo sobre movimentação ortodôntica, os autores chegaram a conclusão que a imunomarcação por TRAP no grupo exposto a doxiciclina durante a movimentação dentária foi menor que em grupos controles 
(MAVRAGANI; BRUDVIK; SELVIG, 2005). Isso corrobora mais uma vez com os resultados do presente trabalho, onde ocorreu diminuição da imunomarcação por TRAP nos grupos exposto a doxiciclina. Gomes e Fernandes mostraram em estudo in vitro que a doxiciclina e a minociclina promovem uma proliferação de células humanas osteoblásticas e isso leva a uma mineralização tardia, o que demonstra que neste estudo em questão a doxiciclina pode induzir a mineralização óssea, além de formação óssea (GOMES, P. S.; FERNANDES, 2007). No entanto, no estudo de Zhang e colaboradores, os achados histológicos foram diferentes dos achados no presente trabalho. Isso pode ser explicado facilmente visto que no estudo mencionado anteriormente foram realizados procedimentos metodológicos primordialmente in vitro. Zhang e colaboradores administraram a doxiciclina por via intraperitoneal por 7 dias apenas $(1 \mathrm{mg} / \mathrm{kg} / \mathrm{dia}$ e $10 \mathrm{mg} / \mathrm{kg} / \mathrm{dia})$ com dados quantificados em amostras de calvária, portanto foi um estudo de doxiciclina em modelo de reparo ósseo (ZHANG et al., 2007).

O medicamento doxiciclina promove diferenças estatisticamente significantes quando analisamos a quantificação do trabeculado ósseo por tricromo de Masson (Tabela 3). Este medicamento provoca malefícios dose-dependentes nos grupos controles (C10 e C30), ou seja, quanto maior a dose pior a qualidade do trabeculado. Por outro lado, nos grupos sedentários e ovariectomizados (Se e OVX), a doxiciclina melhora o trabeculado ósseo sendo esta uma melhora dose-dependente. Observa-se um aumento claro do trabeculado ósseo quando se aumenta a dose de doxiciclina.

Ao analisar a Tabela 1, onde se tem o escore de imunomarcação por TRAP, é mostrado a supressão osteoclástica promovida pela doxiciclina em um osso sadio (Grupo C10 e C30), sedimentando essa piora no quadro em comparação com o grupo controle (C). Em contrapartida observa-se que a supressão osteoclástica promovida pela doxiciclina nas duas doses é benéfica para os grupos sedentários e ovariectomizados, limitando assim a ação osteoclástica em ossos acometidos por modelos de indução de osteopenia.

Pode-se dizer que a doxiciclina inibe a ação osteoclástica em ossos, porém quando a ação é aumentada, a doxiciclina promove efeitos benéficos ao osso. Quando o osso está em sua fisiologia normal essa supressão promove malefícios. Vale salientar que a doxiciclina 
pode aumentar a ação osteoblástica, talvez modificando o desbalanço provocado pela osteoporose, onde se observa um aumento na ação de osteoclastos e uma diminuição na ação de osteoblastos (TEITELBAUM, 2000). Aparentemente analisando a literatura e os resultados contidos no presente trabalho, pode-se dizer que a doxiciclina diminuiu a ação osteoclástica (ZHANG et al., 2007; ZHOU et al., 2010) e aumentou a ação osteoblástica (GOMES, P. S.; FERNANDES, 2007). No entanto, não se sabe como ocorre esse "rebalanço", sendo necessário novos estudos.

Para as análises morfológicas, tem-se uma melhora da qualidade do trabeculado ósseo em cortes histológicos corados por Tricromo de Masson na porção distal do osso fêmur em ratas Wistar com osteopenia induzida. Esse achado está descrito na Tabela 3 e nas Figuras 9, 13-21. Os resultados discutidos anteriormente corroboram com um estudo de Mavragani e colaboradores, onde a movimentação dental ortodôntica executada em camundongos gerou menor reabsorção radicular dental em grupos submetidos a doxiciclina por 7, 10 e 14 dias de tratamento ortodôntico (MAVRAGANI et al., 2005), uma vez que na movimentação dental tem-se uma reação inflamatória considerada como efeito colateral normal na prática ortodôntica (RYGH, 1977). Outro estudo executado em cães, demonstrou que a doxiciclina reduziu a perda óssea ocasionada pela cirurgia endodôntica periradicular (CUMMINGS, G. R.; TORABINEJAD, 2000). Na literatura tem-se que a doxiciclina não melhorou a qualidade de osso alveolar em reparo tecidual em ratas Wistars submetidas a extração dental e tratadas posteriormente por 7 dias por doxiciclina e eritromicina (SHAHABOOEI, MOHAMMAD et al., 2015). Pode-se entender que no referido trabalho as ratas foram submetidas a um período curto de tratamento com doxiciclina ( 7 dias), e a quantificação de osso neoformado ficou aquém do ideal devido a este fato. Além disso, os autores chegaram à conclusão que tanto a doxiciclina quanto a eritromicina aumentam a quantidade de osso neoformado em comparação aos ossos controle, mas não houve diferenças estatisticamente significantes no estudo de Shahabooei e colaboradores.

A doxiciclina liga-se fortemente com metais divalentes (PALM et al., 2008) e essa interação entre doxiciclina e o metal divalente cálcio é importante para a saúde de nosso 
tecido ósseo. O estudo de Weaver e colaboradores procurou medir a qualidade óssea através da excreção urinária de isótopos de cálcio usando um isótopo de tetraciclina para fazer essa medição em tempo real. Os resultados advindos do tratamento para correção da osteopenia só são quantificáveis através da densitometria óssea e as diferenças só são visíveis depois de 6 meses do início do tratamento. Com o uso do isótopo de tetraciclina como auxiliador dessa medição na urina, foi possível medir quase que de modo imediato a indução de osteopenia por ovariectomia (WEAVER et al., 2007).

Quando se discute sobre a quantificação de cálcio em soro na Tabela 3, tem-se que não houve diferenças em sua quantidade quando observou-se os grandes grupos $\mathrm{C}$ e Se. No entanto, quando observou-se o grande grupo OVX, é visto que há diferença entre os grupos OVX (sem doxiciclina) vs. os grupos OVX10 e OVX30 com aumentos gradativos de quantidade de cálcio dose-dependentes. Isso demonstra que em ratas Wistar com indução de osteopenia por ovariectomia bilateral tem-se uma diferença do carreamento de cálcio por soro, sendo maior para os grupos expostos ao medicamento (chegando perto dos valores do grupo controle). Ou seja, a doxiciclina induz a um maior carreamento de cálcio em soro de ratas osteopênicas por ovariectomia bilateral. Estes dados mostram que a quantidade de cálcio presente em soro foi aumentada nas amostras dos grupos OVX10 e OVX30 em comparação com OVX. Os achados histológicos e densitométricos corroboram com a melhora do quadro osteopênico. Isso mostra que ocorreu algo que vai contra a homeostase normal do cálcio no soro sanguíneo, um mecanismo intimamente regulado em nosso organismo (BODEN; KAPLAN, 1990).

Os resultados levam a crer que houve tendência de aumento de cálcio em ossos e, mesmo não ocorrendo uma diferença estatisticamente significante, pode-se ver que os valores médios de cálcio, zinco e magnésio em ossos aumentam em ratas osteopênicas expostas à doxiciclina (Tabela 3). Com estes resultados, podemos considerar que a doxiciclina pode carrear o cálcio até o osso em ratas osteopênicas. O mesmo não aconteceu com controles, onde ocorreram efeitos deletérios quando se colocou ratas sadias com doxiciclina, sendo dose-dependente esse efeito. 
Existem ainda controvérsias acerca do uso da doxiciclina em doses subantimicrobianas. Folwarczna e colaboradores mostraram que em modelo experimental de indução de osteopenia por ovariectomia bilateral em ratas, a doxiciclina provocou efeitos deletérios nos ossos dessas ratas (FOLWARCZNA; PYTLIK; JANIEC, 2003). Pode-se explicar isto devido ao fato dos animais ainda não terem a osteopenia estabelecida. De acordo com os autores, as ratas receberam o medicamento por 4 semanas, poucos dias após a indução de osteopenia. O presente trabalho foi embasado em um estudo prévio de nosso grupo de trabalho, onde tem-se que em 3 meses se estabelece a osteopenia nos modelos experimentais de ovariectomia (ISSA et al., 2015). Além disso, Folwarczna e colaboradores administraram a doxiciclina de modo concomitante com o estabelecimento da osteopenia por 1 mês. No presente estudo, aguardamos 90 dias para o estabelecimento da osteopenia e, com a osteopenia estabelecida, nós realizamos o tratamento com duas doses distintas do medicamento por 60 dias. Isso explica a diferença os resultados obtidos no trabalho de Folwarczna aos do presente trabalho.

Os controles expostos ao medicamento (grupos C10 e C30) não apresentaram efeitos benéficos quando analisamos os resultados obtidos pela densitometria óssea (BMC), quantificação de trabeculado ósseo na porção distal e quantificação de Ca, Zn e Mg.

Transpondo aos seres humanos, Payne e colaboradores demonstraram em seu estudo longitudinal de 2 anos com 128 pacientes randomizados que o uso de doxiciclina em dose de $20 \mathrm{mg}$ duas vezes ao dia (dose considerada subantimicrobiana) acrescentada a uma dose diária de cálcio e vitamina $\mathrm{D}$ não apresentou melhoria ou danos a mulheres em menopausa com doença periodontal (PAYNE et al., 2007). Por outro lado, em outros estudos anteriores foi demonstrado que o uso de doxiciclina nas mesmas condições demonstradas acima, associada a raspagens dentais (raspagem de cálculo dental ou placa), promoveu uma melhora expressiva na qualidade óssea alveolar (CATON et al., 2000; GOLUB et al., 2001; PRESHAW et al., 2004). No entanto, existem diversos questionamentos sobre o fato de a doxiciclina ser um antibiótico e não apresentar aumento de resistência microbiana em doses subantimicrobianas. Em humanos a dose subantimicrobiana de $20 \mathrm{mg} / \mathrm{kg} / \mathrm{dia}$ não apresenta 
aumento da flora subgengival (WALKER et al., 2007) e o seu uso como inibidor de metaloproteinase para tratamento de periodontite já foi comprovado como seguro (GOLUB et al., 1995; THOMAS et al., 2000). Além disto, o uso da doxiciclina em doses subantimicrobianas já se provou como não antimicrobiano não afetando as floras comensais da pele (SKIDMORE et al., 2003), uma vez que as tetraciclinas, mais precisamente a minociclina e a doxiciclina, são largamente usadas para este fim (problemas de pele) em doses antimicrobianas (BHAMBRI; KIM, 2009; COHEN, 2007; COHEN; GROSSMAN, 2004; DEL ROSSO, 2004; ELSTON, 2007; PELLE; CRAWFORD; JAMES, 2004).

Fowlkes et al. demonstraram que a doxiciclina dada em ração (em uma dose não específica com um intervalo de administração de $28-92 \mathrm{mg} / \mathrm{kg} / \mathrm{dia}$ por 10 semanas) para ratos machos com osteopenia induzida por diabetes, não apresentou nenhum efeito deletério ao osso, porém não foi demonstrado que o medicamento fosse capaz de aliviar ou diminuir os efeitos deletérios promovidos pela diabetes nos ossos (FOWLKES et al., 2015). No presente estudo, realizou-se a ingestão de doxiciclina na água de beber. A dose foi cuidadosamente baseada no peso corporal das ratas, para garantir a ingestão de doxiciclina de maneira fiel aos miligramas/quilo por dia para cada grupo exposto ao medicamento.

Em coelhos com osteoartrite induzida metodologicamente, houve uma melhora em estágio inicial dos danos articulares dos animais tratados com uma dose subantimicrobiana de doxiciclina $(2,2 \mathrm{mg} / \mathrm{kg} / \mathrm{dia})$, o que demonstra que os danos articulares futuros podem ser amenizados (PINNEY et al., 2012). A doxiciclina, em doses subantimicrobianas 1,5mg/kg/dia em tratamento por 3 semanas, diminuiu consideravelmente a perda óssea em ratos machos com indução de diabetes (TELLA et al., 2014). Além disto, foi demonstrado que em modelo in vitro e in vivo a doxiciclina é capaz de promover uma melhor combinação entre o osso e implante e, ainda, evitar substancialmente que o implante seja acometido por infecções (WALTER et al., 2014). Kutan e colaboradores comprovaram que em modelo experimental de regeneração óssea auxiliada por membrana de colágeno e doxiciclina $1 \mathrm{mg} / \mathrm{cm}^{2} \mathrm{em}$ sítio tibial contaminado por bactéria, a doxiciclina leva à regeneração óssea de boa qualidade (KUTAN et al., 2016). A doxiciclina em forma de gel apresentou maior vantagem sobre o 
reparo ósseo em calvárias de ratos em comparação com grupos com enchimento de coágulo sanguíneo no defeito ósseo critico e preenchido por natrosol gel (SILVA et al., 2016).

A doxiclina administrada por via oral $(1,5 \mathrm{mg} / \mathrm{kg} / \mathrm{dia})$ concomitante com eritromicina $(2 \mathrm{mg} / \mathrm{kg} / \mathrm{dia})$ intraperitoneal em modelos experimentais de reparo ósseo em ratos com extração de molares, aferidos nos períodos de 7, 14 e 28 dias pós-operatórios, apresentaram melhor reparo ósseo no grupo com os antibióticos administrados em comparação aos controles (SHAHABOOEI, M. et al., 2015). A administração de doxiciclina promoveu a regulação negativa de mediadores inflamatórios e recombinantes genéticos pró-inflamatórios, além de promover uma menor perda alveolar óssea em ratos machos (CASTRO, M. L. et al., 2016), portanto, podemos afirmar que a doxiciclina é um modulador inflamatório que promove efeitos benéficos em reparos ósseos. Isto explica os resultados contidos no presente estudo que demonstraram o favorecimento ósseo nos grupos submetidos à osteopenia e tratados com doxiciclina.

No presente trabalho, olhando a Tabela 3, os resultados demonstram que a doxiciclina não modifica os pesos corporais de ratas, a massa seca do osso fêmur e o seu comprimento. Vale relatar que os ossos dessas ratas apresentaram diferenças morfológicas na proporção de 2/7 (28\% dos grupos) nos grupos Se10, Se30, OVX10 e OVX30 dos ossos, indicando uma forma leve de nanismo, uma vez que o uso do inibidor de MMP-9 e 14 leva a este quadro (HOLMBECK et al., 1999; ULICl et al., 2009; VU et al., 1998). Foram apresentados dados que mostram uma melhora expressiva em ossos acometidos com osteopenia induzida pelo sedentarismo e ovariectomia bilateral tratados com doxiciclina nas duas doses, dados comprovados por densitometria BMC (com a dose $10 \mathrm{mg} / \mathrm{kd} / \mathrm{dia}$ sendo o suficiente para melhora do quadro de osteopenia induzida), porém não se observa isso com BMD, onde só teve uma melhora óssea estatisticamente diferente quando comparou-se OVX com OVX10. Essa melhora também é evidente quando quantificou-se o magnésio no grupo sedentarismo, demonstrando uma melhora em sua presença no grupo Se10 comparado ao grupo Se (Se vs. Se10 $\mathrm{p}<0,01$ e Se10 vs. Se30 $\mathrm{p}=0,007)$. 
A densitometria óssea mostrou que ocorreram diferenças benéficas para o osso, uma vez que fica claro que do controle até a dose de $10 \mathrm{mg} / \mathrm{kg} / \mathrm{dia}$ existiu uma melhora da qualidade óssea nos grupos sedentarismo e ovariectomizados. Por outro lado, ao se comparar as doses 10 e 30mg/kg/dia percebe-se que não há diferenças. Quando se olha os resultados de quantificação de cálcio, zinco e magnésio nos ossos do grupo sedentário, comparando os grupos Se vs. Se30, percebe-se que ocorre uma diferença discreta na quantificação de cálcio e uma diferença não tão discreta quando visualizamos as quantificações magnésio e zinco. Na quantificação de magnésio e zinco, ocorrem diferenças estatisticamente significantes entre os as doses Se10 versus Se30, porém não são vistas diferenças entre os grupos Se e Se10. Podemos dizer que a dose é importante para a modificação da quantidade de magnésio e zinco no osso, uma vez que são macroelementos presentes nos osso, porém em menor proporção do que o cálcio. Na quantificação de cálcio no soro percebe-se que não existem diferenças entre os grupos, com exceção do grupo ovariectomizado. Este grupo apresentou diferenças estatisticamente significantes entre o grupo OVX vs. OVX30, demonstrando que quanto maior a dose do medicamento maior o trânsito de cálcio na corrente sanguínea em ratas acometidas por osteopenia. Tais diferenças mostram que a doxiciclina fez um papel chave no transporte desse metal, uma vez que este medicamento tem a capacidade de quelar metais bivalentes (PALM et al., 2008; SAPADIN; FLEISCHMAJER, 2006) e levá-los até os ossos através do soro.

\section{CONCLUSÃO}

De acordo com os modelos experimentais empregados e as metodologias executadas, chegou-se a conclusão que a doxiciclina promoveu efeitos deletérios em controles à medida que aumentou-se a concentração do medicamento. Para ratas submetidas ao sedentarismo e ovariectomizadas, a dose de $10 \mathrm{mg} / \mathrm{kg} / \mathrm{dia}$ parece ser suficiente para gerar benefícios à qualidade óssea, dados comprovados pela quantificação de trabeculado ósseo por tricromo de Masson na porção distal do osso fêmur, densitometria óssea e imunomarcação por TRAP (pois ocorreu a inibição de osteoclastos, células muito 
presentes nos grupos Se e OVX). São necessários novos estudos para sedimentar à nível molecular estes achados, uma vez que foram feitos estudos em padrão ouro de quantificação e qualificação da qualidade óssea. Estudos sobre as modificações osteoblásticas, modificações hormonais e quantificações proteicas são ainda necessários.

\section{REFERÊNCIAS}

\section{Reference List}

ABDUL-HUSSIEN, H. et al. Doxycycline therapy for abdominal aneurysm: Improved proteolytic balance through reduced neutrophil content. J Vasc Surg, v. 49, n. 3, p. 741-9, Mar 2009.

AMMERMAN, C. B. et al. Mineral Composition of Tissues from Beef Cattle under Grazing Conditions in Panama. Journal of Animal Science, v. 38, n. 1, p. 158-162, January 1, 19741974.

AUGUSTO TOCCHINI DE FIGUEIREDO, F. et al. Reduced Bone and Body Mass in Young Male Rats Exposed to Lead. BioMed Research International, v. 2014, p. 571065, 2014.

BABU, E. et al. Human organic anion transporters mediate the transport of tetracycline. Jpn J Pharmacol, v. 88, n. 1, p. 69-76, Jan 2002.

BANDEIRA, F.; CARVALHO, E. F. D. Prevalência de osteoporose e fraturas vertebrais em mulheres na pós-menopausa atendidas em serviços de referência. Revista Brasileira de Epidemiologia, v. 10, p. 86-98, 2007.

BASS, S. et al. Exercise before puberty may confer residual benefits in bone density in adulthood: studies in active prepubertal and retired female gymnasts. J Bone Miner Res, v. 13, n. 3, p. 500-7, Mar 1998.

BHAMBRI, S.; KIM, G. Use of Oral Doxycycline for Community-acquired Methicillin-resistant Staphylococcus aureus (CA-MRSA) Infections. The Journal of Clinical and Aesthetic Dermatology, $v$. 2, n. 4, p. 45-50, 2009.

BLUMENTHAL, J. A. et al. Effects of exercise training on bone density in older men and women. J Am Geriatr Soc, v. 39, n. 11, p. 1065-70, Nov 1991.

BODEN, S. D.; KAPLAN, F. S. Calcium homeostasis. Orthop Clin North Am, v. 21, n. 1, p. 31-42, Jan 1990. 
BOULOS, P. R.; KNOEPP, S. M.; RUBIN, P. A. Green bone. Arch Ophthalmol, v. 125, n. 3, p. 380-6, Mar 2007.

BOUVET, C. et al. Sequential activation of matrix metalloproteinase 9 and transforming growth factor beta in arterial elastocalcinosis. Arterioscler Thromb Vasc Biol, v. 28, n. 5, p. 856-62, May 2008.

BRIEST, W. et al. Significance of matrix metalloproteinases in norepinephrine-induced remodelling of rat hearts. Cardiovasc Res, v. 57, n. 2, p. 379-87, Feb 2003.

CASTRO, M. L. et al. Downregulation of Proteinase-Activated Receptor-2, Interleukin-17, and Other Proinflammatory Genes by Subantimicrobial Doxycycline Dose in a Rat Periodontitis Model. J Periodontol, v. 87, n. 2, p. 203-10, Feb 2016.

CASTRO, M. M. et al. Doxycycline ameliorates $2 \mathrm{~K}-1 \mathrm{C}$ hypertension-induced vascular dysfunction in rats by attenuating oxidative stress and improving nitric oxide bioavailability. Nitric Oxide, v. 26, n. 3, p. 162-168, 2012/03/31/ 2012.

CASTRO, M. M. et al. Metalloproteinase inhibition ameliorates hypertension and prevents vascular dysfunction and remodeling in renovascular hypertensive rats. Atherosclerosis, v. 198, n. 2, p. 32031, Jun 2008.

CATON, J. G. et al. Treatment with subantimicrobial dose doxycycline improves the efficacy of scaling and root planing in patients with adult periodontitis. J Periodontol, v. 71, n. 4, p. 521-32, Apr 2000.

CHEN, Y.; HEIMAN, M. L. Increased weight gain after ovariectomy is not a consequence of leptin resistance. Am J Physiol Endocrinol Metab, v. 280, n. 2, p. E315-22, Feb 2001.

CHOWDHURY, M. H. et al. Effect of tetracyclines which have metalloproteinase inhibitory capacity on basal and heparin-stimulated bone resorption by chick osteoclasts. Agents Actions, v. 40, n. 1-2, p. 124-8, Sep 1993.

COHEN, P. R. Community-acquired methicillin-resistant Staphylococcus aureus skin infections: implications for patients and practitioners. Am J Clin Dermatol, v. 8, n. 5, p. 259-70, 2007.

COHEN, P. R.; GROSSMAN, M. E. Management of cutaneous lesions associated with an emerging epidemic: community-acquired methicillin-resistant Staphylococcus aureus skin infections. J Am Acad Dermatol, v. 51, n. 1, p. 132-5, Jul 2004.

CUMMINGS, G. R.; TORABINEJAD, M. Effect of Systemic Doxycycline on Alveolar Bone Loss after Periradicular Surgery. Journal of Endodontics, v. 26, n. 6, p. 325-327, 2000/06/01/ 2000. 
CUMMINGS, S. R. et al. Epidemiology of osteoporosis and osteoporotic fractures. Epidemiol Rev, v. 7, p. 178-208, 1985.

DAl, Q. et al. Estrogen effects on MMP-13 and MMP-14 regulation of left ventricular mass in Dahl salt-induced hypertension. Gend Med, v. 5, n. 1, p. 74-85, Mar 2008.

DAVIDSON, M. K.; LINDSEY, J. R.; DAVIS, J. K. Requirements and selection of an animal model. Isr J Med Sci, v. 23, n. 6, p. 551-5, Jun 1987.

DEL ROSSO, J. Q. A status report on the use of subantimicrobial-dose doxycycline: a review of the biologic and antimicrobial effects of the tetracyclines. Cutis, v. 74, n. 2, p. 118-22, Aug 2004.

DEMPSTER, D. W. Chapter 22 - Histomorphometric Analysis of Bone Remodeling A2 - Bilezikian, John P. In: RAISZ, L. G. e MARTIN, T. J. (Ed.). Principles of Bone Biology (Third Edition). San Diego: Academic Press, 2008. p.447-463. ISBN 978-0-12-373884-4.

DUNCAN, $S$. et al. Modifiable risk factors for overweight and obesity in children and adolescents from Sao Paulo, Brazil. BMC Public Health, v. 11, n. 1, p. 585, 2011.

ELSTON, D. M. Community-acquired methicillin-resistant Staphylococcus aureus. J Am Acad Dermatol, v. 56, n. 1, p. 1-16; quiz 17-20, Jan 2007.

ERIKSEN, E. F. et al. Reconstruction of the formative site in iliac trabecular bone in 20 normal individuals employing a kinetic model for matrix and mineral apposition. Metab Bone Dis Relat Res, v. 5, n. 5, p. 243-52, 1984.

ERIKSEN, E. F.; MELSEN, F.; MOSEKILDE, L. Reconstruction of the resorptive site in iliac trabecular bone: a kinetic model for bone resorption in 20 normal individuals. Metab Bone Dis Relat Res, v. 5, n. 5, p. 235-42, 1984.

FARIA, P. E. et al. Immunohistochemical, tomographic and histological study on onlay iliac grafts remodeling. Clin Oral Implants Res, v. 19, n. 4, p. 393-401, Apr 2008.

FERNANDES, R. A. et al. Prevalence of dyslipidemia in individuals physically active during childhood, adolescence and adult age. Arq Bras Cardiol, v. 97, n. 4, p. 317-323, 10/01 2011.

FISKE CH, S. Y. The colorimetric determination of phosphorus. J Biol Chem, v. 66, p. 375-400, 1925.

FOLWARCZNA, J.; PYTLIK, M.; JANIEC, W. Effects of doxycycline on development of changes in histomorphometric parameters of bones induced by bilateral ovariectomy in rats. Pol J Pharmacol, v. 55, n. 3, p. 433-41, May-Jun 2003. 
FOWLKES, J. L. et al. Effects of long-term doxycycline on bone quality and strength in diabetic male DBA/2J mice. Bone Reports, v. 1, p. 16-19, 1// 2015.

FREITAS, S. H. D. et al. Tomographic imaging of fragmented cortical bone heteroimplant and methylmethacrylate in segmental bone defect of rabbit tibia. Acta Cirurgica Brasileira, v. 29, p. 794800, 2014.

GALLAGHER, J. C. The pathogenesis of osteoporosis. Bone Miner, v. 9, n. 3, p. 215-27, Jun 1990.

GALLAGHER, J. C. et al. Epidemiology of fractures of the proximal femur in Rochester, Minnesota. Clin Orthop Relat Res, n. 150, p. 163-71, Jul-Aug 1980.

GARCíA, R. A. et al. Molecular Interactions between Matrilysin and the Matrix Metalloproteinase Inhibitor Doxycycline Investigated by Deuterium Exchange Mass Spectrometry. Molecular Pharmacology, v. 67, n. 4, p. 1128-1136, April 1, 20052005.

GOLUB, L. M. et al. Tetracyclines inhibit connective tissue breakdown by multiple non-antimicrobial mechanisms. Adv Dent Res, v. 12, n. 2, p. 12-26, Nov 1998.

GOLUB, L. M. et al. Adjunctive treatment with subantimicrobial doses of doxycycline: effects on gingival fluid collagenase activity and attachment loss in adult periodontitis. J Clin Periodontol, v. 28, n. 2, p. 146-56, Feb 2001.

GOLUB, L. M. et al. Doxycycline inhibits neutrophil (PMN)-type matrix metalloproteinases in human adult periodontitis gingiva. J Clin Periodontol, v. 22, n. 2, p. 100-9, Feb 1995.

GOMES, B. C.; GOLUB, L. M.; RAMAMURTHY, N. S. Tetracyclines inhibit parathyroid hormoneinduced bone resorption in organ culture. Experientia, v. 40, n. 11, p. 1273-5, Nov 151984.

GOMES, P. S.; FERNANDES, M. H. Effect of therapeutic levels of doxycycline and minocycline in the proliferation and differentiation of human bone marrow osteoblastic cells. Archives of Oral Biology, v. 52 , n. 3, p. 251-259, 2007/03/01/ 2007.

GREENWALD, R. A. et al. In vitro sensitivity of the three mammalian collagenases to tetracycline inhibition: relationship to bone and cartilage degradation. Bone, v. 22, n. 1, p. 33-8, Jan 1998.

GRIFFIN, M. O. et al. Tetracyclines: a pleitropic family of compounds with promising therapeutic properties. Review of the literature. American Journal of Physiology - Cell Physiology, v. 299, n. 3, p. C539-C548, 2010.

GUIMARAES, D. A. et al. Doxycycline dose-dependently inhibits MMP-2-mediated vascular changes in 2K1C hypertension. Basic Clin Pharmacol Toxicol, v. 108, n. 5, p. 318-25, May 2011. 
GURKAN, A. et al. Post-treatment effects of subantimicrobial dose doxycycline on clinical parameters and gingival crevicular fluid transforming growth factor-beta1 in severe, generalized chronic periodontitis. Int J Dent Hyg, v. 6, n. 2, p. 84-92, May 2008.

HABERMANN, B. et al. Tartrate-resistant acid phosphatase $5 b$ (TRAP $5 b$ ) as a marker of osteoclast activity in the early phase after cementless total hip replacement. Acta Orthop, v. 78, n. 2, p. 221-5, Apr 2007.

HEANEY, R. P.; ABRAMS, S. A. Improved estimation of the calcium content of total digestive secretions. J Clin Endocrinol Metab, v. 89, n. 3, p. 1193-5, Mar 2004.

HOLMBECK, K. et al. MT1-MMP-deficient mice develop dwarfism, osteopenia, arthritis, and connective tissue disease due to inadequate collagen turnover. Cell, v. 99, n. 1, p. 81-92, Oct 11999.

HSIAO, H. B. et al. Kinsenoside prevents ovariectomy-induced bone loss and suppresses osteoclastogenesis by regulating classical NF-KB pathways. Osteoporosis International, v. 24, n. 5, p. 1663-1676, 2013.

HSIAO, H. B. et al. Kinsenoside isolated from Anoectochilus formosanus suppresses LPS-stimulated inflammatory reactions in macrophages and endotoxin shock in mice. Shock, v. 35, n. 2, p. 184-90, Feb 2011.

INSTITUTE OF MEDICINE STANDING COMMITTEE ON THE SCIENTIFIC EVALUATION OF DIETARY REFERENCE, I. The National Academies Collection: Reports funded by National Institutes of Health. In: (Ed.). Dietary Reference Intakes for Calcium, Phosphorus, Magnesium, Vitamin D, and Fluoride. Washington (DC): National Academies Press (US)

National Academy of Sciences., 1997.

IONESCU, A. et al. FoxA family members are crucial regulators of the hypertrophic chondrocyte differentiation program. Developmental Cell, v. 22, n. 5, p. 927-939, 2012.

ISSA, J. P. M. et al. The effect of simvastatin treatment on bone repair of femoral fracture in animal model. Growth Factors, v. 33, n. 2, p. 139-148, 2015/03/04 2015.

JEE, W. S.; YAO, W. Overview: animal models of osteopenia and osteoporosis. J Musculoskelet Neuronal Interact, v. 1, n. 3, p. 193-207, Mar 2001.

JOHNSON, M. S. et al. Comparison of software versions for body composition analysis using the PIXImus dual-energy X-ray absorptiometer. International journal of body composition research, $\mathrm{v}$. 3, n. 2, p. 69-72, 2005.

JUNQUEIRA, L. C.; CARNEIRO, J. Citologia básica. Koogan, 2008. 
KARLSSON, M. K. et al. Exercise during growth and bone mineral density and fractures in old age. Lancet, v. 355, n. 9202, p. 469-70, Feb 052000.

KIMURA, M. et al. The Obesity in Bilateral Ovariectomized Rats Is Related to a Decrease in the Expression of Leptin Receptors in the Brain. Biochemical and Biophysical Research Communications, v. 290, n. 4, p. 1349-1353, 2002/02/01/ 2002.

KLAPISZ-WOLIKOW, M.; SAFFAR, J. L. Minocycline impairment of both osteoid tissue removal and osteoclastic resorption in a synchronized model of remodeling in the rat. J Cell Physiol, v. 167, n. 2, p. 359-68, May 1996.

KONTULAINEN, S. et al. Good maintenance of exercise-induced bone gain with decreased training of female tennis and squash players: a prospective 5-year follow-up study of young and old starters and controls. J Bone Miner Res, v. 16, n. 2, p. 195-201, Feb 2001.

KUTAN, E. et al. Efficacy of doxycycline release collagen membrane on surgically created and contaminated defects in rat tibiae: A histopathological and microbiological study. Arch Oral Biol, v. 63, p. 15-21, Mar 2016.

LAMPARTER, S.; SLIGHT, S. H.; WEBER, K. T. Doxycycline and tissue repair in rats. Journal of Laboratory and Clinical Medicine, v. 139, n. 5, p. 295-302, 2002/05/01/ 2002.

LEES, B. et al. Differences in proximal femur bone density over two centuries. Lancet, v. 341, n. 8846, p. 673-5, Mar 131993.

LELOVAS, P. P. et al. The laboratory rat as an animal model for osteoporosis research. Comp Med, v. 58, n. 5, p. 424-30, Oct 2008.

LEWANDROWSKI, K.-U. et al. Improved osteoinduction of cortical bone allografts: A study of the effects of laser perforation and partial demineralization. Journal of Orthopaedic Research, v. 15, n. 5, p. 748-756, 1997.

LORENZO, J.; HOROWITZ, M.; CHOI, Y. Osteoimmunology: interactions of the bone and immune system. Endocr Rev, v. 29, n. 4, p. 403-40, Jun 2008.

MACEDO, A. P. et al. Influence of treadmill training on bone structure under osteometabolic alteration in rats subjected to high-fat diet. Scandinavian Journal of Medicine \& Science in Sports, v. 27, n. 2, p. 167-176, 2017.

MACKELVIE, K. J. et al. A school-based exercise intervention elicits substantial bone health benefits: a 2-year randomized controlled trial in girls. Pediatrics, v. 112, n. 6 Pt 1, p. e447, Dec 2003. 
MALINA, R. M.; BOUCHARD, C.; BAR-OR, O. Growth, Maturation, and Physical Activity. Human Kinetics, 2004. ISBN 9780880118828.

MARTIN, R. M.; CORREA, P. H. Bone quality and osteoporosis therapy. Arq Bras Endocrinol Metabol, v. 54, n. 2, p. 186-99, Mar 2010.

MATSUO, K. Cross-talk among bone cells. Curr Opin Nephrol Hypertens, v. 18, n. 4, p. 292-7, Jul 2009.

MAVRAGANI, M.; BRUDVIK, P.; SELVIG, K. A. Orthodontically induced root and alveolar bone resorption: inhibitory effect of systemic doxycycline administration in rats. European Journal of Orthodontics, v. 27, n. 3, p. 215-225, 2005.

MCEVOY, G. AHFS Drug Information - Tetracyclines. 2008

MITAZAKI, S. et al. Apocynin reduced doxycycline-induced acute liver injury in ovariectomized mice. Toxicology Reports, v. 3, p. 357-363, 2016/01/01/ 2016.

MOCHIZUKI, M.; HASEGAWA, N. Metabolic Effect of Exercise in Ovariectomized Mature Multiparous Rats. Journal of Health Science, v. 51, n. 6, p. 731-733, 2005.

MONTEIRO, L. O. et al. Effect of treatment with simvastatin on bone microarchitecture of the femoral head in an osteoporosis animal model. Microscopy Research and Technique, v. 79, n. 8, p. 684-690, 2016.

MORRIS, F. L. et al. Prospective ten-month exercise intervention in premenarcheal girls: positive effects on bone and lean mass. J Bone Miner Res, v. 12, n. 9, p. 1453-62, Sep 1997.

NORDSLETTEN, L. et al. The development of femoral osteopenia in ovariectomized rats is not reduced by high intensity treadmill training: a mechanical and densitometric study. Calcif Tissue Int, v. 55, n. 6, p. 436-42, Dec 1994.

NOVAK, M. J. et al. Adjunctive benefits of subantimicrobial dose doxycycline in the management of severe, generalized, chronic periodontitis. J Periodontol, v. 73, n. 7, p. 762-9, Jul 2002.

OKUBO, R. et al. Jumping exercise preserves bone mineral density and mechanical properties in osteopenic ovariectomized rats even following established osteopenia. Osteoporosis International, v. 28, n. 4, p. 1461-1471, April 012017.

PALM, G. J. et al. Specific binding of divalent metal ions to tetracycline and to the Tet repressor/tetracycline complex. J Biol Inorg Chem, v. 13, n. 7, p. 1097-110, Sep 2008. 
PAUTKE, C. et al. Tetracycline Bone Fluorescence: A Valuable Marker for Osteonecrosis Characterization and Therapy. Journal of Oral and Maxillofacial Surgery, v. 68, n. 1, p. 125-129, 2010/01/01/ 2010.

PAUTKE, C. et al. Characterization of eight different tetracyclines: advances in fluorescence bone labeling. Journal of Anatomy, v. 217, n. 1, p. 76-82, 2010.

PAYNE, J. B. et al. Subantimicrobial dose doxycycline effects on alveolar bone loss in postmenopausal women. J Clin Periodontol, v. 34, n. 9, p. 776-87, Sep 2007.

PELLE, M. T.; CRAWFORD, G. H.; JAMES, W. D. Rosacea: II. Therapy. J Am Acad Dermatol, v. 51, n. 4, p. 499-512; quiz 513-4, Oct 2004.

PEREIRA, B. F. et al. Effects of biodegradable detergents in morphological parameters of liver in two neotropical fish species (Prochilodus lineatus and Astyanax altiparanae). Microscopy Research, v. 2, n. 02, p. 39, 2014.

PEREIRA, G. B. et al. Effects of ovariectomy and resistance training on MMP-2 activity in rat calcaneal tendon. Connect Tissue Res, v. 51, n. 6, p. 459-66, Dec 2010.

PETERSON, J. T. Matrix metalloproteinase inhibitor development and the remodeling of drug discovery. Heart Fail Rev, v. 9, n. 1, p. 63-79, Jan 2004.

PINNEY, J. R. et al. Imaging longitudinal changes in articular cartilage and bone following doxycycline treatment in a rabbit anterior cruciate ligament transection model of osteoarthritis. Magnetic Resonance Imaging, v. 30, n. 2, p. 271-282, 2// 2012.

PRALL, A. K. et al. Doxycycline in patients with abdominal aortic aneurysms and in mice: comparison of serum levels and effect on aneurysm growth in mice. J Vasc Surg, v. 35, n. 5, p. 923-9, May 2002.

PRESHAW, P. M. et al. Subantimicrobial dose doxycycline enhances the efficacy of scaling and root planing in chronic periodontitis: a multicenter trial. J Periodontol, v. 75, n. 8, p. 1068-76, Aug 2004.

PRESTES, J. et al. Effects of ovariectomy and resistance training on MMP-2 activity in skeletal muscle. Appl Physiol Nutr Metab, v. 34, n. 4, p. 700-6, Aug 2009.

RIGGS, B. L.; MELTON, L. J., 3RD. Involutional osteoporosis. N Engl J Med, v. 314, n. 26, p. 1676-86, Jun 261986.

RIGGS, B. L. et al. Clinical trial of fluoride therapy in postmenopausal osteoporotic women: extended observations and additional analysis. J Bone Miner Res, v. 9, n. 2, p. 265-75, Feb 1994. 
ROSS, P. D. et al. Predicting vertebral fracture incidence from prevalent fractures and bone density among non-black, osteoporotic women. Osteoporos Int, v. 3, n. 3, p. 120-6, May 1993.

RYGH, P. Orthodontic root resorption studied by electron microscopy. Angle Orthod, v. 47, n. 1, p. 116, Jan 1977.

SALMINEN, A. et al. Subantimicrobial dose doxycycline treatment increases serum cholesterol efflux capacity from macrophages. Inflammation research : official journal of the European Histamine Research Society ... [et al.], v. 62, n. 7, p. 711-720, 05/07 2013.

SAPADIN, A. N.; FLEISCHMAJER, R. Tetracyclines: nonantibiotic properties and their clinical implications. J Am Acad Dermatol, v. 54, n. 2, p. 258-65, Feb 2006.

SASAKI, T. et al. Effects of chemically modified tetracycline, CMT-8, on bone loss and osteoclast structure and function in osteoporotic states. Ann N Y Acad Sci, v. 878, p. 347-60, Jun 301999.

SAWAN, R. M. et al. Fluoride increases lead concentrations in whole blood and in calcified tissues from lead-exposed rats. Toxicology, v. 271, n. 1-2, p. 21-6, Apr 302010.

SHAHABOOEI, M. et al. A histomorphometric study of the effect of doxycycline and erythromycin on bone formation in dental alveolar socket of rat. Adv Biomed Res, v. 4, p. 71, 2015.

SHAHABOOEI, M. et al. A histomorphometric study of the effect of doxycycline and erythromycin on bone formation in dental alveolar socket of rat. Advanced Biomedical Research, v. 4, p. 71, 2015.

SHIMANO, A. C.; VOLPON, J. B.; LIMA, R. S. Ação do Treinamento Físico Antes e Após a Instalação da Osteopenia de Ratas Ovariectomizadas: Faculdade de Medicina de Ribeirão Preto/USP. 2008.

SHIMANO, R. C. et al. Biomechanical and microstructural benefits of physical exercise associated with risedronate in bones of ovariectomized rats. Microsc Res Tech, v. 77, n. 6, p. 431-8, Jun 2014.

SHIMANO, R. C. et al. Biomechanical and microstructural benefits of physical exercise associated with risedronate in bones of ovariectomized rats. Microscopy Research and Technique, v. 77, n. 6, p. 431-438, 2014.

SILVA, A. C. et al. Effect of Doxycycline in Gel Form on Bone Regeneration: Histomorphometric and Tomographic Study in Rat Calvaria. J Periodontol, v. 87, n. 1, p. 74-82, Jan 2016.

SIOEN, I. et al. The influence of dairy consumption, sedentary behaviour and physical activity on bone mass in Flemish children: a cross-sectional study. BMC Public Health, v. 15, n. 1, p. 717, July 28 2015. 
SKIDMORE, R. et al. Effects of subantimicrobial-dose doxycycline in the treatment of moderate acne. Arch Dermatol, v. 139, n. 4, p. 459-64, Apr 2003.

SORSA, T. et al. Collagenase-2 (MMP-8) as a point-of-care biomarker in periodontitis and cardiovascular diseases. Therapeutic response to non-antimicrobial properties of tetracyclines. Pharmacol Res, v. 63, n. 2, p. 108-13, Feb 2011.

SORSA, T.; TJADERHANE, L.; SALO, T. Matrix metalloproteinases (MMPs) in oral diseases. Oral Dis, v. 10, n. 6, p. 311-8, Nov 2004.

SPECKER, B.; VUKOVICH, M. Evidence for an interaction between exercise and nutrition for improved bone health during growth. Med Sport Sci, v. 51, p. 50-63, 2007.

SPECKER, B. L. Evidence for an interaction between calcium intake and physical activity on changes in bone mineral density. J Bone Miner Res, v. 11, n. 10, p. 1539-44, Oct 1996.

STEWART, A. K.; MAGEE, A. C. Effect of Zinc Toxicity on Calcium, Phosphorus and Magnesium Metabolism of Young Rats. J Nutr, v. 82, p. 287-95, Feb 1964.

TAN, K. R. et al. Doxycycline for Malaria Chemoprophylaxis and Treatment: Report from the CDC Expert Meeting on Malaria Chemoprophylaxis. The American Journal of Tropical Medicine and Hygiene, v. 84, n. 4, p. 517-531, April 5, 20112011.

TEITELBAUM, S. L. Bone Resorption by Osteoclasts. Science, v. 289, n. 5484, p. 1504-1508, September 1, 20002000.

TELLA, E. et al. The Effect of Systemic Delivery of Aminoguanidine versus Doxycycline on the Resorptive Phase of Alveolar Bone Following modified Widman Flap in Diabetic Rats: A Histopathological and Scanning Electron Microscope (SEM) study. Int J Health Sci (Qassim), v. 8, n. 3, p. 275-85, Jul 2014.

THARAPPEL, J. C. et al. Doxycycline shows dose-dependent changes in hernia repair strength after mesh repair. Surg Endosc, v. 30, n. 5, p. 2016-21, May 2016.

THOMAS, J.; WALKER, C.; BRADSHAW, M. Long-Term Use of Subantimicrobial Dose Doxycycline Does Not Lead to Changes in Antimicrobial Susceptibility. Journal of Periodontology, v. 71, n. 9, p. 1472$1483,2000 / 09 / 012000$.

TSCHOP, M.; HEIMAN, M. L. Rodent obesity models: an overview. Exp Clin Endocrinol Diabetes, v. 109, n. 6, p. 307-19, 2001.

TURNER, A. S. Animal models of osteoporosis--necessity and limitations. Eur Cell Mater, v. 1, p. 6681, Jun 222001. 
$\mathrm{ULICl}, \mathrm{V}$. et al. The role of Akt1 in terminal stages of endochondral bone formation: angiogenesis and ossification. Bone, v. 45, n. 6, p. 1133-45, Dec 2009.

VALTUENA, J. et al. Vitamin D status and physical activity interact to improve bone mass in adolescents. The HELENA Study. Osteoporos Int, v. 23, n. 8, p. 2227-37, Aug 2012.

$\mathrm{VU}, \mathrm{T}$. H. et al. MMP-9/gelatinase B is a key regulator of growth plate angiogenesis and apoptosis of hypertrophic chondrocytes. Cell, v. 93, n. 3, p. 411-22, May 11998.

WALKER, C. et al. Subantimicrobial dose doxycycline effects on osteopenic bone loss: microbiologic results. J Periodontol, v. 78, n. 8, p. 1590-601, Aug 2007.

WALTER, M. S. et al. Bioactive implant surface with electrochemically bound doxycycline promotes bone formation markers in vitro and in vivo. Dent Mater, v. 30, n. 2, p. 200-14, Feb 2014.

WANG, Y.; MONTEIRO, C.; POPKIN, B. M. Trends of obesity and underweight in older children and adolescents in the United States, Brazil, China, and Russia. The American Journal of Clinical Nutrition, v. 75, n. 6, p. 971-977, June 1, 20022002.

WEAVER, C. et al. (3)H-tetracycline as a proxy for (41)Ca for measuring dietary perturbations of bone resorption. Nuclear instruments \& methods in physics research. Section B, Beam interactions with materials and atoms, v. 259, n. 1, p. 790-795, 2007.

WILLIAMS, S. et al. Effect of minocycline on osteoporosis. Adv Dent Res, v. 12, n. 2, p. 71-5, Nov 1998.

WILSMAN, N. J. et al. Differential growth by growth plates as a function of multiple parameters of chondrocytic kinetics. J Orthop Res, v. 14, n. 6, p. 927-36, Nov 1996.

WRONSKI, T. J.; CINTRON, M.; DANN, L. M. Temporal relationship between bone loss and increased bone turnover in ovariectomized rats. Calcif Tissue Int, v. 43, n. 3, p. 179-83, Sep 1988.

WRONSKI, T. J. et al. Long-term effects of ovariectomy and aging on the rat skeleton. Calcif Tissue Int, v. 45, n. 6, p. 360-6, Dec 1989.

WU, J. B. et al. The hepatoprotective activity of kinsenoside from Anoectochilus formosanus.

Phytother Res, v. 21, n. 1, p. 58-61, Jan 2007.

YAO, X. et al. Morphological alterations in the growth plate cartilage of ovariectomized mice. Med Mol Morphol, v. 39, n. 4, p. 193-7, Dec 2006. 
ZHANG, C. et al. Inhibiting wear particles-induced osteolysis with doxycycline. Acta Pharmacol Sin, v. 28 , n. 10, p. 1603-10, Oct 2007.

ZHOU, X. et al. Tetracyclines Inhibit Rat Osteoclast Formation and Activity In Vitro and Affect Bone Turnover in Young Rats In Vivo. Calcified Tissue International, v. 86, n. 2, p. 163-171, February 01 2010. 